University of Rhode Island

DigitalCommons@URI

Open Access Dissertations

1972

\title{
Thermodynamics and Molecular Orbital Calculations for the Parabens
}

Kenneth S. Alexander

University of Rhode Island

Follow this and additional works at: https://digitalcommons.uri.edu/oa_diss

\section{Recommended Citation}

Alexander, Kenneth S., "Thermodynamics and Molecular Orbital Calculations for the Parabens" (1972). Open Access Dissertations. Paper 545.

https://digitalcommons.uri.edu/oa_diss/545

This Dissertation is brought to you for free and open access by DigitalCommons@URI. It has been accepted for inclusion in Open Access Dissertations by an authorized administrator of DigitalCommons@URI. For more information, please contact digitalcommons@etal.uri.edu. 
THERMODYNAMICS AND MOLECULAR ORBITAL CALCULATIONS FOR THE PARABENS

BY

KENNETH S. ALEXANDER

A THESIS SUBMITTED IN PARTIAL FULFILIMENT OF

THE REQUIREMENTS FOR THE DEGREE OF

DOCTOR OF PHILOSOPHY

IN

PHARMACEUTICAI SCIENCES

UNIVERSITY OF RHODE ISLAND

1972 
DOCTOR OF PHILOSOPHY THESIS

OF

KENNETH S. ALEXANDER

Approved:

Thesis Committee
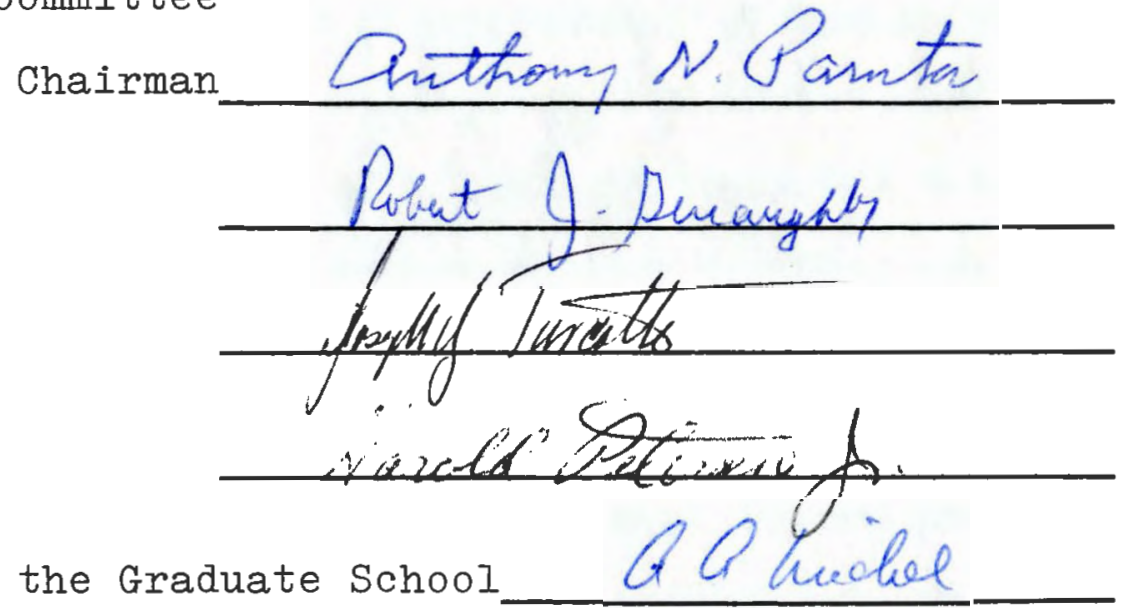

Dean of the Graduate School

\section{UNIVERSITY OF RHODE ISLAND \\ 1972}


To

KAREN, BITSY, AND ? 


\section{ABSTRACT}

The intent of this study was to follow two approaches of scientific methodology in the investigation of a chemically related series of pharmaceutical preservatives, the parabens (esters of para-hydroxybenzoic acid). One approach involved the experimental determination of the solubilities of these compounds and also included their partition coefficient determination. The other approach, strictly theoretical in nature, was manifest by the utilization of molecular orbital theory in the determination of molecular parameters and their possible correlation with physico-chemical parameters and/or drug action.

The solubilities of a series of solutes related to each other by their increasing size in alkyl chain in an ester moiety are determined and compared. These compounds include benzoic acid, para-hydroxybenzoic acid and the methyl, ethyl, propyl, and butyl esters of parahydroxybenzoic acid. The effect of temperature upon the solubilities of these compounds in a series of n-alkanols allows for the calculation of thermodynamic parameters for these systems. Since heat of fusion values are available in the literature, then this leads to the determination of other theoretically important thermodynamic 
quantities which have been presented. This coupled with the experimentally evaluated thermodynamic elements, allows for some insight into the solubility mechanism. Previously enunciated empirical theory of dielectric requirements may be placed on a more quantitative basis. The rather extensive experimental support of the multiplicity of solubility peak maxima for a single solute can be interpreted on a thermodynamic basis.

The partition coefficient, an important physicalchemical property of biologically active drugs, was determined from a biphasic system of n-octanol-water at $25^{\circ} \mathrm{C}$ for each of the solutes. Correlation of this work with the previous work of Hansch and with rank order of activity of these compounds is given.

With respect to the determination of molecular parameters, appropiate computer programs were utilized to obtain the desired results for the following: aniline, para-aminobenzoic acid, phenol, benzoic acid, parahydroxybenzoic acid, methyl and ethyl esters of parahydroxybenzoic acid. It should be pointed out that the computer elements utilize the Iterated Extented Huckel Theory (IEHT) approach, which contains assumptions of various types. For any series of molecules these assumptions are self consistent, however, so that comparisons can easily be made.

The approach taken in this portion of the study was to characterize these systems in terms of atomic 
charge distributions, effect of hydroxy $(-\mathrm{OH})$ and ester groups (both sterically and electronically), preferred molecular conformations and distinguishing features of the molecular orbitals. A hypothesis as to the possible site of action leading to biological activity of these compounds has been proposed. 


\section{ACKNOWLEDGEMENT}

The author wishes to express his appreciation to all those persons with whom he has come in contact at the University of Rhode Island and whose help he has gratefully received during his course of study there.

In particular, thanks are due to:

Professor Anthony N. Paruta, under whose supervision this work was carried out, for his professional guidance and his insistence upon the goal of scientific excellence.

Doctor Harold Petersen, Jr., for his unwavering support and many helpful discussions.

Mr. Frank Caraccia, Manager of Operations at the University of Rhode Island Computer Laboratory, and his staff, for their assistance and perseverance in maintaining a diligent vigil while Harmon worked.

Doctor George E. Osborn, for his help in maintaining logical integrity and continuity throughout the writing of this thesis.

Doctor Joseph G. Turcotte, for his moral support and advice.

My wife, Karen, for whose devotion and inspiration I am always indebted. 
TABLE OF CONTENTS

ABSTRACT . . . . . . . . . . . . iv

ACKNOWLEDGEMENT . . . . . . . . . . . . vii

TABLE OF CONTENTS . . . . . . . . . . . . viii

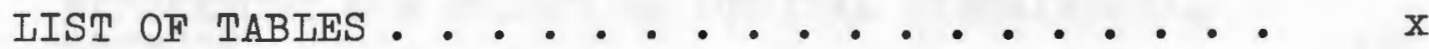

IIST OF FIGURES . . . . . . . . . . . . XIV

BOOK I: SOLUBILITY AND THERMODYNAMICS

I. INTRODUCTION . . . . . . . . . . . I

II. PARABENS ................ 2

III. EXPERIMENTAL . . . . . . . . . . . . 5

IV. RESULTS AND DISCUSSION FOR PARTITION COEFFICIENT DETERMINATIONS . . . . . . . . 13

V. RESULTS AND DISCUSSION OF SOLUBILITY AND THERMODYNAMICS . • . . . . . . . . 24

BOOK II: MOLECULAR ORBITAL CONSIDERATIONS

I. INTRODUCTION . . . . . . . . . . 83

II. STRUCTURE ACTIVITY RELATIONSHIPS OF ANTIMICROBIAI AGENTS . . . . . . . 86

III. EXPERIMENTAL . . . . . . . . . . 99

IV. RESULTS AND DISCUSSION OF THE MOLECULAR ORBITAL CALCULATIONS AND CONSIDERATIONS

OF MECHANISMS OF ACTION OF THE PARABENS. • . . 103

CONCLUSION . . . . . . . . . . . . . . . . . . . . REFERENCES

A REFERENCES FOR PARABENS ........ 167 
B REFERENCES FOR SOLUBIIITY AND PARTITION COEFFICIENT EXPERIMENTAL . . . . . . . . 170

C REFERENCES FOR RESULTS AND DISCUSSION OF PARTITION COEFFICIENTS

D REFERENCES FOR RESULTS AND DISCUSSION OF SOLUBILITY AND THERMODYNAMIC CONSIDERATIONS. •

E REFERENCES FOR MOLECUJAR ORBITAL CONSIDERATIONS INTRODUCTION . . . . . . . . . . 173

F REFERENCES FOR STRUCTURE ACTIVITY RELATIONSHIPS OF ANTIMICROBIAL AGENTS. . . . • . • 174

G REFERENCES FOR MOLECULAR ORBITAL EXPERIMENTAL SECTION

H REFERENCES FOR RESULTS AND DISCUSSION FOR MOLECULAR ORBITAL CALCULATIONS AND CONSIDERATIONS OF MECHANISMS OF ACTION OF THE PARABENS. 
LIST OF TABLES

TABLE

PAGE

1. A Comparison of Experimental and Literature Values for the Partition Coefficients and Phenol Coefficient of para-Hydroxybenzoic Acid and its Esters . . . . . . . .

2. A Compilation of Physico-Chemical Parameters for the Substances Noted from Experimental and Literature Values . . . . . . .

3. Benzoic Acid Solubility . . . . . . 25

4. Para-Hydroxy Benzoic Acid Solubility . . . 26

5. Methyl Paraben Solubility .. . . . 27

6. Ethyl Paraben Solubility. . . . . . 28

7. Propyl Paraben Solubility . . . . . . 29

8. Butyl Paraben Solubility. . . . . . 30

9. Comparison of Slope and Intercept for Ideal and Non-Ideal Solubility. . . . . . .

10. A Summary of the Iiterature and Calculated Thermodynamic Elements of the Stated Solutes as well as the Calculated Ideal Mole Fraction Solubilities . . . . . . .

11. A Summary of the falculated solute Activity Coefficients ( $r_{2}$ for the Experimental Systems Studied ............

12. A Summary of the Calculated Solvent Activity Coefficients ( $\gamma_{I}$ ) for the Experimental Systems Studied $1 . . . . . . . .$.

13. A Summary of the Enthalpic and Entropic Values for Benzoic Acid in the Solvent Utilized Determined by Graphical Means. .

14. A Summary of the Enthalpic and Entropic Values for para-Hydroxybenzoic Acid in the Solvents Utilized Determined by Graphical Means .............. 
TABIE

15. A Summary of the Enthalpic and Entropic Values for Methyl Paraben in the Solvents Utilized Determined by Graphical Means. .

16. A Summary of the Enthalpic and Entropic Values for Ethyl Paraben in the Solvents Utilized Determined by Graphical Means. .

17. A Summary of the Enthalpic and Entropic Values for Propyl Paraben in the Solvents Utilized Determined by Graphical Means. .

18. A Summary of the Enthalpic and Entropic Values for Butyl Paraben in the Solvents Utilized Determined by Graphical Means. . .

19. Summary of Ideal and Non-Ideal Solutions. .

20. Classification of the Investigational

Solutes by their Non-Ideal Behavior as Defined in Table 19 . . . . . . . .

21. A Summary of the Free Energies Including Partial, Overall and Excess Free Energy Determined in Calories/Mole for Benzoic Acid in the Solvent Systems Studied. . . .

22. A Summary of the Free Energies Including Partial, Overall and Excess Free Energy Determined in Calories/Mole for paraHydroxybenzoic Acid in the Solvent Systems Studied ................

23. A Summary of the Free Energies Including Partial, Overall and Excess Free Energy Determined in Calories/Mole for Methyl Paraben in the Solvent Systems Studied. . .

24. A Summary of the Free Energies Including Partial, Overall and Excess Free Energy Determined in Calories/Mole for Ethyl Paraben in the Solvent Systems Studied. . .

25. A Summary of the Free Energies Including Partial, Overall and Excess Free Energy Determined in Calories/Mole for Propyl Paraben in the Solvent Systems Studied. . 
TABIE

26. A Summary of the Free Energies Including Partial, Overall and Excess Free Energy Determined in Calories/Mole for Butyl

Paraben in the Solvent Systems Studied. .

27. Atomic Orbital Valence State Ionization Potentials. . . . . . . . . . 102

28. Charge Distribution within the Molecules of the Type (Noted) . . . . . . . 128

29. Charge Distribution within the Molecules of the Type (Noted)......... . . 129

30. Total Energy within the Molecules and Their HOMO and LEMO Energies. . . . . . 130

31. Total Energy within the Molecules and Their HOMO and LEMO Energies. . . . . . .

32. HOMO and IEMO Basis Set Orbital Coefficients for para-Hydroxybenzoic Acid. . . . . . 132

33. HOMO and LEMO Basis Set Orbital Coefficients for Methyl-para-Hydroxybenzoate . . . . .

34. HOMO Basis Set Orbital Coefficients for Ethyl para-Hydroxybenzoate. . . . . . 134

35. LEMO Basis Set Orbital Coefficients for Ethyl para-Hydroxybenzoate. . . . . . APPENDIX

A. Cartesian Coordinate Calculation (Using Computer Program Corcal) for Aniline.

B. Cartesian Coordinate Calculation (Using Computer Program Corcal) for p-Amino Benzoic Acid. . . . . . . . . . . 179

C. Cartesian Coordinate Calculation (Using Computer Program Corcal) for Benzoic Acid

D. Cartesian Coordinate Calculation (Using Computer Program Corcal) for Benzoic Acid 
E. Cartesian Coordinate Calculation (Using Computer Program Corcal) for Phenol. . . 182

F. Cartesian Coordinate Calculation (Using Computer Program Corcal) for p-Hydroxy Benzoic Acid..............

G. Cartesian Coordinate Calculation (Using Computer Program Corcal) for p-Hydroxy Benzolc Acid............ 184

H. Cartesian Coordinate Calculation (Using Computer Program Corcal) for Methyl Paraben........... 185

I. Cartesian Coordinate Calculation (Using Computer Program Corcal) for Methyl Paraben............. 186

J. Cartesian Coordinate Calculation (Using Computer Program Corcal) for Methyl Paraben . . . . . . . . . 187

K. Cartesian Coordinate Calculation (Using Computer Program Corcal) for Methyl Paraben ............ 188

I. Cartesian Coordinate Calculation (Using Computer Program Corcal) for Ethyl Paraben . . . . . . . . . . .

M. Cartesian Coordinate Calculation (Using Computer Program Corcal) for Ethyl Paraben........... 190

N. Cartesian Coordinate Calculation (Using Computer Program Corcal) for Ethyl Paraben ...............

0. Cartesian Coordinate Calculation (Using Computer Program Corcal) for Ethyl Paraben ............. 192

P. Cartesian Coordinate Calculation (Using Computer Program Corcal) for Ethyl

Q. Cartesian Coordinate Calculation (Using Computer Program Corcal) for Ethyl Paraben ............. 194 


\section{IIST OF FIGURES}

FIGURE

PAGE

1. Solubility of the Experimental Solutes vs. Carbon Number of the Normal Alcohols. . .

2. Solubility of the Experimental Solutes in the Experimental Solvents vs. the Carbon Number of the Experimental Solutes. . . .

3. Solubility of the Noted Solutes in the Experimental Solvents vs. Temperature $\left({ }^{\circ} \mathrm{C}\right) .33$

4. Solubility of Methyl Paraben at the Experimental Temperatures vs. Carbon Number of the Normal Alcohols . . . . . . . . .

5. Solubility Differential at $30^{\circ} \mathrm{C}$ for the Noted Systems vs. Carbon Number of the Normal Alcohols . . . . . . . . . . .

6. Mole Fraction Solubility for the Experimental Solutes vs. Dielectric Constant of the Individual Normal Alcohol Solvents at

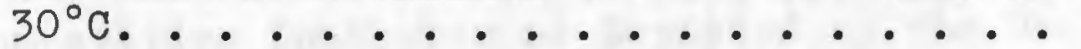

7. Comparison of Ideal and Experimental log Mole Fraction Solubility for the Noted Solutes vs. Reciprocal Temperature (Kelvin)

8. Log Mole Fraction Solubility of Benzoic Acid in the Experimental Solvents vs. Reciprocal Temperature and Log Temperature (Kelvin). . . . . . . . . . . . . .

9. Log Mole Fraction Solubility of paraHydroxybenzoic Acid in the Experimental Solvents vs. Reciprocal Temperature and Log Temperature (Kelvin). . . . . . . .

10. Log Mole Fraction Solubility of Methyl Paraben in the Experimental Solvents vs. Reciprocal Temperature and Log Temperature (Kelvin) 
FIGURE

1I. Log Mole Fraction Solubility of Ethyl Paraben in the Experimental Solvents vs. Reciprocal Temperature and Log Temperature (Kelvin).............

12. Iog Mole Fraction Solubility of Propyl Paraben in the Experimental Solvents vs. Reciprocal Temperature and Log Temperature (Kelvin)...............

13. Log Mole Fraction Solubility of Butyl Paraben in the Experimental Solvents vs. Reciprocal Temperature and Log Temperature (Kelvin) ............

14. Comparison of the Ideal and Actual Partial Free Energy, Enthalpy and Entropy Values for Methyl Paraben vs. the Carbon Number of the Normal Alcohol . . . . . . . .

15. Part of the Proposed Glycosaminopeptide "backbone" that Contributes to the Rigidity of the Bacterial Cell Wall . . . 92

16. Inhibition of Enzyme Action by Chemical Competition.

17. Competitive Inhibitor as Depicted by the Replacement of para-Aminobenzoic Acid, an Essential Part of Folic Acid, by Sulfanilamide to Prevent Folic Acid Formation. . .

18. Aniline Molecular Conformation. ...... 111

19. Para-Aminobenzoic Acid: carboxyl group coplanar with the phenyl ring . . . . . 112

20. Benzoic Acid: carboxyl group coplanar with the phenyl ring........... . 113

21. Benzoic Acid: carboxyl group perpendicular to the plane of the phenyl ring..... 114

22. Phenol Molecular Conformation . . . . . 115

23. Para-Hydroxybenzoic Acid: carboxyl group coplanar with the phenyl ring . . . . 116 
FIGURE

PAGE

24. Para-Hydroxybenzoic Acid: carboxyl group perpendicular to the plane of the phenyl ring..................

25. Methyl para-Hydroxybenzoate: carboxyl group and ester moiety coplanar with the phenyl ring; methyl group directed toward the carbonyl oxygen .............

26. Methyl para-Hydroxybenzoate: carboxyl group and ester moiety coplanar with the phenyl ring; methyl group directed toward the phenyl ring ...............

27. Methyl para-Hydroxybenzoate: carboxyl group and ester moiety perpendicular to the plane of the phenyl ring; methyl group directed toward the carbonyl oxygen.........

28. Methyl para-Hydroxybenzoate: carboxyl group and ester moiety perpendicular to the plane of the phenyl ring; methyl group directed under the phenyl ring. ......

29. Ethyl para-Hydroxybenzoate: carboxyl group and ester moiety coplanar with the phenyl ring; ethyl group in a hooked position directed toward the carbonyl oxygen ....

30. Ethyl para-Hydroxybenzoate: carboxyl group and ester moiety perpendicular to the plane of the phenyl ring; ethyl group in a hooked position directed toward the carbonyl oxygen .............

31. Ethyl para-Hydroxybenzoate: carboxyl group and ester moiety perpendicular to the plane of the phenyl ring; ethyl group in a hooked position directed toward the phenyl ring..............

32. Ethyl para-Hydroxybenzoate: carboxyl group and ester moiety coplanar with the phenyl ring; methyl group directed away from the carbonyl oxygen .............

33. Ethyl para-Hydroxybenzoate: carboxyl group and ester moiety perpendicular to the 
plane of the phenyl ring; methyl group directed away from the carbonyl oxygen . . 126

34. Ethyl para-Hydroxybenzoate: carboxyl group and ester moiety perpendicular to the plane of the phenyl ring; methylene group directed under the phenyl ring; methyl group directed away from the phenyl ring.............

35. Theoretical Receptor for the Postulated Active Form of the Paraben Preservatives. - 158 
BOOK I

SOLUBILITY AND THERMODYNAMICS 


\section{I}

\section{INTRODUCTION}

In this investigation the effect of temperature upon the solubility of chemically related and activity related solutes was determined. Values of heats of fusion for most of these compounds are available in the literature which enables the determination of other important thermodynamic quantities such as activity coefficients. This, coupled with the experimentally evaluated thermodynamic elements, allows for a powerful insight into solubility mechanisms.

Additionally, it was felt that previously enunciated empirical theory of dielectric requirements would be placed on a more quantitative basis. The rather extensive experimental support of the multiplicity of solubility peak maxima for a single solute might be interpreted on a thermodynamic basis. This may lend additional support to this work.

A moderate effort was made by determining partition coefficients for these solutes, correlating this with the previous work of Hansch and with rank order of activity of these compounds. 
PARABENS

While preservatives such as benzoic acid, sodium benzoate, salicylic acid and derivatives, and parahydroxybenzoic acid and derivatives have been used in foods, cosmetics, pharmaceuticals, textiles, etc., for many years the complexity of the problems resulting from their use in pharmaceuticals is of more recent concern. Of the various descriptions of the ideal preservative for pharmaceuticals (1-4), the list of characteristics given by Gershenfeld and Perlstein (3) are pertinent:

It must be effective against all types of microorganisms that cause decomposition.

It must be soluble at the concentration used.

It must not be toxic internally or externally depending upon where it is to be used at the concentration in which it is employed.

It must be compatible: i.e., it must not alter the character of the preparation as to give rise to odor, color, taste, etc.; and it should be practically neutral so that it will not affect the $\mathrm{pH}$ of the preparation.

The cost of the preservative should not increase the price of the preparation to any marked extent.

The inhibiting effect must be a lasting one; therefore, non-volatile substances are to be preferred.

The preservative agents which most nearly fulfill the above characteristics are esters of parahydroxybenzoic acid. 
Using benzoic acid, salicylic acid, and parahydroxybenzoic acid, Sabalitscka (5-19) initiated theoretical investigations concerning the relationship between preservative action and chemical structure. His comparisons provided the following:

The esters of benzoic acid and salicylic acid exert weaker preservative action than the free acid, while the esters of para-hydroxybenzoic acid are more effective in their action than is the free acid $(10,11,20)$.

The larger the alkyl group in the ester, the greater the inhibiting action ( 11,21 ).

The para-hydroxybenzoic acid esters are two to three times as effective as benzoic acid in inhibiting bacterial growth (22).

The suitability of these compounds for the preservation of food stuffs, pharmaceuticals, leather, textiles, ink, etc. has been reviewed in the literature (23-28).

Contrary to these findings, early work of Boeseken and Waterman (29) showed that molds utilized para-hydroxybenzoic acid as a nutrient, and more recently, Davis (30) reported that para-hydroxybenzoic acid is indeed a bacterial vitamin, a possible intermediate in the synthesis of various aromatic compounds from shikimic acid. Nevertheless, Davis proposed using para-hydroxybenzoic acid as a model for chemotherapeutic analogs selectively toxic to microorganisms. To date, however, the "true" mechanism of their preservative action has not been elucidated. Microbiological proof of their microbial and therefore their preservative action has received acceptance despite 
the paucity of information regarding their microbial pharmacology or biochemistry.

The solubility phenomenon of a solute in a given solvent has been of interest to generations of scientists. Pharmacists have been concerned with non-electrolyte solubility in particular. The basis for much of the investigation in the field is the work of Hildebrand; indeed the applications of Hildebrand's theories and its use has been discussed recently by Mauger (32). Much of it is indispensible to the work at hand and will be dealt with in subsequent chapters.

Chertkoff and Martin (33) initiated studies on the solubility of benzoic acid in mixed solvents. Restino and Martin (34) continued the investigation using esters of para-hydroxybenzoic acid, in a series of $n-$ alkanols. The alkanol range was later expanded by Paruta (38), who also studied the solubility of the parabens in sucrose solutions (35), in dioxane-water mixtures (36), and in ethanol-water mixtures (37). In as much as no thermodynamic data for these solubility studies was included in the reports, explanations of the experimental findings were based on semi-qualitative analysis. 
EXPERIMENTAL

Materials

Items of equipment utilized in this study Include:

6406-H Thomas Hoover Melting Point Apparatus ${ }^{1}$

Leeds and Northrup pH Meter Model $7401^{2}$

Sargent Chemical Oscillometer, Model $\mathrm{v}^{3}$

Cary Model 16 Spectrophotometer 4

Temptrol 150 Tempunit 5

Mettler Balance, Type $\mathrm{H}^{6} \mathrm{~T}^{6}$

Abbe - 3I Refractometer ${ }^{7}$

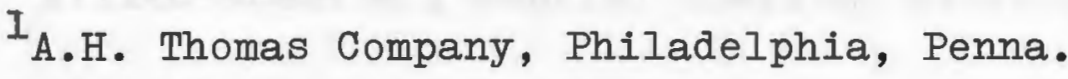

${ }^{2}$ Leeds and Northrup, Philadelphia, Penna.

${ }^{3}$ E.H. Sargent and Company, Chicago, Illinois

${ }^{4}$ Cary Instruments, Monr via, California

${ }^{5}$ Precision Scientific Company, Chicago, Illinois

${ }^{6}$ A.H. Thomas Company, Philadelphia, Penna.

7 Bausch and Lomb Optical Company, Rochester, N.Y. 
Materials (continued)

Chemical utilized in this study were as follows:

Benzoic Acid, Baker Adamson Quality, Lot $\mathrm{I09}^{1}$

Para-Hydroxybenzoic Acid, Lot $120191^{2}$

Methyl para-hydroxybenzoate, Lot $14^{3}$

Ethyl para-hydroxybenzoate, Lot EX665 3

Propyl para-hydroxybenzoate, Lot PX1910 3

Butyl para-hydroxybenzoate, Lot $1^{3}$

Methyl Alcohol Anhydrous, Spectrophotometric Grade Solvent, Iot $\mathrm{VMN}^{4}$

Absolute Ethyl Alcohol, U.S.P.-N.F., Reagent Quality 5

1-Propanol, "Baker Analyzed" Reagent, Iot $35592^{6}$

Normal Butyl Alcohol, Analytical Reagent, Lot TDY 7

${ }^{I}$ Allied Chemical, General Chemical Division

${ }^{2}$ Aldrich Chemical Company

${ }^{3}$ Matheson Coleman and $\mathrm{Bell}$

${ }^{4}$ Mallinckrodt Chemical Works

${ }^{5}$ U.S. Industrial Chemicals Company

${ }^{6}$ J.T. Baker Chemical Company

7 Mallinckrodt Chemical Works 
Materials (continued)

Chemicals (continued)

Normal Hexyl Alcohol, Certified Lot $020251^{8}$

l-Octanol, oR ${ }^{\text {tm }}$, Lot $22^{9}$

Decyl Alcohol, Lot $16^{10}$

Certified Acetone, 99 Mol \% Pure, Lot $792902^{11}$

Certified Benzene, 99 Mol \% Pure (Thiophene

Free), Lot $793869^{12}$

Hydrochloric Acid, C. P. Reagent, Lot El08262 13

Potassium Chloride, U.S.P., Lot $8678^{14}$

$8_{\text {Fisher Scientific Company }}$

${ }^{9}$ Mallinckrodt Chemical Works

${ }^{10}$ Matheson, Coleman and $\mathrm{Bell}$

${ }^{1 I_{\text {Fisher Scientific Company }}}$

12 Fisher Scientific Company

${ }^{13}$ Allied Chemical, General Chemical Division

${ }^{14} \mathrm{~J}$. T. Baker Chemical Company 
Purity of the Alcohols

The purity of the alcohols used in the solubility determinations for the investigational compounds was established by refractive index and dielectric constant measurements. These methods have been previously reported (I) and the dielectric constant measurements documented $(2,3)$. The results were consistent with previous findings. The use of dielectric constants as an indication of the presence of water as a contaminant in alcohols has been established (4).

\section{Melting Points of Pure Parabens}

The 6406 H. Thomas Hoover melting point apparatus was used to determine the melting points of the pure parabens. The results were consistent with previously reported and accepted values $(5,6)$,

Assay Procedure for the Quantitative Determination of Benzoic Acid and the Parabens

The Cary Model 16 Spectrophotometer was used to generate absorbance data. The quantitative relationship between absorbance and concentration can be deduced by analogy if the wavelength at which maximum absorbance is known. The wavelengths used for the compounds were as follows: benzoic acid, $272 \mathrm{mu}$; para-hydroxybenzoic acid, $258 \mathrm{mu}$; and $255 \mathrm{mu}$ for the methyl, ethyl, propyl and butyl ester. Each Benzoic Acid and Paraben was dissolved in 95\% Ethanol and inserted in stanard silica couvettes with a 
$1.00 \mathrm{~cm}$. Iight path. Standard curves were obtained by the method of Beer before analysis of the concentrated solutions were determined. A modified IBM Scientific Subroutine Computer Program provided a method for obtaining least squares.

\section{Procedure for Solubility Studies}

Solubility of Benzoic Acid and the Parabens in numerous solvents was determined by the process outlined by Martin (7). A slight excess of solute and a quantity of solvent were placed in a glass vial which was covered with a plastic cap with a teflon liner and sealed by several layers of plastic electrical tape. Once sealed, all of the vials were placed on an apparatus which rotated them in a temperature-controlled water bath at a speed of thirty-two revolutions per minute. The apparatus had a capacity of forty-eight vials of twenty-one ml. volume, and was constructed to revolve such that the solute traversed the entire length of the vial twice per revolution. The fact that sufficlent content agitation was provided was assumed, since only slight caking was observed in some of the sample vials. The apparatus was immersed in a ten gallon water bath, maintained at the appropriate temperature $\pm 0.3^{\circ} \mathrm{C}$ by a Temptrol 150 unit. Solution equilibrium, as experimentally determined, was reached after thirty hours of rotation. 
After equilbrium was attained, rotation was ceased so that the excess solute could settle in the vials to whatever extent the viscosity of the solution permitted. All samples were kept in the temperature bath until immediately prior to assay.

For assay, a sample vial was removed from the water bath and opened. A portion of the contents was drawn immediately into a warmed pipette fitted with a glass-wool pledget, which was removed before draining the pipette into the tared volumetric flask. The weight of each sample of solution was taken at this time. Thereafter, the concentration of solute was determined by the spectrophotometric assay previously described, and the sample was diluted with $95 \%$ ethanol as required. Solution samples were read against a 95\% ethanol blank. Procedures were carried out in triplicate to arrive at each solubility value; aberrant results which could not be interpreted on the basis of experimental error were re-examined. Average values and their respective standard deviations were derived from the general equation for standard deviation given by Martin (7).

Procedure for Partition Coefficient Studies

Due to the aqueous insolubility of the parabens, it was necessary to prepare stock solutions in watersaturated octanol and then permit partitioning into the aqueous phase. Benzoic acid and p-Hydroxy Benzoic acid did not present this problem and octanol-saturated aqueous 
stock solutions were prepared. The concentration of solute found initially in the stock solutions prepared was approximately $10^{-3}$ molar.

Equal volumes of previously prepared stock solution and appropriate immiscible solvent, either octanol or deionized distilled water, in every case each saturated with the other were added to the vials. A few drops of Hydrochloric Acid added to the aqueous layer of Benzoic Acid and p-Hydroxy Benzoic Acid assured maintenance of the ionized species. Turbulence during the partitioning process was minimized by substituting round bottom $50 \mathrm{ml}$. pyrex screw-capped vials for flat bottomed ones. Again teflon-lined caps were used to seal the vials.

Subsequent to assay the samples, kept at room temperature, were secured to a rocking apparatus and rocked at a constant frequency of approximately one cycle per minute until equilibrium was reached. Equilibrium time was arbitrarily set at 72 hours. The rocking device, similar to those used by Doluisio and Swintoski (8), possessed the distinct advantage that, during every cycle, the sample vials moved from a horizontal to a vertical plane and back again. This process greatly reduced the turbulence, as compared to the process by which samples are allowed to rotate through a full $360^{\circ}$ cycle. Following removal from the rocker apparatus, the sample containers were examined visually to see whether emulsification might have occurred; however, upon standing, all 
samples reverted to biphasic systems leaving no apparent disturbance at the interface. Samples were pipetted from each layer and examined spectrophotometrically with the Cary Model 16 Spectrophotometer. All samples were diluted as required and then read at a pre-determined wavelength against a 95\% ethanol blank.

The initial solute concentration present in the aqueous or octanol phases was determined spectrophotometrically utilizing the identical stock solution as that employed to prepare that portion of the sample. At least three runs were made before an average partition coefficient was calculated. These partition coefficient values were subjected to the same statistical analysis as that described for the solubility determinations. 


\section{RESULTS AND DISCUSSION FOR PARTITION COEFFICIENT DETERMINATIONS}

Physical organic chemists have long appreciated the effects that positional substituents can have upon the rate and equilibrium constants of organic reactions. Medicinal chemists also have recognized that such substitutions can bring about dramatic changes in the potency of a drug; thus the basic problem is reduced to the determination of which substituent produces the most advantageous effect in the biological profile of a related series of compounds.

In general, potency is a function of several physical properties operating simultaneously to produce an observed biological effect. Since these physical properties change more or less independently from one compound to another in a homologous series, it is usually not possible to discern an underlying pattern of change by the mere inspection of structure activity data. Medicinal chemists seeking to understand structure-activity relationships ( $S A R$ ) have, until recently, confined their studies either to cases in which potency is largely a 
function of one physical property (1) or to a drug series in which the nature of the structural changes dictates significant alteration of only one physical property $(2-4)$.

Hansch (5) introduced a new method for the treatment of more complicated cases. He proposed a general equation for determining the quantitative SAR in a drug series, expressing potency as a function of both the partition coefficient and either a rate constant or an equilibrium constant. Hansch's long list of publications (6-24) amply demonstrates that his equation is able to correlate quantitatively a great many sets of structure activity data (6-8). This equation can take several different forms of which two are pertinent. Eq. 1, derived by Hansch and Fujita (6),

$\log \left(\frac{l}{c}\right)=a\left(\log \frac{k}{I}\right)^{2}+b\left(\log \frac{k}{I}\right)+c \log k_{\text {rate }}+f$

deals directly with the associated physical properties: $\log \left(\frac{l}{C}\right)$ is an expression of the drugs potency; $\left(\frac{k}{l}\right)$ is the partition coefficient (25); and $K_{\text {rate }}$ is some rate constant. The expression, Iog ( $\left.\frac{I}{C}\right)$, appears frequently in work of this type and is generally referred to as the potency index. The parabolic relationship between the logarithm of the drug's partition coefficient and its potency index is commonly interpreted as reflecting the probability that a drug will reach a receptor site after 
administration at some external site and traversing numerous aqueous/lipid interfaces. The logarithm of a rate or equilibrium constant is a term associated with the influence that some chemical process at the receptor site may have upon the biological response. Hence, the dependent variable, $\log \left(\frac{l}{C}\right)$, is a function of the drug-associated independent variables $\left(\frac{k}{l}\right)$ and $k_{\text {rate }}$ or $k_{e}$. The regression coefficients $a, b, c$, and $f$ are unique to the series of drugs under examination in a particular biological system, and they can be determined from the total set of dependent and independent variables by the method of least squares (26). In Eq. 2,

$\log \left(\frac{l}{c}\right)=a \pi^{2}+b \pi+c \sigma+f$

the term $\sigma$ is the familiar Hammett substituent constant (27), defined as

$\log \frac{\mathrm{K}_{\mathrm{X}}}{\mathrm{K}_{\mathrm{H}}}=\widetilde{O}=\mathrm{k} \Delta \Delta \mathrm{G}_{\text {ionization }}$

where $\mathrm{K}_{\mathrm{X}}$ is the ionization constant of a benzoic acid derivative substituted by a group $X$, and $\mathrm{K}_{\mathrm{H}}$ is the ionization constant of benzoic acid itself. A new substituent constant, $\pi$, has been introduced, using the Hammett relationship as a model, thus,

$\log \frac{\left(\frac{k}{l}\right)_{x}}{\left(\frac{k}{I}\right)_{H}}=7=k \Delta \Delta G_{\text {Hydrophobicity }}$. 
As can be seen, relative equilibrium constants are being utilized; and instead of the ionization constant, the partition coefficient is being considered. Eq. 2 is most convenient for treating substituent effects, since $\sigma$ and $\pi$ are characteristics of the substituents alone and since values for the most common ones have been determined $(28,29)$.

Hansch used Eq. I to generate the regression coefficients which he then substituted into the following equation:

$\log P^{\prime}=-0.1653(\log P)^{2}+1.784(\log P)-2.201$

$$
\mathrm{R}=0.996
$$

where $P C^{\prime}$ is the phenol coefficient for the drug activity. Table 7 gives the data necessary for the generation of regression analysis data and comparison with the data reported by Hansch (30). The regression analysis was performed on the reported data with the following result:

$$
\begin{aligned}
\log P C^{\prime} & =-0.1653(\log P)^{2}+1.7743(\log P)-2.1897 \\
R & =\text { correlation coefficient }=0.993
\end{aligned}
$$

The exclusion of the data for phenol itself gave

$$
\begin{aligned}
\log P C^{\prime} & =-0.1028(\log P)^{2}+1.3794(\log P)-1.5915 \\
R & =0.992
\end{aligned}
$$

Hence it can already be seen that regression coefficients may readily change by the inclusion or exclusion of per- 


\section{TABIE 1}

A COMPARISON OF EXPERIMENTAL AND IITERATURE VALUES FOR THE PARTITION COEFFICIENTS AND PHENOI COEFFICIENT OF PARA-HYDROXYBENZOIC ACID AND ITS ESTERS

\begin{tabular}{|c|c|c|c|c|c|c|}
\hline $\mathrm{R}$ & $\begin{array}{c}\text { Experimental } \\
\text { Log } \mathrm{P} \\
\end{array}$ & $\begin{array}{l}\text { Hansch } \\
\text { Log } \mathrm{P}^{\mathrm{a}} \\
\end{array}$ & $\begin{array}{l}\text { Phenol } \\
\text { Coeff. }\end{array}$ & $\begin{array}{c}\text { Iiterature } \\
\text { Iog } \\
\text { Phenol } \\
\text { Coefficient } \\
\end{array}$ & $\begin{array}{l}\text { Phenol }^{a} \\
\text { Coefficient } \\
\text { Normalized } \\
\end{array}$ & $\begin{array}{l}\text { Hansch Normalized } \\
\text { Log Phenol } \\
\text { Coefficient } \\
\text { From Literature }\end{array}$ \\
\hline $\mathrm{H}$ & 0.51202 & - & 2.0 & 0.3010 & 2.94 & - \\
\hline $\mathrm{Me}$ & 2.03096 & 1.88 & 2.6 & 0.415 & 4.16 & 0.62 \\
\hline Et & 2.45413 & 2.38 & 7.1 & 0.8513 & 12.59 & 1.10 \\
\hline$n-P r$ & 2.83577 & 2.88 & 15.0 & 1.1761 & 28.84 & 1.46 \\
\hline iso-Pr & - & 2.68 & 12.0 & - & 22.91 & 1.40 \\
\hline$n-B u$ & 3.25557 & 3.38 & 37.0 & 1.5563 & 75.86 & 1.88 \\
\hline Allyl & - & 2.58 & 13.0 & - & 25.12 & 1.36 \\
\hline Benzyl & - & 4.01 & 83.0 & - & 199.50 & $2 \cdot 30$ \\
\hline Phenol & - & 1.46 & 1.0 & 0.0000 & 1.0 & 0.00 \\
\hline
\end{tabular}

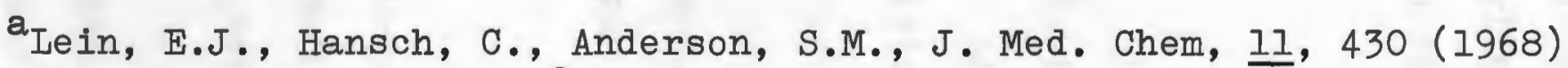

$$
\begin{aligned}
\operatorname{Iog} P C^{\prime}= & -0.167(\operatorname{Iog} P)^{2}+1.784 \log P-2.201 \\
R & =0.996 \\
s & =0.066
\end{aligned}
$$


tinent data, and they should be considered to be relative values.

The following five equations were tested for exactness of fit with the experimental data wi.th or without the inclusion of Hansch data for missing members in the series

$\log P C^{\prime}=a P+b$

$\log P C^{\prime}=a \log P+b$

$\log P C^{\prime}=a P^{2}+b P+c$

$\log \mathrm{PC}^{\prime}=a \log (\mathrm{P})^{2}+\mathrm{b} \log \mathrm{P}+\mathrm{c}$

$\log P^{\prime}=a(\log P)^{2}+b \log P+c$

where $P C^{\prime}$ is the phenol coefficient and $P$ the partition coefficient. The results follow:

I) Experimental data without phenol

$\begin{array}{rllll}\text { Eq. } 9 & a=0.7864 & b=-1.0497 & & R=0.965 \\ \text { Eq. } 12 & a=0.2171 & b=-0.2617 & c=0.1398 & R=0.984\end{array}$

2) Experimental data without phenol and parahydroxybenzoic acid

$\begin{array}{lllll}\text { Eq. } 9 & a=0.9338 & b=-1.4679 & & R=0.993 \\ \text { Eq. } 12 & a=-0.0709 & b=1.3089 & c=-1.950 & R=0.993\end{array}$

3) Experimental data with Hansch data for missing members without phenol

$\begin{array}{lllll}\text { Eq. } 9 & a=0.7195 & b=-0.8741 & & R=0.966 \\ \text { Eq. } 12 & a=-0.9532 & b=1.0174 & c=-1.2651 & R=0.971\end{array}$

4) Experimental data with Hansch data included for missing members without phenol or para-hydroxybenzoic acid 
Eq. $9 a=0.7414 \quad b=-0.9420$

$R=0.953$

Eq. Il $a=0.25 \quad b=0.25 \quad c=-0.9665 \quad R=0.964$

Eq. $12 a=-0.2244 \quad b=2.1164 \quad c=-2.9587 \quad R=0.990$

5) All experimental data

Eq. $9 a=1.2098 \quad b=1.4066 \quad R=0.9812$

Eq. $12 a=0.0859 \quad b=0.4097 \quad c=-0.6958 \quad R=0.984$

6) Experimental data without para-hydroxybenzoic acid

Eq. $9 a=0.8703 \quad b=-1.3221 \quad R=0.994$

Eq. $11 \mathrm{a}=0.1875 \quad \mathrm{~b}=0.50 \quad \mathrm{c}=-1.333 \quad \mathrm{R}=0.9995$

Eq. $12 a=0.0965 \quad b=0.4140 \quad c=-0.8219 \quad R=0.998$

7) All experimental data with Hansch data included for missing members

Eq. $9 a=0.7567 \quad b=-0.9882 \quad R=0.971$

Eq. $12 a=-0.0764 \quad b=1.1634 \quad c=-1.485 \quad R=0.978$

8) Averages of experimental data without para-hydroxybenzoic acid and phenol

Eq. $9 a=0.9393 \quad b=-1.4837 \quad R=0.9982$

Eq. II $a=0.1875 \quad b=0.5625 \quad c=-1.4790 \quad R=0.9963$

Eq. $12 a=-0.0774 \quad b=1.3497 \quad c=-2.0116 \quad R=0.9992$

Without doubt, there may or may not be other equations which will also fit the data; however, as a rule, Eq. 12 gave the best fit of any of the equations tested.

A point of interest should be noted that the experimentally determined partition coefficients agreed totally with the calculated, theoretical Log $P$ values as determined by Hansch and listed in Table 1. This agree- 
ment is not unexpected, since $\log P$ is additive and constitutive in nature. In general the following rules are applicable to the paraben series:

1) 0.5 can be added for each $\mathrm{CH}_{2}$ unit to the experimental value determined or calculated for the parent or starting compound

2) for a branch in a chain 0.2 units are subtracted

3) 2.13 units can be added for a phenyl moiety

4) 1.46 units for phenol

5) 0.90 units for aniline

Further discussion and methods of calculation can be found in the work of Hansch (3-21).

Table 2 lists for the parabens certain physicochemical parameters which may be used to determine their contribution to the biological activity of this series. These data were derived from the regression coefficients and correlation coefficients, as follows:

1) Dependency of protein binding

$$
\begin{array}{lll}
\log \mathrm{K}=0.4812 \Pi_{0}+2.6804 & \mathrm{R}=0.9718 \\
\log \mathrm{K}=3.191 \log \mathrm{S}_{0}+2.7269 & \mathrm{R}=0.9609 \\
\log \mathrm{K}=-0.9488 \log \mathrm{S}_{\mathrm{W}}+1.1745 & \mathrm{R}=0.7680 \\
\log \mathrm{K}=0.0241 \mathrm{MW}-0.8236 & \mathrm{R}=0.8573 \\
\log \mathrm{K}=0.4881 \mathrm{MW}-0.0004 \Pi_{0}+2.7387 & \mathrm{R}=0.9718 \\
\log \mathrm{K}=0.0843 \mathrm{MW}+3.0665 \log \mathrm{S}_{\mathrm{w}} & & \\
& +0.0931 \pi_{0}-5.8592 & \mathrm{R}=0.9999
\end{array}
$$


TABLE 2

A COMPILATION OF PHYSICO-CHEMICAL PARAMETERS FOR THE SUBSTANCES NOTED FROM EXPERIMENTAL AND IITERATURE VALUES

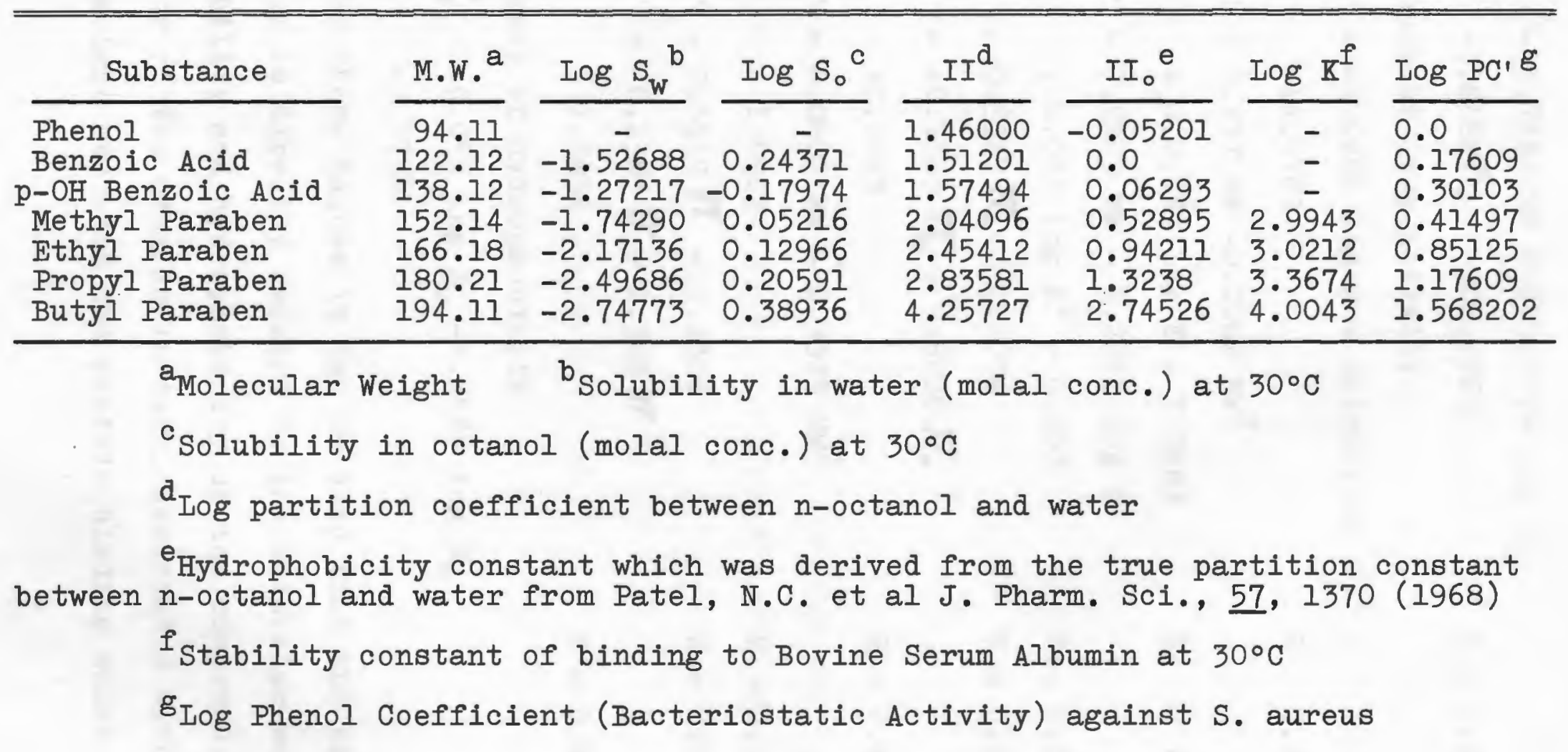


$\log K=-26.7188 \mathrm{MW}+259.0624 \log \mathrm{S}_{\mathrm{o}}$

$$
-0.6482 \pi \cdot-102.2768 \quad R=0.9680
$$

2) Dependency of drug activity

$\log \mathrm{PC}^{\prime}=-1.0261 \log \mathrm{K}+8.1399(\log \mathrm{K})^{2}$

$$
-14.5762
$$$$
R=0.8964
$$

log $\mathrm{PC}^{\prime}=0.137 \mathrm{MW}-0.0002 \mathrm{MW}^{2}$

$$
+0.07153 \log K-7.0283 \quad R=0.7268
$$

$\log \mathrm{PC}^{\prime}=0.2909 \mathrm{MW}-2.2232 \log \mathrm{K}$

$$
+0.032 \log K^{2}-0.403 \quad R=1.0000
$$

$\log \mathrm{PC}^{\prime}=0.5517 \pi_{\bullet}+0.2036$

$\mathrm{R}=0.9298$

$\log \mathrm{PC}^{\prime}=-0.1383 \pi_{0}+0.9098 \pi_{0}^{2}$

$$
+0.1263
$$$$
\mathrm{R}=0.9727
$$

$\log \mathrm{PC}^{\prime}=0.0002 \mathrm{MW}-0.9325 \mathrm{MW}^{2}$

$$
+1.5962
$$

$\log \mathrm{PC}^{\prime}=0.5517 \pi-0.6306$

$R=0.9298$

$\log \mathrm{PC}^{\prime}=-0.1383 \pi+1.328 \pi^{2}$

$$
-1.5654
$$$$
R=0.9727
$$

3) Dependency of hydrophobicity

$$
\begin{aligned}
\pi_{0}= & -0.055 \log S_{w}-1.6636 \log S_{0} \\
& -2.3739
\end{aligned}
$$

From these values it can be seen that the protein binding is directly related to the molecular weight, water solubility and hydrophobicity of the compound. The activity of the drug is in turn, associated with the molecular weight and with the protein binding which occurs. 
This discussion would appear to support the hypothesis that valid relationships between physico-chemical variables and biological activity can be established within the defined boundary conditions for these systems. 


\section{RESULTS AND DISCUSSION OF SOLUBIIITY}

\section{AND THERMODYNAMICS}

The solubility of a series of chemically related solutes, including parent moieties, was determined in a chemically related series of solvents at various temperatures over a range of $25^{\circ}$ to $40^{\circ} \mathrm{C}$. The data on the solubility values determined in the various concentration notations are given in Tables 3 to 8 .

In Figure 1 , the solubility of the solutes under study is plotted as mgm/Gm. of solution versus the carbon number in the n-alkanol solvent series used. Typical non-linear curves were generated in all cases; for each solute, the highest solubility occurred in methanol and decreased in values to $\mathrm{n}$-decanol. Among the solutes themselves, the n-butyl ester had the highest solubility values followed in order by the n-propyl, ethyl, methyl, and the unesterified parent compound. Benzoic acid itself had solubility values in these alcohols intermediate to the ethyl and methyl esters, but its solubility curve did not parallel those of the other solutes in the series. The parent acid and the n-alkyl esters were approximately parallel to one another. 


\section{TABLE 3}

BENZOIC ACID SOLUBILITY*

\begin{tabular}{|c|c|c|c|c|c|c|c|c|}
\hline \multirow[b]{2}{*}{ Solvent } & \multicolumn{2}{|c|}{$25^{\circ} \mathrm{C}$} & \multicolumn{2}{|l|}{$30^{\circ} \mathrm{C}$} & \multicolumn{2}{|l|}{$35^{\circ} \mathrm{C}$} & \multicolumn{2}{|l|}{$40^{\circ} \mathrm{C}$} \\
\hline & $\begin{array}{c}\text { Mole } \\
\text { Fraction } \\
\end{array}$ & $\mathrm{mgm} / \mathrm{Gm}$. & $\begin{array}{c}\text { Mole } \\
\text { Fraction }\end{array}$ & $\mathrm{mgm} / \mathrm{Gm}$. & $\begin{array}{c}\text { Mole } \\
\text { Fraction } \\
\end{array}$ & $\mathrm{mgm} / \mathrm{Gm}$. & $\begin{array}{c}\text { Mole } \\
\text { Fraction }\end{array}$ & $\mathrm{mgm} / \mathrm{Gm}$. \\
\hline Methanol & 0.162 & 423.0 & 0.174 & 445.0 & 0.193 & 477.0 & 0.207 & 498.0 \\
\hline Ethanol & 0.181 & 366.0 & 0.194 & 391.0 & 0.207 & 412.0 & 0.232 & 445.0 \\
\hline n-Propanol & 0.175 & 299.0 & 0.203 & 338.0 & 0.213 & 353.0 & 0.245 & 395.0 \\
\hline n-Butanol & 0.180 & 266.0 & 0.199 & 290.0 & 0.216 & 313.0 & 0.248 & 352.0 \\
\hline n-Hexanol & 0.194 & 223.0 & 0.222 & 254.0 & 0.234 & 267.0 & 0.264 & 300.0 \\
\hline n-Octanol & 0.202 & 192.0 & 0.225 & 214.0 & 0.250 & 238.0 & 0.276 & 268.0 \\
\hline n-Decanol & 0.207 & 168.0 & 0.222 & 180.0 & 0.252 & 206.0 & 0.291 & 223.0 \\
\hline
\end{tabular}

*A summary of the experimentally determined solubilities of Benzoic Acid in the listed n-alkanols at 4 temperatures expressed as mgm/Gm. of solution and mole fraction solubility. 
TABLE 4

PARA-HYDROXY BENZOIC ACID SOLUBILITY*

\begin{tabular}{|c|c|c|c|c|c|c|c|c|}
\hline \multirow[b]{2}{*}{ Solvent } & \multicolumn{2}{|c|}{$25^{\circ} \mathrm{C}$} & \multicolumn{2}{|c|}{$30^{\circ} \mathrm{C}$} & \multicolumn{2}{|c|}{$35^{\circ} \mathrm{C}$} & \multicolumn{2}{|c|}{$40^{\circ} \mathrm{C}$} \\
\hline & $\begin{array}{c}\text { Mole } \\
\text { Fraction }\end{array}$ & 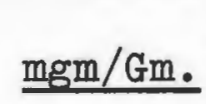 & $\begin{array}{c}\text { Mole } \\
\text { Fraction }\end{array}$ & mgm/Gm. & $\begin{array}{c}\text { Mole } \\
\text { Fraction }\end{array}$ & $\mathrm{mgm} / \mathrm{Gm}$. & $\begin{array}{c}\text { Mole } \\
\text { Fraction }\end{array}$ & $\underline{\mathrm{mgm}} / \mathrm{Gm}$. \\
\hline Methanol & 0.109 & 368.0 & 0.124 & 380.0 & 0.129 & 392.0 & 0.136 & 404.0 \\
\hline Ethanol & 0.135 & 318.0 & 0.134 & 317.0 & 0.146 & 338.0 & 0.152 & 349.0 \\
\hline n-Propanol & 0.112 & 240.0 & 0.126 & 245.0 & 0.138 & 266.0 & 0.145 & 277.0 \\
\hline n-Butanol & 0.108 & 200.0 & 0.125 & 210.0 & 0.128 & 215.0 & 0.137 & 228.0 \\
\hline n-Hexanol & 0.109 & 154.0 & 0.126 & 163.0 & 0.126 & 163.0 & 0.139 & 179.0 \\
\hline n-Octanol & 0.104 & 120.0 & 0.114 & 120.0 & 0.118 & 125.0 & 0.125 & 131.0 \\
\hline n-Decanol & 0.099 & 87.0 & 0.107 & 94.0 & 0.113 & 99.0 & 0.121 & 107.0 \\
\hline
\end{tabular}

*A summary of the experimentally determined solubilities of Para-Hydroxy Benzoic Acid in the listed n-alkanols at 4 temperatures expressed as $\mathrm{mgm} / \mathrm{Gm}$. of solution and mole fraction solubility. 


\section{TABLE 5}

METHYL PARABEN SOLUBILITY*

\begin{tabular}{|c|c|c|c|c|c|c|c|c|}
\hline \multirow[b]{2}{*}{ Solvent } & \multicolumn{2}{|c|}{$25^{\circ} \mathrm{C}$} & \multicolumn{2}{|c|}{$30^{\circ} \mathrm{C}$} & \multicolumn{2}{|c|}{$35^{\circ} \mathrm{C}$} & \multicolumn{2}{|c|}{$40^{\circ} \mathrm{C}$} \\
\hline & $\begin{array}{c}\text { Mole } \\
\text { Fraction }\end{array}$ & $\mathrm{mgm} / \mathrm{Gm}$. & $\begin{array}{c}\text { Mole } \\
\text { Fraction }\end{array}$ & $\mathrm{mgm} / \mathrm{Gm}$. & $\begin{array}{c}\text { Mole } \\
\text { Fraction }\end{array}$ & $\mathrm{mgm} / \mathrm{Gm}$. & $\begin{array}{c}\text { Mole } \\
\text { Fraction }\end{array}$ & $\mathrm{mgm} / \mathrm{Gm}$. \\
\hline Methanol & 0.121 & 395.0 & 0.139 & 433.0 & 0.162 & 479.0 & 0.178 & 508.0 \\
\hline Ethanol & 0.147 & 360.0 & 0.156 & 379.0 & 0.174 & 410.0 & 0.201 & 454.0 \\
\hline n-Propanol & 0.138 & 295.0 & 0.152 & 309.0 & 0.180 & 355.0 & 0.199 & 383.0 \\
\hline n-Butanol & 0.146 & 262.0 & 0.154 & 272.0 & 0.172 & 298.0 & 0.191 & 326.0 \\
\hline n-Hexanol & 0.155 & 205.0 & 0.166 & 212.0 & 0.186 & 253.0 & 0.205 & 262.0 \\
\hline n-Octanol & 0.111 & 147.0 & 0.151 & 172.0 & 0.166 & 188.0 & 0.172 & 195.0 \\
\hline n-Decanol & 0.141 & 125.0 & 0.143 & 138.0 & 0.157 & 152.0 & 0.175 & 169.0 \\
\hline
\end{tabular}

*A summary of the experimentally determined solubilities of Methyl Paraben in the listed n-alkanols at 4 temperatures expressed as mgm/Gm. of solution and mole fraction solubility. 
TABIE 6

ETHYL PARABEN SOLUBILITY*

\begin{tabular}{|c|c|c|c|c|c|c|c|c|}
\hline \multirow[b]{2}{*}{ Solvent } & \multicolumn{2}{|c|}{$25^{\circ} \mathrm{C}$} & \multicolumn{2}{|c|}{$30^{\circ} \mathrm{C}$} & \multicolumn{2}{|c|}{$35^{\circ} \mathrm{C}$} & \multicolumn{2}{|c|}{$40^{\circ} \mathrm{C}$} \\
\hline & $\begin{array}{c}\text { Mole } \\
\text { Fraction } \\
\end{array}$ & $\mathrm{mgm} / \mathrm{Gm}$. & $\begin{array}{c}\text { Mole } \\
\text { Fraction } \\
\end{array}$ & mgm/Gm. & $\begin{array}{c}\text { Mole } \\
\text { Fraction }\end{array}$ & $\mathrm{mgm} / \mathrm{Gm}$. & $\begin{array}{c}\text { Mole } \\
\text { Fraction }\end{array}$ & $\mathrm{mgm} / \mathrm{Gm}$. \\
\hline Methanol & 0.135 & 452.0 & 0.157 & 490.0 & 0.185 & 541.0 & 0.208 & 576.0 \\
\hline Ethanol & 0.165 & 412.0 & 0.184 & 449.0 & 0.218 & 501.0 & 0.220 & 505.0 \\
\hline n-Propanol & 0.176 & 362.0 & 0.188 & 388.0 & 0.216 & 429.0 & 0.229 & 447.0 \\
\hline n-Butanol & 0.178 & 340.0 & 0.183 & 335.0 & 0.210 & 373.0 & 0.234 & 407.0 \\
\hline n-Hexanol & 0.189 & 260.0 & 0.195 & 282.0 & 0.212 & 305.0 & 0.228 & 325.0 \\
\hline n-Octanol & 0.156 & 207.0 & 0.183 & 222.0 & 0.204 & 246.0 & 0.226 & 271.0 \\
\hline n-Decanol & 0.115 & 148.0 & 0.175 & 182.0 & 0.192 & 200.0 & 0.215 & 223.0 \\
\hline
\end{tabular}

*A summary of the experimentally determined solubilities of Ethyl Paraben in the listed n-alkanols at 4 temperatures expressed as mgm/Gm. of solution and mole fraction solubility. 
TABLE 7

PROPYI PARABEN SOLUBIIITY*

\begin{tabular}{|c|c|c|c|c|c|c|c|c|}
\hline \multirow[b]{2}{*}{ Solvent } & \multicolumn{2}{|c|}{$25^{\circ} \mathrm{C}$} & \multicolumn{2}{|c|}{$30^{\circ} \mathrm{C}$} & \multicolumn{2}{|c|}{$35^{\circ} \mathrm{C}$} & \multicolumn{2}{|c|}{$40^{\circ} \mathrm{C}$} \\
\hline & $\begin{array}{c}\text { Mole } \\
\text { Fraction } \\
\end{array}$ & $\mathrm{mgm} / \mathrm{Gm}$. & $\begin{array}{c}\text { Mole } \\
\text { Fraction } \\
\end{array}$ & mgm/Gm. & $\begin{array}{c}\text { Mole } \\
\text { Fraction } \\
\end{array}$ & $\underline{m g} \mathrm{~m} / \mathrm{Gm}$. & $\begin{array}{c}\text { Mole } \\
\text { Fraction }\end{array}$ & $\mathrm{mgm} / \mathrm{Gm}$. \\
\hline Methanol & 0.172 & 540.0 & 0.207 & 595.0 & 0.240 & 639.0 & 0.276 & 682.0 \\
\hline Ethanol & 0.197 & 490.0 & 0.228 & 535.0 & 0.296 & 621.0 & 0.298 & 624.0 \\
\hline n-Propanol & 0.198 & 436.0 & 0.236 & 478.0 & 0.273 & 527.0 & 0.298 & 557.0 \\
\hline n-Butanol & 0.206 & 394.0 & 0.245 & 441.0 & 0.278 & 484.0 & 0.316 & 528.0 \\
\hline n-Hexanol & 0.210 & 326.0 & 0.256 & 362.0 & 0.285 & 412.0 & 0.303 & 434.0 \\
\hline n-octanol & 0.200 & 266.0 & 0.228 & 290.0 & 0.271 & 339.0 & 0.298 & 370.0 \\
\hline n-Decanol & 0.171 & 217.0 & 0.225 & 248.0 & 0.264 & 290.0 & 0.285 & 312.0 \\
\hline
\end{tabular}

*A summary of the experimentally determined solubilities of Propyl Paraben in the listed n-alkanols at 4 temperatures expressed as $\mathrm{mgm} / \mathrm{Gm}$. of solution and mole fraction solubility. 
TABLE 8

BUTYI PARABEN SOLUBILITY*

\begin{tabular}{|c|c|c|c|c|c|c|c|c|}
\hline \multirow[b]{2}{*}{ Solvent } & \multicolumn{2}{|c|}{$25^{\circ} \mathrm{C}$} & \multicolumn{2}{|c|}{$30^{\circ} \mathrm{C}$} & \multicolumn{2}{|c|}{$35^{\circ} \mathrm{C}$} & \multicolumn{2}{|c|}{$40^{\circ} \mathrm{C}$} \\
\hline & $\begin{array}{c}\text { Mole } \\
\text { Fraction }\end{array}$ & $\mathrm{mgm} / \mathrm{Gm}$. & $\begin{array}{c}\text { Mole } \\
\text { Fraction } \\
\end{array}$ & $\underline{\mathrm{mg}} \mathrm{m} / \mathrm{Gm}$. & $\begin{array}{c}\text { Mole } \\
\text { Fraction }\end{array}$ & $\underline{\mathrm{mgm}} / \mathrm{Gm}$. & $\begin{array}{c}\text { Mole } \\
\text { Fraction } \\
\end{array}$ & $\mathrm{mgm} / \mathrm{Gm}$. \\
\hline Methanol & 0.336 & 755.0 & 0.369 & 779.0 & 0.457 & 834.0 & 0.491 & 854.0 \\
\hline Ethanol & 0.360 & 703.0 & 0.395 & 734.0 & 0.437 & 766.0 & 0.500 & 807.0 \\
\hline n-Propanol & 0.355 & 647.0 & 0.402 & 682.0 & 0.458 & 729.0 & 0.502 & 763.0 \\
\hline n-Butanol & 0.364 & 601.0 & 0.388 & 625.0 & 0.439 & 672.0 & 0.501 & 725.0 \\
\hline n-Hexanol & 0.369 & 526.0 & 0.395 & 552.0 & 0.444 & 603.0 & 0.507 & 661.0 \\
\hline n-Octanol & 0.331 & 457.0 & 0.379 & 476.0 & 0.440 & 539.0 & 0.497 & 595.0 \\
\hline n-Decanol & 0.293 & 392.0 & 0.371 & 421.0 & 0.427 & 477.0 & 0.491 & 542.0 \\
\hline
\end{tabular}

*A summary of the experimentally determined solubilities of Butyl Paraben in the listed n-alkanols at 4 temperatures expressed as mgm/Gm. of solution and mole fraction solubility. 


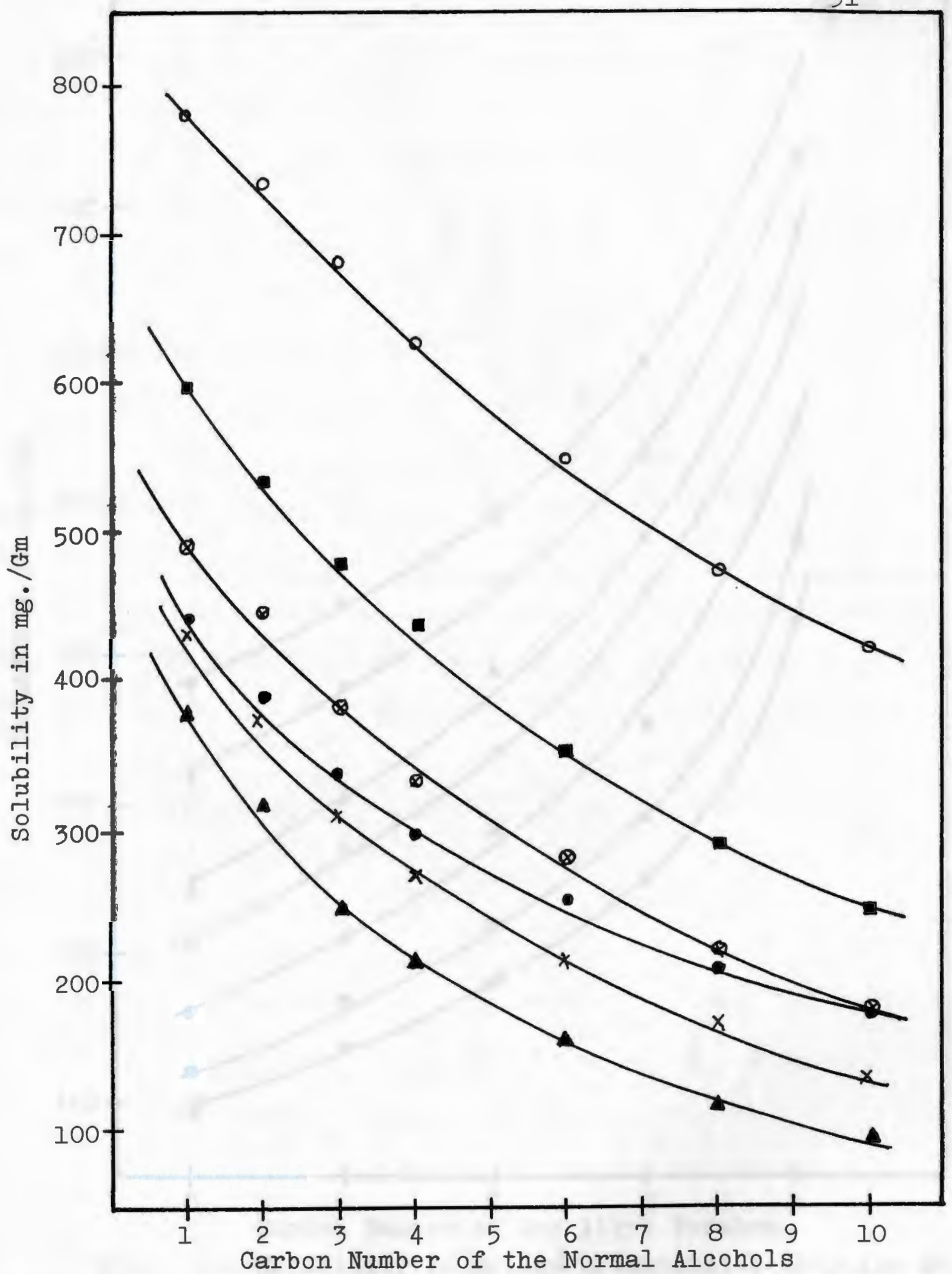

Fig. 1.--Solubility in $\mathrm{mg} . / \mathrm{Gm}$ of saturated solution at $30^{\circ} \mathrm{C}$ for: Benzoic acid; $\Delta$ para-hydroxybenzoic acid; $x$ methyl paraben; ethyl paraben; propyl paraben; and o butyl paraben vs. the carbon number of the normal alcohols. 


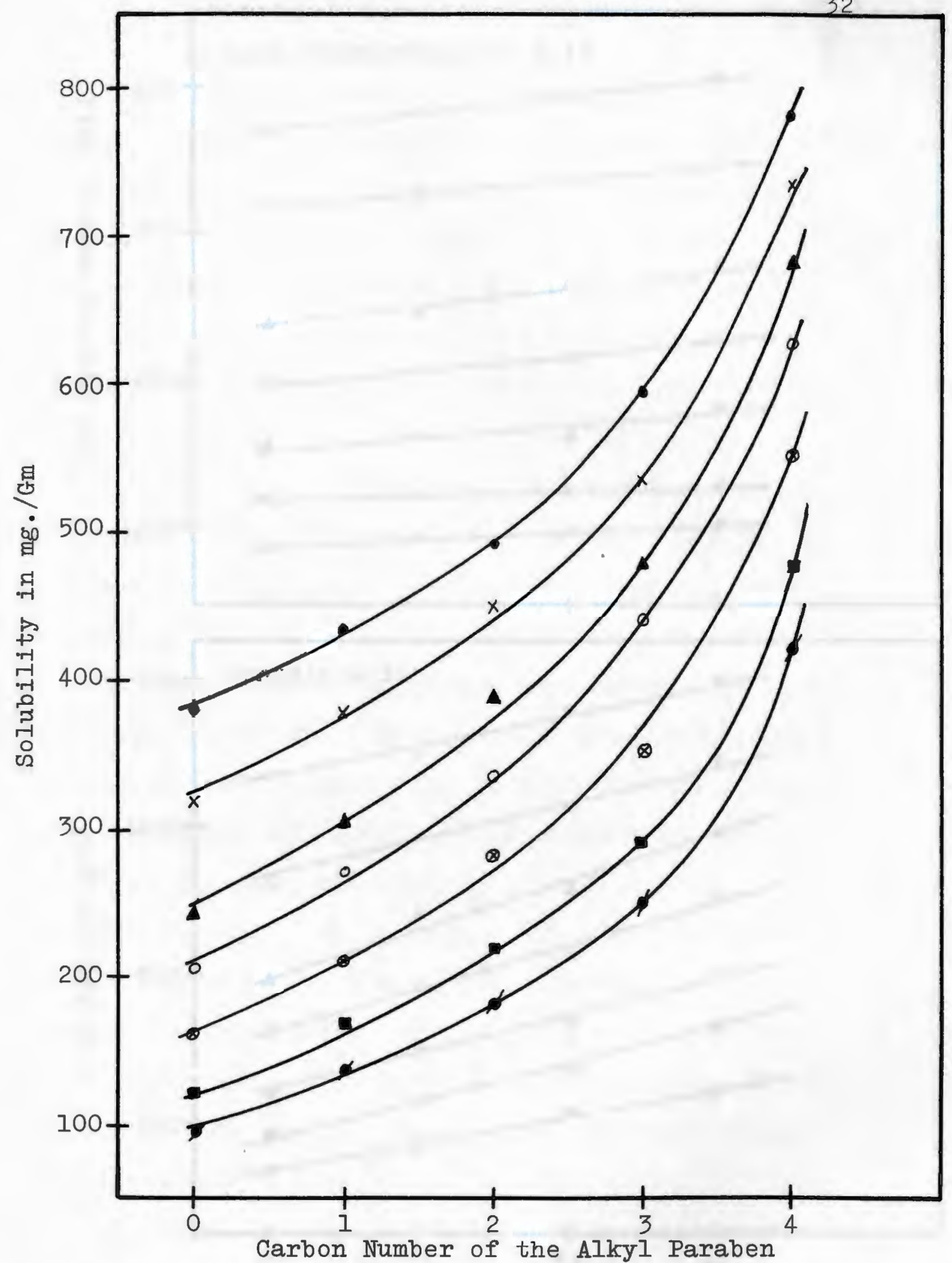

Fig. 2.--Solubility in $\mathrm{mg} . / \mathrm{Gm}$ of Saturated Solution at $30^{\circ}$ for the parabens vs. the number of carbons in each alkyl paraben in - methanol; $x$ ethanol; 1 -propanol; ol-butanol; 1 hexanol; 1 -octanol; and 1 -decanol. 


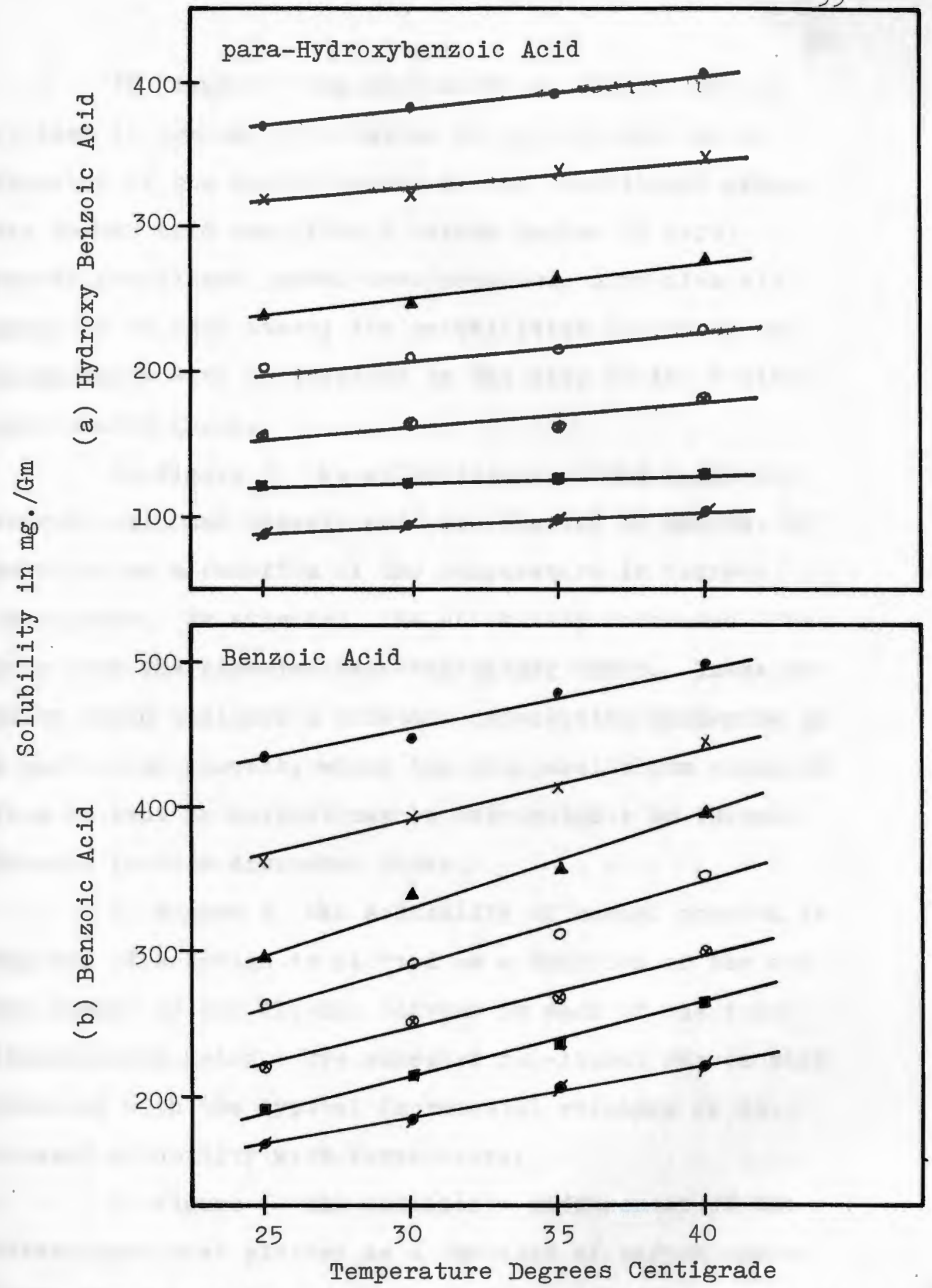

Fig. 3.--Solubility in $\mathrm{mg}$./ $\mathrm{Gm}$ of saturated solution at $30^{\circ} \mathrm{C}$ for noted solutes vs. temperature in methanol; x ethanol; - l-propanol; o l-butanol; $₫ 1$-hexanol; - l-octanol; and ldecanol. 
In Figure 2 the solubility of each solute is plotted in mgm/Gm. of solution in each alcohol as a function of the carbon number of the substituent group; the parent acid was given a carbon number of zero. Smooth non-linear curves were obtained, approximately parallel to each other; the solubilities increased exponentially with an increase in the size of the n-alkyl substituted group.

In Figure 3 the solubilities of the p-hydroxy benzoic acid and benzoic acid are plotted in mgm/Gm. of solution as a function of the temperature in degrees centigrade. As expected, the solubility increased linearly over the experimental temperature range. These results would indicate a constant dissolution mechanism in a particular solvent, while the non-parallelism observed from solvent to solvent may be attributable to thermodynamic factors discussed later.

In Figure 4 the solubility of methyl paraben in $\mathrm{mgm} / \mathrm{Gm}$. of solution is plotted as a function of the carbon number of the alcohol solvent at each of the four temperatures noted. The expected non-linear curves were observed with the typical incremental response of increased solubility with temperature.

In Figure 5 the solubility differences of the esters have been plotted as a function of carbon number; thus, the solubility of each paraben has been subtracted 
from either the next highest or lowest member of the series. It is interesting to note that a one methylene group $\left(-\mathrm{CH}_{2}-\right)$ effect is virtually invariant with the carbon number of the alcohol, indicating parallel and incremental effects. The ethylene $\left(-\mathrm{CH}_{2}-\mathrm{CH}_{2}-\right)$ and propylene $\left(-\mathrm{CH}_{2}-\mathrm{CH}_{2}-\mathrm{CH}_{2}-\right)$ are obviously vector quantities possessing small negative slopes with increasing values as the non-polar groups increase in size. Further, it might be anticipated that the ethylene and propylene differences would become zero if liquid alcohols existed where concentration could be determined by extrapolating to an iso-solubility value.

In Figure 6 the mole fraction solubility is plotted as a function of the dielectric constant of the solvents; for each compound a twin peak array is observed possessing values of dielectric constants of about 10 13 and 19 - 22 which had previously been observed in other work (I). It should be emphasized that the mole fraction values in this series of alcohols were very close to one another; the peak or maximum solubilities in most cases were quite similar in magnitude. It may be inferred from these types of results (especially when the chemical relationship of the alcohols is considered) that the solubility maxima which occur may be the net result of the magnitudes of the enthalpic and entropic effects in each system. These 


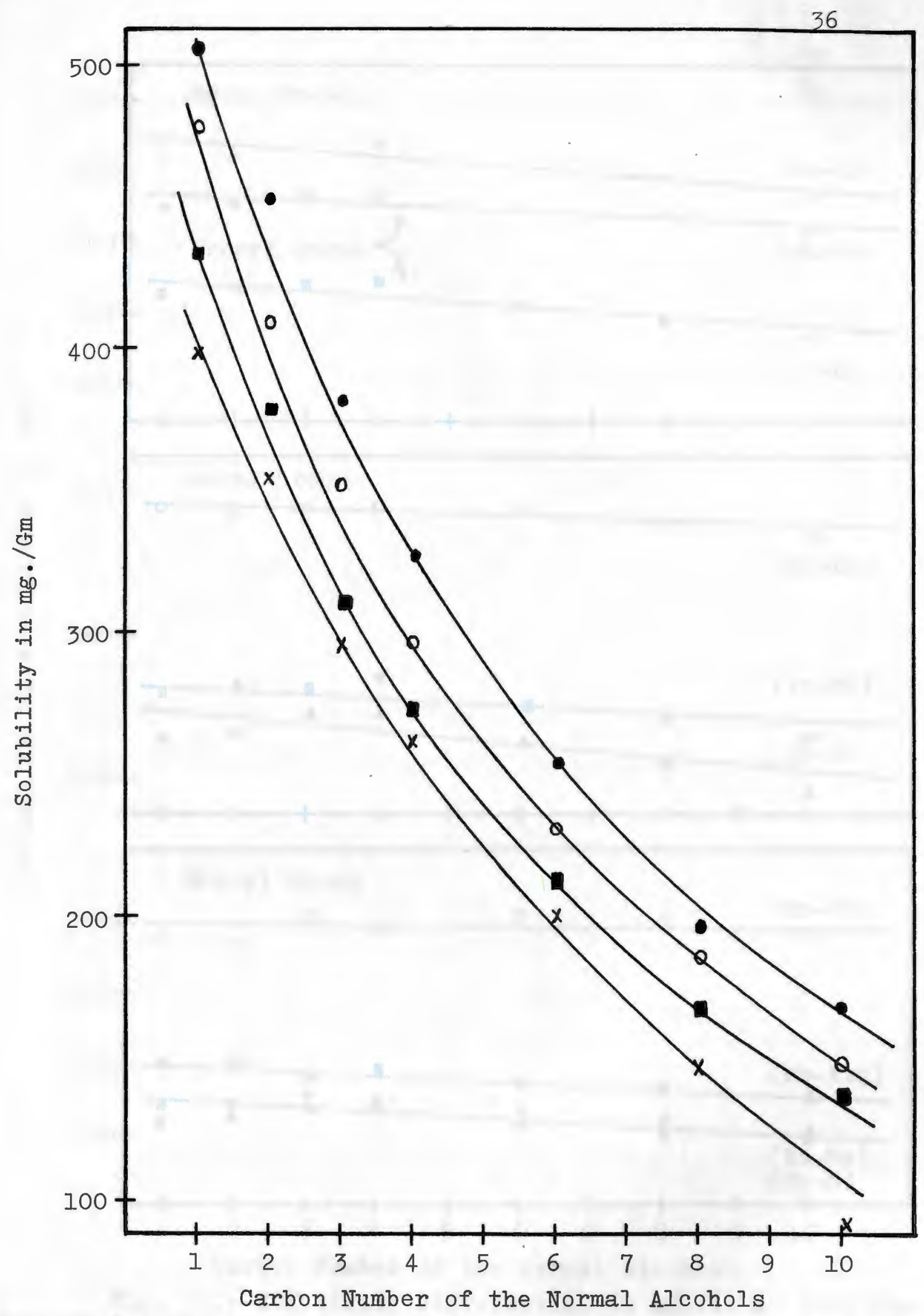

Fig. 4.--Solubility in $\mathrm{mg}$./Gm of saturated solution for methyl paraben at $\mathrm{x} 25^{\circ} \mathrm{C}$; $30^{\circ} \mathrm{C}$; $35^{\circ} \mathrm{C}$; and $\cdot 40^{\circ} \mathrm{C}$ Vs. the carbon number of the normal alcohols. 


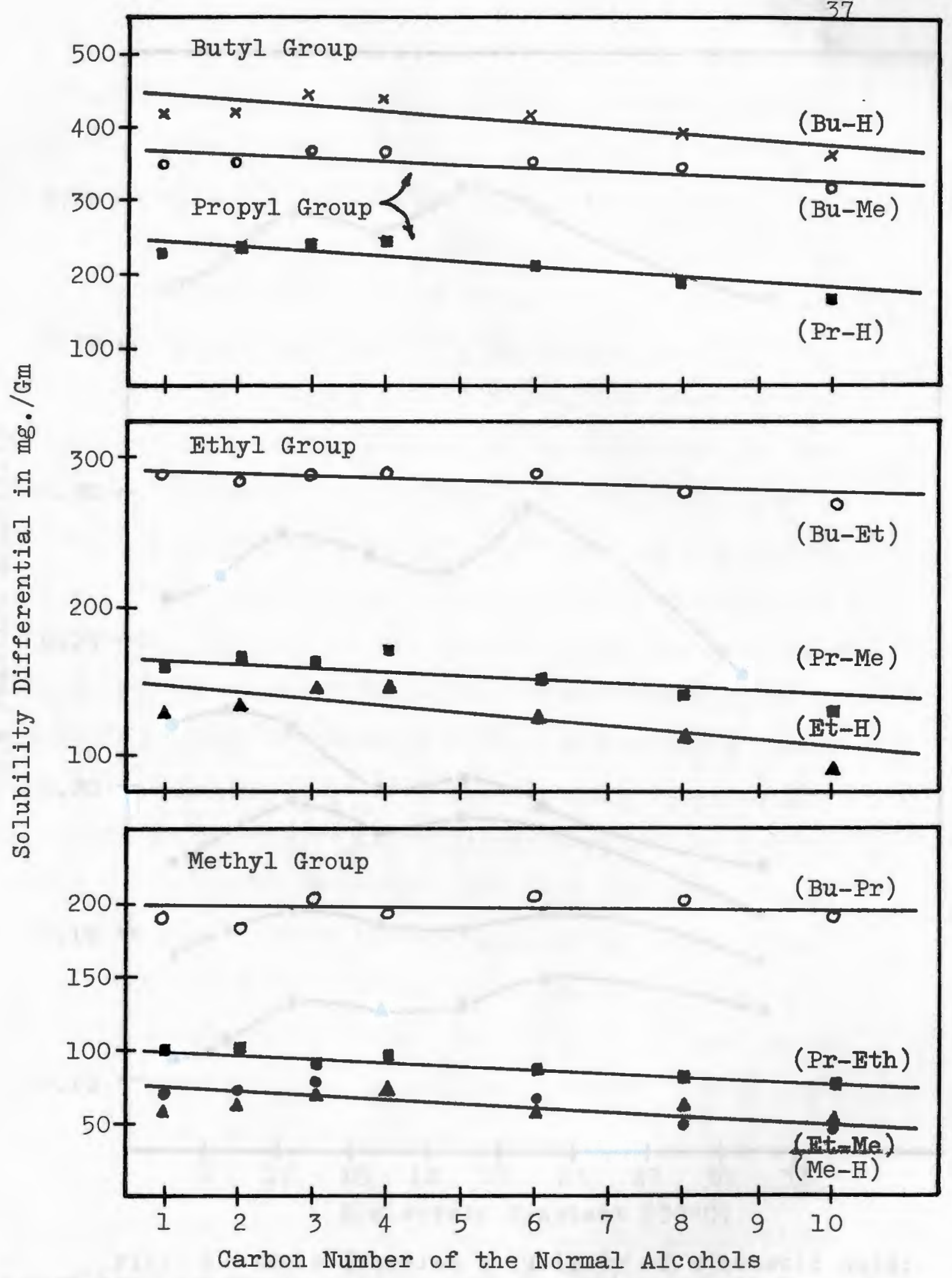

Fig. 5.--Solubility differential in $\mathrm{mg} . / \mathrm{Gm}$ at $30^{\circ} \mathrm{C}$ for the noted systems vs. the carbon number of the normal alcohols. 


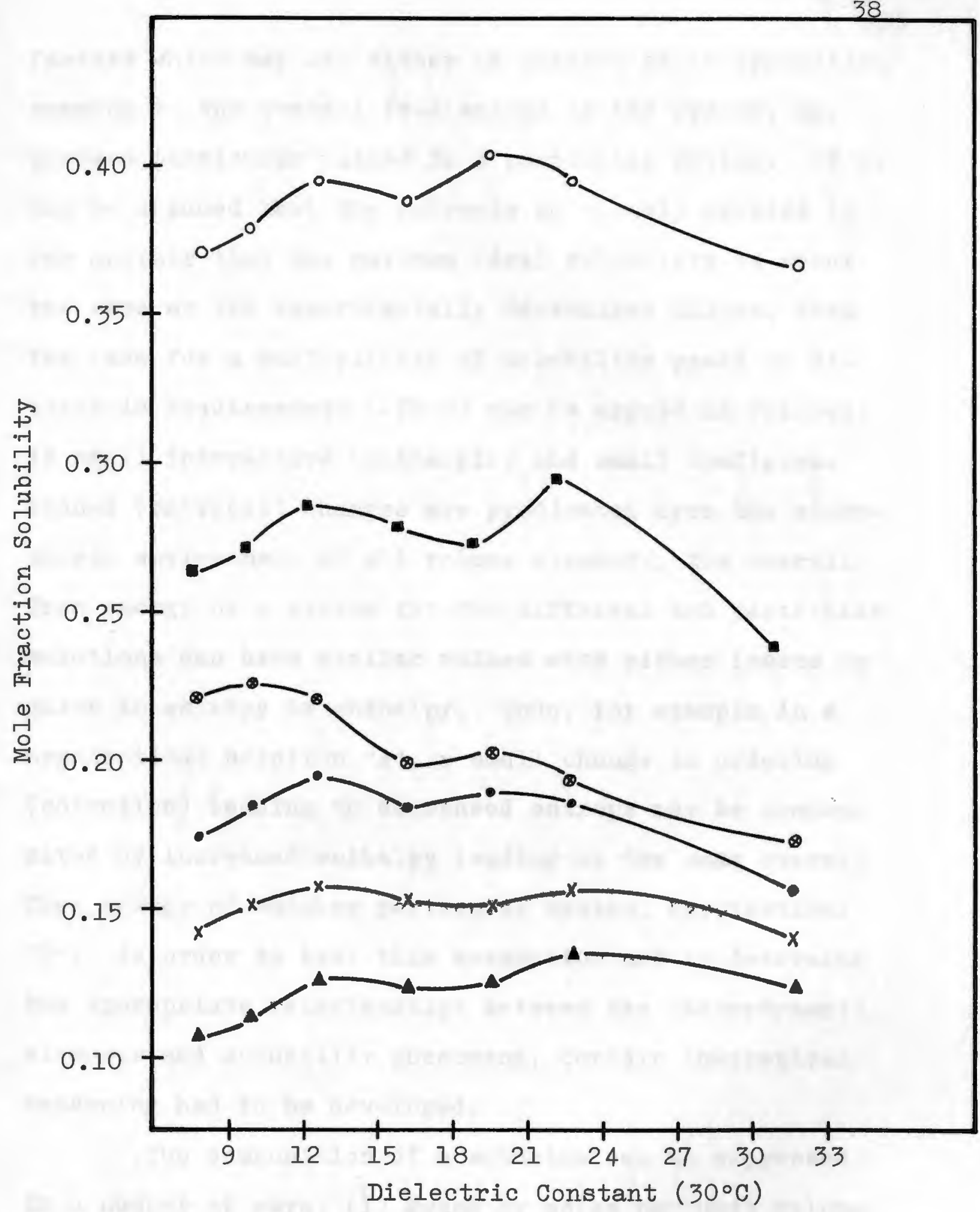

Fig. 6.--Mole fraction solubility of 区enzoic acid; - para-hydroxybenzoic acid; $x$ methyl paraben; - ethyl paraben; - propyl paraben; and - butyl paraben vs. dielectric constant of the individual normal alcohol solvents at $30^{\circ} \mathrm{C}$. 
factors which may act either in concert or in opposition, summing to the overall free energy of the system, may possess particular values in a particular system. If it can be assumed that the solvents so closely related to one another that the maximum ideal solubility is about the same as the experimentally determined maxima, then the case for a multiplicity of solubility peaks or dielectric requirements ( $-D R^{\prime} s$ ) can be argued as follows: if small interactive (enthalpic) and small configurational (entropic) changes are predicated upon the microscopic environment of all volume elements, the overall free energy of a system for two different and particular solutions can have similar values with either losses or gains in entropy or enthalpy. Thus, for example in a hypothetical solution "A", a small change in ordering (solvation) leading to decreased entropy may be compensated by increased enthalpy leading to the same overall free energy of another particular system, hypothetical "B". In order to test this assumption and to determine the appropriate relationships between the thermodynamic elements and solubility phenomena, certain theoretical reasoning had to be developed.

The composition of a solution can be expressed in a number of ways: (1) grams or moles per unit volume; (2) ratio of the moles of one component of a binary solution to the number of moles of a second component, 
i.e $n_{1} / n_{2} ;$ (3) mole fraction $x_{1}=n_{1} /\left(n_{1}+n_{2}+\ldots . n_{n}\right)$; or (4) volume fraction. Mole fraction notation has been adopted due to its acceptance in the scientific community, and $x_{1}$ is solvent and $x_{2}$ solute.

Analytical expressions for free energy can be given as follows:

$$
\begin{aligned}
& \Delta \mathrm{F}=\Delta \mathrm{H}-\mathrm{T} \Delta \mathrm{S} \\
& \Delta \mathrm{F}=-2.3 \mathrm{RT} \log \mathrm{x}_{2}
\end{aligned}
$$

Equating Eq. (I) and (2) leads to

$$
\Delta H-\mathrm{T} \Delta \mathrm{S}=-2.3 \mathrm{RT} \log \mathrm{x}_{2}
$$

The rearrangement of Eq. 3 gives

$$
-\log x_{2}=\frac{\Delta H}{2.3 R T}-\frac{\Delta S}{2.3 R T}
$$

Equation 4 is now in the form $y=m x+b$ and therefore a plot of the $\log x_{2}$ versus $\left(\frac{1}{T}\right)$ yields a straight line with

$$
\text { slope }=\frac{-\Delta H}{2.3 R}=\frac{\text { enthalpy }}{2.3 \mathrm{R}}
$$


and

$$
\text { intercept }=\frac{\Lambda S}{2.3 R}=\frac{\text { entropy }}{2.3 R} \text {. }
$$

The application of basic thermodynamics to the solubility phenomenon requires the following definition of the solution process:

Solid Solute ${\stackrel{H_{f}}{-}}_{(I)}-$ Liquid State $--\frac{\mathrm{X}}{(2)}$ Solute in Solution

As the solid solute proceeds through step one to the liquid state, the enthalpy change is the heat of fusion, $\mathrm{H}_{f}$. If the solution is "ideal" the enthalpy of the second step is zero. When a solid solute passes to a liquid state and then into solution, its behavior is said to be "non-ideal" if the enthalpy of the second step is not zero. Under conditions where both steps one and two are operative, the total enthalpy of the process is commonly expressed as the heat of solution, $\mathrm{H}_{\mathrm{S}}$, where

$$
\mathrm{H}_{\mathrm{s}}=\mathrm{H}_{f}+\mathrm{X} \text {. }
$$

In this solubility pathway, $X$ reflects the enthalpy involved in the transfer of the solute from the liquid to the solution phase. As the $\mathrm{X}$ term approaches zero, the heat of solution and the heat of fusion approach equality, and the system approaches ideal behavior.

When $\mathrm{H}_{f}=\mathrm{H}_{\mathrm{g}}$ then the pathway is ideal, the solubility process is athermal, and $X$, which is identified as a thermodynamic mixing function $\left(H_{m}=\right.$ heat of mixing), is zero. Therefore 


$$
\mathrm{S}_{\mathrm{m}}=\text { enthalpy of mixing }=-\mathrm{R} \text { In } \mathrm{x}_{2} \text {. }
$$

In the ideal case then Eq. 6 becomes

$$
-\log X_{2}(\text { ideal })=\frac{\Delta H_{f}\left(T_{m}-T\right)}{2.3 R T_{m}^{T}}
$$

and can be expanded to give

$$
-\log X_{2}(\text { ideal })=\frac{\Delta \mathrm{H}_{f}}{2.3 \mathrm{RT}}-\frac{\Delta \mathrm{H}_{f}}{2.3 \mathrm{RT}_{\mathrm{m}}} .
$$

In the ideal case

$$
\Delta S_{f}=\frac{\Delta H_{f}}{\Delta T_{m}}
$$

therefore, substituting Eq. 12 into Eq. 11 yields

$$
-\log X_{2}(\text { ideal })=\frac{\Delta H_{f}}{2.3 R T}-\frac{\Delta S_{f}}{2.3 R} \text {. }
$$

If, however, we are dealing with a "non-ideal" solution process

$$
\Delta S_{f} \neq \Delta S_{S} \text { and } \Delta H_{f} \neq \Delta H_{S}
$$

and therefore the equation becomes

$$
-\log x_{2}(\text { non-ideal })=\frac{\Delta H_{S}}{2.3 R T}-\frac{\Delta S_{S}}{2.3 R}
$$

which is in the form $\mathrm{y}=\mathrm{mx}+\mathrm{b}$ and when plotted yields a straight line with

$$
\text { slope }=\frac{-\Delta \mathrm{H}_{\mathrm{S}}}{2 \cdot 3 \mathrm{R}}
$$

and

$$
\text { intercept }=\frac{\Delta \mathrm{S}_{\mathrm{S}}}{2.3 \mathrm{R}} \text { at } \mathrm{T}_{\mathrm{m}} \text {. }
$$

In summary then: 
TABLE 9

COMPARISON OF SLOPE AND INTERCEPT FOR IDEAL

AND NON-IDEAL SOLUBILITY

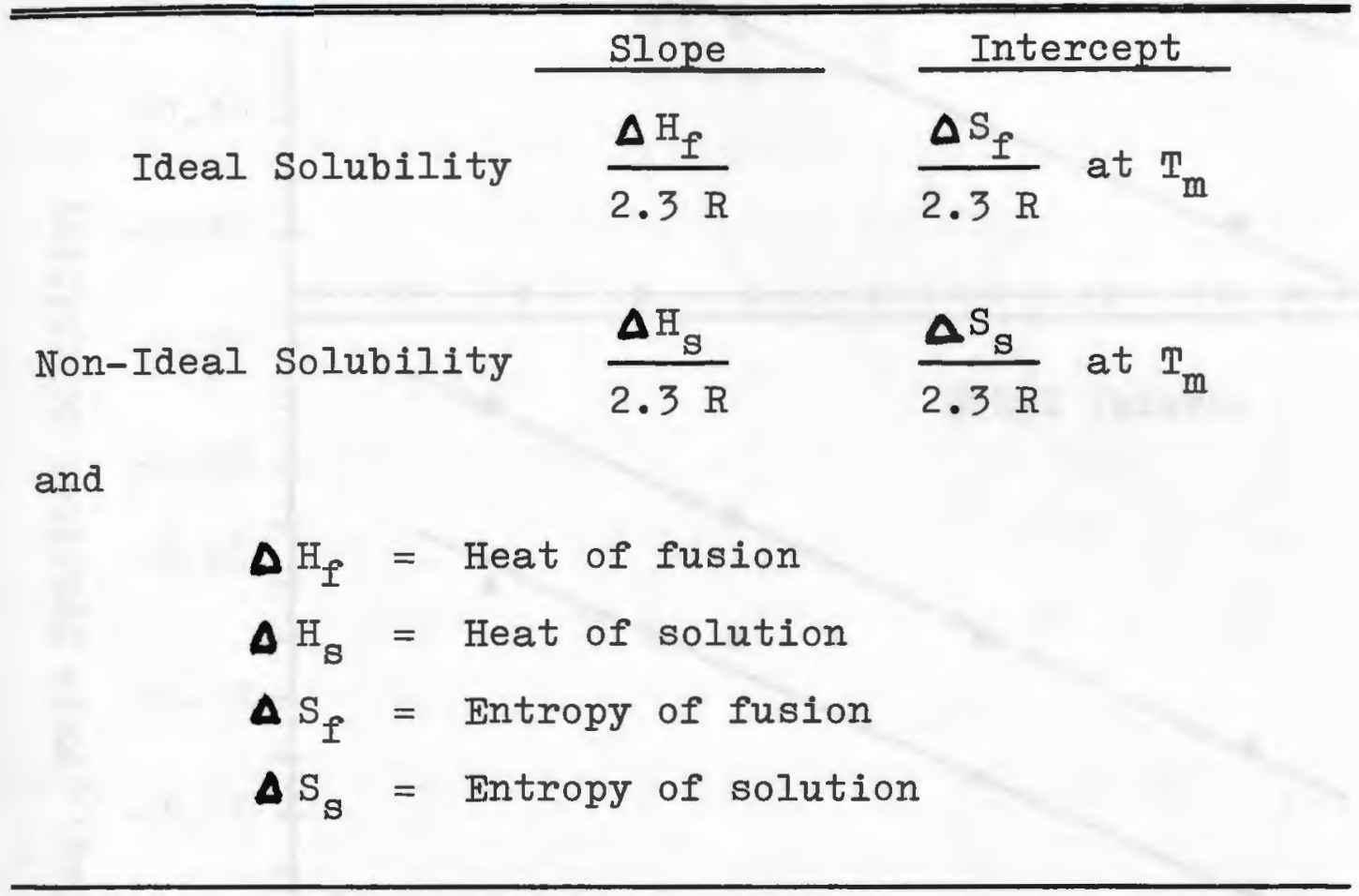

Typical examples for the above table are given in Figure 7.

When the $\log \mathrm{x}_{2}$ is plotted versus the $\log \mathrm{T}$, a slope for the straight line function results which is greater than the entropy of solution when $\log \mathbb{X}_{2}$ is plotted versus ( $\left.\frac{1}{T}\right)$.

$$
\text { slope }=\frac{\Delta S_{\text {system }}}{R}=\text { Entropy of the system }
$$

The entropy of the system is greater because of the increase in disorder on mixing two different random arrays, i.e., that of the solvent and that of the solute. 


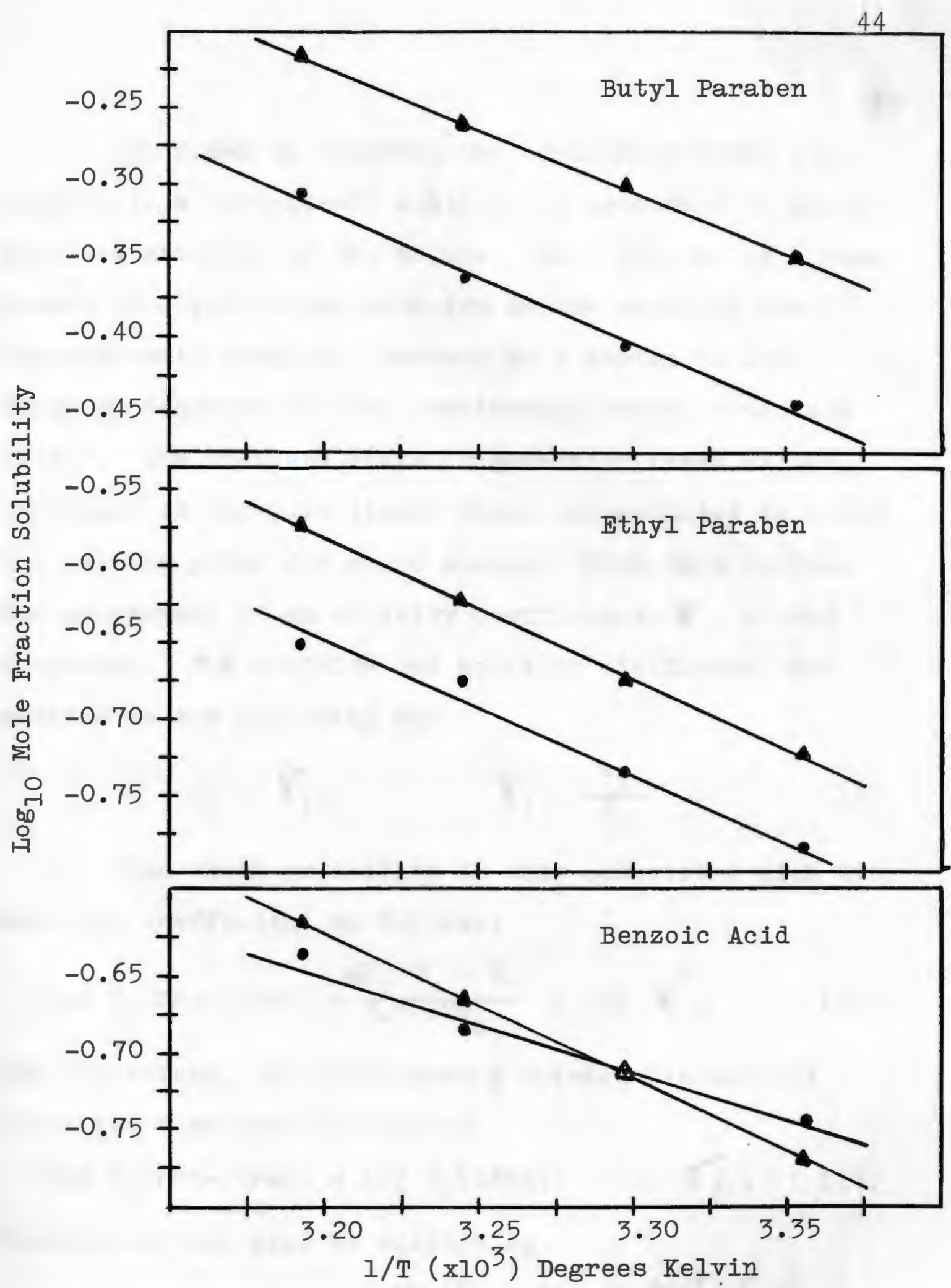

Fig. 7.--Comparison of the $\Delta$ ideal and - experimental log mole fraction solubility for the solutes noted above vs. reciprocal temperature. (Kelvin) 
In order to describe the conditions which contribute to a "non-ideal" state it is necessary to ascertain the activity of the solute. Activity, a, of a component in a particular solution is the ratio of the thermodynamic escaping tendency in a system to its escaping tendency in some arbitrarily chosen "standard state". The standard state is generally taken as the component in the pure liquid state extrapolated to below the melting point for solid states. From this follows the assignment of an activity coefficient, $\gamma$, to the component. The activity and activity coefficient are related in the following way

$$
a_{1}=\gamma_{1} x_{1} \quad \gamma_{1}=\frac{a_{1}}{x_{1}} .
$$

Non-ideal solubility is thus associated with the activity coefficient as follows:

$$
\log x_{2}(\text { non-ideal })=\frac{\Delta_{f}\left(T_{m}-T\right)}{2.3 R T T}+\log \gamma_{2}
$$

and, therefore, the relationship between "ideal" and "non-ideal" solubility becomes

$$
\log \mathrm{x}_{2}(\text { non-ideal })=\log \mathrm{x}_{2}(\text { ideal })+\log \gamma_{2} .
$$

Equation 17 may also be written as

$$
\log x_{2}(\text { non-ideal })=-\frac{\Delta \mathrm{H}_{f}\left(\mathrm{~T}_{\mathrm{m}}-\mathrm{T}\right)}{2.3 \mathrm{RT} \mathrm{T}}+\frac{\mathrm{V}_{2}{ }_{1}^{2}\left(\delta_{2}-\delta_{1}\right)^{2}}{2.3 \mathrm{RT}}
$$

and therefore the overall process may be seen as 
Non-Ideal Solubility = Ideal Solubility + Deviation Term (Activity Coefficient)

If the "ideal" solubility is greater than the "non-ideal" solubility, the difference amounts to a function of the activity coefficient. Thus

$$
\begin{aligned}
x_{2}(\text { ideal })=\frac{a_{2}}{\gamma_{2}} \text { where } a_{2} & =\text { activity } \\
\gamma_{2} & =\text { activity coefficient }
\end{aligned}
$$

as $\gamma_{2}$ approaches unity, the mole fraction approaches the activity of the component, it therefore follows that

$$
a_{2}=x_{2}(\text { ideal })=x_{2}(\text { actual }) \gamma_{2}
$$

and

$$
\gamma_{2}=\frac{x_{2(\text { ideal })}}{x_{2}(\text { actual })}
$$

It thus becomes desirable to differentiate "Ideal" and "Non-Ideal" solubility with a view of obtaining thermodynamic elements from literature and experimental data. Thus, "ideal" solubility could be calculated from $\Delta \mathrm{H}_{f}$ values obtained from literature and $\mathrm{Eq}$. 10 for the ideal mole fraction solubility. These values could then be compared with those obtained experimentally. Thus, the ratio of the ideal solubility and the actual solubility could be used to determine activity coefficients. Such a relationship is obvious from Eq. 22 and is sup- 
ported by Eq. 18, since it can be readily observed that actual solubility is always less than "ideal" solubility (Note: The summation of two positive factors leads to a larger negative logarithm or a smaller $x_{2}$ value.). Thus two experimentally determined elements, ideal solubility and activity coefficients, have been added to the existing list of thermodynamic elements $\Delta \mathrm{H}_{f}, \Delta \mathrm{H}_{\mathrm{s}}, \Delta \mathrm{S}_{\mathrm{S}}$, and $\Delta \mathrm{S}_{\text {system }}$.

It would now be judicious to view the thermodynamic elements from the point of view of the overall solution process. In the following section, a scheme has been developed in order to explore this process to gain a greater understanding for it.

In general, solubility deals with a binary mixture, however, pharmaceutically this is not necessarily true. In order to simplify the conditions, theoretically and experimentally, however, a binary solution was employed as a model throughout. It was necessary to determine the factors each component contributes to the overall process. Thus, partial molal quantities and their final summation had to be dealt with. Hildebrand has cautioned users of the partial molal concept to remember that "... a partial molal quantity is really a property of the solution as a whole, not a property of the component in question. One must not succumb to the 
temptation of attributing the physical property to the molecules of one species alone." With this in mind the following conventions are defined.

$\overline{\mathrm{F}}_{1,2}=$ partial free energy for solute $_{2}$ or solvent 1

$\bar{F}_{i, 2}=$ partial free energy for standard state pure liquid $\Delta \overline{\mathrm{F}}_{1,2}=$ partial free energy change for solute sr solvent $_{1}$ When dealing with the solvent then

$\Delta \overline{\mathrm{F}}_{1}=\left(\overline{\mathrm{F}}_{1}-\overline{\mathrm{F}}_{1}^{\circ}\right)=-\mathrm{RT} \ln \mathrm{a}_{1}=-\mathrm{RT} \ln \mathrm{x}_{1}+\mathrm{RT} \ln \gamma_{1}$ and when solubility is "ideal", $\gamma_{1}=1$ and $a_{1}=x_{1}$ and equation 23 simplifies to

$\Delta \bar{F}_{1}=\left(\bar{F}_{1}-\bar{F}_{1}^{0}\right)=-R T \ln X_{1}$.

In the same manner the solute yields similar equations

$\Delta \overline{\mathrm{F}}_{2}=\left(\overline{\mathrm{F}}_{2}-\overline{\mathrm{F}}_{2}^{\circ}\right)=-\mathrm{RT} \ln \mathrm{a}_{2}=-\mathrm{RT} \ln \mathrm{x}_{2}+\mathrm{RT} \ln \boldsymbol{\gamma}_{2}$

and in the "ideal" case, $\gamma_{2}=1$ and $a_{2}=x_{2}$ to give

$\Delta \overline{\mathrm{F}}_{2}=\left(\overline{\mathrm{F}}_{1}-\overline{\mathrm{F}}_{2}^{\circ}\right)=-\mathrm{RT} \ln \mathrm{X}_{2}$

The overall process can therefore be expressed as follows $\Delta \mathrm{F}($ ideal $)=\overline{\mathrm{F}}_{1}+\overline{\mathrm{F}}_{2}=-\mathrm{RT}\left(\mathrm{x}_{1} \ln \mathrm{a}_{1}+\mathrm{x}_{2} \ln \mathrm{a}_{2}\right)$ where

$\Delta F=$ the overall energy change for the system (the molal free energy change)

Therefore, when the solubility is "non-ideal" the following expression is readily obtained

$$
\begin{aligned}
\Delta \mathrm{F}(\text { non-ideal })=-\mathrm{RT}\left(\mathrm{x}_{1} \ln \mathrm{x}_{1}\right. & +\mathrm{x}_{1} \ln \gamma_{1}+\mathrm{x}_{2} \ln \mathrm{x}_{2} \\
& \left.+\mathrm{x}_{2} \ln \gamma_{2}\right) .
\end{aligned}
$$


The energy which is present over and above that which is considered to be ideal is considered to be an "excess" function. Once again the contributions of each component in solution must be recognized. Hence $\overline{\mathrm{F}}_{1}^{\mathrm{F}}=-\mathrm{RT} \ln \gamma_{1}$ and $\overline{\mathrm{F}}_{2}^{\mathrm{F}}=-\mathrm{RT} \ln \gamma_{2}$

where

$\bar{F}_{I, 2}^{\mathrm{F}}=$ the partial excess molal free energy and the overall contribution is seen as $F^{E}=-R T\left(x_{1} \ln \gamma_{1}+x_{2} \ln \gamma_{2}\right)$

where

$F^{F}=$ the overall excess free energy change for the system (Molal excess free energy change).

In summary, then, solubility can be expressed as a function of the energy change in the following manner $\Delta F($ non-ideal $)=\Delta F($ ideal $)+F^{\mathrm{E}}$ (excess $)$;

therefore, as the excess energy approaches zero, the non-ideal solubility approaches the ideal function.

Table 10 presents literature values for the heat of fusion $\left(\boldsymbol{\Delta} \mathrm{H}_{f}\right)$ which were applied to $\mathrm{Eq}$. 10 to calculate "ideal" mole fraction solubility values. The heat of fusion for para-hydroxybenzoic acid was calculated by utilizing solubility in ethanol to approximate ideal solubility. The entropy of fusion $\left(\Delta S_{f}\right)$ presented can be calculated either by plotting $\log \mathrm{X}_{2}^{i}$ versus $\frac{7}{\mathrm{~T}}$ or by 
assuming an isothermal system in which $\Delta \mathrm{S}_{f}$ can be obtained as seen in Eq. 12. Both methods yield values which agree favorably with each other.

The activity coefficients for the solutes in a particular solvent with respect to temperature were calculated by Eq. 22 and are presented in Table 1l. The activity coefficients for the solvent in the above systems were similarly calculated and are presented in Table 12 .

Tables 13 to 18 give thermodynamic elements which have been determined graphically for the heat of solution $\left(\Delta H_{S}\right)$, the entropy of solution $\left(\Delta S_{S}\right)$ and the entropy of the system ( $\boldsymbol{\Delta} S_{\text {sys }}$ ) from Figures 8 to 13 as substantiated by Eq. 14 and $14 a$. The values for the heat of mixing $\left(\boldsymbol{\Delta} \mathrm{H}_{m}\right)$ and the entropy of mixing $\left(\boldsymbol{\Delta} \mathrm{S}_{m}\right)$ were derived from Eq. 8 in which $X$ represents $H_{m}$ and therefore

$$
\Delta H_{m}=\Delta H_{s}-\Delta H_{f}
$$

and

$$
\Delta \mathrm{S}_{\mathrm{m}}=\Delta \mathrm{S}_{\mathrm{s}}-\Delta \mathrm{S}_{\mathrm{f}}
$$

The results of the above thermodynamic determinations indicate several factors which soon become apparent. During the course of the experimental work, the solutions were observed to become cold to the touch. In fact some even formed frost on the sides of their con- 
TABLE 10

A SUMMARY OF THE LITERATURE AND CALCULATED THERMODYNAMIC ELEMENTS OF THE STATED SOLUTES AS WELL AS THE CALCULATED IDEAL MOIE FRACTION SOLUBILITIES

\begin{tabular}{|c|c|c|c|c|c|c|c|c|}
\hline Compound & $\Delta \mathrm{H}_{\mathrm{f}}^{\mathrm{a}} \mathrm{cal}$ & $\begin{array}{c}a \\
\underline{\mathrm{m} m}\left({ }^{\circ} \mathrm{K}\right)\end{array}$ & $\Delta S_{f}^{b}$ & $\Delta S_{f}=\frac{\Delta H_{f}}{M m}$ & $\frac{\text { Ideal M }}{25^{\circ} \mathrm{C}}$ & $\begin{array}{l}2=\mathrm{X}_{2}= \\
1 \mathrm{e} \text { Fract } \\
30^{\circ} \mathrm{C}\end{array}$ & $\begin{array}{l}\mathrm{X}_{2}{ }^{i}= \\
\text { ion Soll } \\
\frac{35^{\circ} \mathrm{C}}{}\end{array}$ & $\frac{\text { ubility }}{40^{\circ} \mathrm{C}}$ \\
\hline Benzoic Acid & 4302 & 394 & 10.94 & 10.92 & 0.170 & 0.1977 & 0.2153 & 0.2409 \\
\hline $\begin{array}{l}\text { para- } \\
\text { Hydroxybenzoic } \\
\text { Acid }\end{array}$ & $3160^{c}$ & 489 & 6.76 & 6.46 & 0.1243 & 0.1357 & 0.1513 & 0.1605 \\
\hline Methyl Paraben & 4352 & 398 & 11.04 & 10.94 & 0.157 & 0.178 & 0.200 & 0.224 \\
\hline Ethyl Paraben & 4243 & 388 & 11.02 & 10.94 & 0.189 & 0.213 & 0.239 & 0.267 \\
\hline Propyl Paraben & 4026 & 368.6 & 10.86 & 10.92 & 0.272 & 0.304 & 0.339 & 0.376 \\
\hline Butyl Paraben & 3737 & 341 & 11.02 & 10.96 & 0.450 & 0.500 & 0.553 & 0.610 \\
\hline
\end{tabular}

$a_{\text {From literature }}$

${ }^{b}$ Calculated from plot $\log x_{2}^{i}$ vs $\frac{1}{T}$

${ }^{c}$ Calculated utilizing solubility in ethanol as ideal solubility 
TABLE 11

A SUIMIARY OF THE CALCULATED SOLUTE ACTIVITY COEFFICIENTS

$\left(\gamma_{2}\right)$ FOR THE EXPERIMENTAL SYSTEMS STUDIED

\begin{tabular}{|c|c|c|c|c|c|c|c|}
\hline Temp. & $\begin{array}{c}\text { Methanol } \\
\mathrm{CH}_{3} \mathrm{OH} \\
\end{array}$ & $\begin{array}{l}\text { Ethanol } \\
\mathrm{C}_{2} \mathrm{H}_{5} \mathrm{OH} \\
\end{array}$ & $\begin{array}{c}\text { Propanol } \\
\mathrm{C}_{3} \mathrm{H}_{7} \mathrm{OH} \\
\end{array}$ & $\begin{array}{l}\text { Butanol } \\
\mathrm{C}_{4} \mathrm{H}_{9} \mathrm{OH} \\
\end{array}$ & $\begin{array}{l}\text { Hexanol } \\
\mathrm{C}_{6} \mathrm{H}_{13} \mathrm{OH} \\
\end{array}$ & $\begin{array}{l}\text { Octanol } \\
\mathrm{C}_{8} \mathrm{H}_{17} \mathrm{OH} \\
\end{array}$ & $\begin{array}{l}\text { Decanol } \\
\mathrm{C}_{10} \mathrm{H}_{21} \mathrm{OH} \\
\end{array}$ \\
\hline \multicolumn{8}{|c|}{ Benzoic Acid } \\
\hline 25 & 1.190 & 1.065 & 1.102 & 1.071 & 0.997 & 0.954 & 0.930 \\
\hline 30 & 1.254 & 1.122 & 1.074 & 1.097 & 0.984 & 0.969 & 0.984 \\
\hline 35 & 1.262 & 1.177 & 1.147 & 1.128 & 1.043 & 0.977 & 0.968 \\
\hline 40 & 1.322 & 1.176 & 1.113 & 1.100 & 1.035 & 0.989 & 0.938 \\
\hline \multicolumn{8}{|c|}{ Para-Hydroxybenzoic Acid } \\
\hline 25 & 1.137 & 0.997 & 1.108 & 1.143 & 1.139 & 1.192 & 1.258 \\
\hline 30 & 1.091 & 1.012 & 1.082 & 1.087 & 1.079 & 1.191 & 1.271 \\
\hline 35 & 1.170 & 1.039 & 1.096 & 1.181 & 1.204 & 1.280 & 1.337 \\
\hline 40 & 1.179 & 1.054 & 1.109 & 1.171 & 1.153 & 1.289 & 1.332 \\
\hline \multicolumn{8}{|c|}{ Methyl Paraben } \\
\hline 25 & 1.298 & 1.068 & 1.138 & 1.075 & 1.013 & 1.415 & 1.118 \\
\hline 30 & 1.284 & 1.141 & 1.175 & 1.156 & 1.072 & 1.190 & 1.248 \\
\hline 35 & 1.238 & 1.148 & 1.109 & 1.167 & 1.078 & 1.165 & 1.275 \\
\hline 40 & 1.257 & 1.113 & 1.126 & 1.172 & 1.212 & 1.305 & 1.281 \\
\hline
\end{tabular}


TABLE II--Continued

\begin{tabular}{|c|c|c|c|c|c|c|c|}
\hline Temp. & $\begin{array}{c}\text { Methanol } \\
\mathrm{CH}_{3} \mathrm{OH} \\
\end{array}$ & $\begin{array}{l}\text { Ethanol } \\
\mathrm{C}_{2} \mathrm{H}_{5} \mathrm{OH} \\
\end{array}$ & $\begin{array}{c}\text { Propanol } \\
\mathrm{C}_{3} \mathrm{H}_{7} \mathrm{OH} \\
\end{array}$ & $\begin{array}{l}\text { Butanol } \\
\mathrm{C}_{4} \mathrm{H}_{9} \mathrm{OH} \\
\end{array}$ & $\begin{array}{l}\text { Hexanol } \\
\mathrm{C}_{6} \mathrm{H}_{13} \mathrm{OH} \\
\end{array}$ & $\begin{array}{l}\text { Octanol } \\
\mathrm{C}_{8} \mathrm{H}_{17} \mathrm{OH} \\
\end{array}$ & $\begin{array}{l}\text { Decanol } \\
\mathrm{C}_{10 \mathrm{H}_{21}} \mathrm{OH} \\
\end{array}$ \\
\hline \multicolumn{8}{|c|}{ Ethyl Paraben } \\
\hline 25 & 1.400 & 1.146 & 1.074 & 1.062 & 1.000 & 1.212 & 1.644 \\
\hline 30 & 1.361 & 1.156 & 1.132 & 1.163 & 1.094 & 1.164 & 1.221 \\
\hline 35 & 1.290 & 1.110 & 1.106 & 1.140 & 1.126 & 1.173 & 1.244 \\
\hline 40 & 1.286 & 1.212 & 1.168 & 1.141 & 1.170 & 1.183 & 1.244 \\
\hline \multicolumn{8}{|c|}{ Propyl Paraben } \\
\hline 25 & 1.582 & 1.381 & 1.374 & 1.321 & 1.295 & 1.360 & 1.591 \\
\hline 30 & 1.466 & 1.336 & 1.288 & 1.242 & 1.291 & 1.336 & 1.353 \\
\hline 35 & 1.414 & 1.149 & 1.241 & 1.218 & 1.191 & 1.253 & 1.203 \\
\hline 40 & 1.361 & 1.262 & 1.262 & 1.192 & 1.240 & 1.263 & 1.321 \\
\hline \multicolumn{8}{|c|}{ Butyl Paraben } \\
\hline 25 & 1.339 & 1.250 & 1.268 & 1.235 & 1.220 & 1.360 & 1.536 \\
\hline 30 & 1.354 & 1.265 & 1.243 & 1.290 & 1.268 & 1.321 & 1.347 \\
\hline 35 & 1.209 & 1.266 & 1.208 & 1.260 & 1.245 & 1.256 & 1.297 \\
\hline 40 & 1.244 & 1.220 & 1.215 & 1.217 & 1.204 & 1.229 & $1.243 U$ \\
\hline
\end{tabular}




\section{TABLE 12}

A SUMMARY OF THE CALCULATED SOLUTE ACTIVITY COEFFICIENTS

$\left(\gamma_{1}\right)$ FOR THE EXPERIMENTAL SYSTEMS STUDIED

\begin{tabular}{|c|c|c|c|c|c|c|c|}
\hline Temp. & $\begin{array}{c}\text { Methanol } \\
\mathrm{CH}_{3} \mathrm{OH} \\
\end{array}$ & $\begin{array}{l}\text { Ethanol } \\
\mathrm{C}_{2} \mathrm{H}_{5} \mathrm{OH} \\
\end{array}$ & $\begin{array}{c}\text { Propanol } \\
\mathrm{C}_{3} \mathrm{H}_{7} \mathrm{OH} \\
\end{array}$ & $\begin{array}{l}\text { Butanol } \\
\mathrm{C}_{4} \mathrm{H}_{9} \mathrm{OH} \\
\end{array}$ & $\begin{array}{l}\text { Hexanol } \\
\mathrm{C}_{6} \mathrm{H}_{13} \mathrm{OH} \\
\end{array}$ & $\begin{array}{l}\text { Octanol } \\
\mathrm{C}_{8} \mathrm{H}_{17} \mathrm{OH} \\
\end{array}$ & $\begin{array}{l}\text { Decanol } \\
\mathrm{C}_{10 \mathrm{H}_{21}} \mathrm{OH} \\
\end{array}$ \\
\hline \multicolumn{8}{|c|}{ Benzoic Acid } \\
\hline 25 & 0.991 & 1.014 & 1.007 & 1.013 & 1.030 & 1.041 & 1.047 \\
\hline 30 & 0.979 & 1.004 & 1.014 & 0.998 & 1.038 & 1.043 & 1.038 \\
\hline 35 & 0.973 & 0.990 & 0.997 & 1.002 & 1.024 & 1.046 & 1.049 \\
\hline 40 & 0.957 & 0.989 & 1.006 & 1.010 & 1.031 & 1.049 & 1.071 \\
\hline \multicolumn{8}{|c|}{ Para-Hydroxybenzoic Acid } \\
\hline 25 & 0.983 & 1.001 & 0.986 & 0.983 & 0.983 & 0.978 & 0.972 \\
\hline 30 & 0.987 & 0.998 & 0.988 & 0.986 & 0.989 & 0.976 & 0.968 \\
\hline 35 & 0.975 & 0.993 & 0.985 & 0.974 & 0.971 & 0.963 & 0.957 \\
\hline 40 & 0.972 & 0.991 & 0.982 & 0.973 & 0.975 & 0.959 & 0.955 \\
\hline \multicolumn{8}{|c|}{ Methyl Paraben } \\
\hline 25 & 0.959 & 0.988 & 0.978 & 0.987 & 0.998 & 0.948 & 0.981 \\
\hline 30 & 0.966 & 0.986 & 0.981 & 0.984 & 0.998 & 0.980 & 0.971 \\
\hline 35 & 0.954 & 0.969 & 0.976 & 0.966 & 0.982 & 0.959 & 0.949 \\
\hline 40 & 0.945 & 0.972 & 0.969 & 0.959 & 0.964 & 0.937 & 0.941 \\
\hline
\end{tabular}


TABLE 12--Continued

\begin{tabular}{|c|c|c|c|c|c|c|c|}
\hline Temp. & $\begin{array}{c}\text { Methanol } \\
\mathrm{CH}_{3} \mathrm{OH} \\
\end{array}$ & $\begin{array}{l}\text { Ethanol } \\
\mathrm{C}_{2} \mathrm{H}_{5} \mathrm{OH} \\
\end{array}$ & $\begin{array}{c}\text { Propanol } \\
\mathrm{C}_{3} \mathrm{H}_{7} \mathrm{OH} \\
\end{array}$ & $\begin{array}{l}\text { Butanol } \\
\mathrm{C}_{4} \mathrm{H}_{9} \mathrm{OH} \\
\end{array}$ & $\begin{array}{l}\text { Hexanol } \\
\mathrm{C}_{6} \mathrm{H}_{13} \mathrm{OH} \\
\end{array}$ & $\begin{array}{l}\text { Octanol } \\
\mathrm{C}_{8} \mathrm{H}_{17} \mathrm{OH} \\
\end{array}$ & $\begin{array}{l}\text { Decanol } \\
\mathrm{C}_{10 \mathrm{H}_{21}} \mathrm{OH} \\
\end{array}$ \\
\hline & & & Ethyl & raben & & & \\
\hline 25 & 0.938 & 0.972 & 0.984 & 0.987 & 1.000 & 0.961 & 0.917 \\
\hline 30 & 0.933 & 0.965 & 0.970 & 0.964 & 0.977 & 0.963 & 0.942 \\
\hline 35 & 0.934 & 0.973 & 0.971 & 0.963 & 0.966 & 0.956 & 0.942 \\
\hline \multirow[t]{2}{*}{40} & 0.925 & 0.940 & 0.950 & 0.957 & 0.950 & 0.947 & 0.934 \\
\hline & & \multicolumn{4}{|c|}{ Propyl Paraben } & & \\
\hline 25 & 0.879 & 0.907 & 0.908 & 0.917 & 0.922 & 0.910 & 0.878 \\
\hline 30 & 0.878 & 0.901 & 0.911 & 0.922 & 0.911 & 0.901 & 0.898 \\
\hline 35 & 0.870 & 0.939 & 0.910 & 0.916 & 0.924 & 0.919 & 0.898 \\
\hline \multirow[t]{2}{*}{40} & 0.862 & 0.889 & 0.889 & 0.912 & 0.896 & 0.889 & 0.872 \\
\hline & \multicolumn{6}{|c|}{ Butyl Paraben } & \\
\hline 25 & 0.813 & 0.844 & 0.837 & 0.850 & 0.856 & 0.807 & 0.764 \\
\hline 30 & 0.793 & 0.827 & 0.837 & 0.817 & 0.826 & 0.805 & 0.795 \\
\hline 35 & 0.824 & 0.794 & 0.825 & 0.797 & 0.804 & 0.799 & 0.780 \\
\hline 40 & 0.766 & 0.780 & 0.784 & 0.782 & 0.790 & 0.775 & 0.766 \\
\hline
\end{tabular}




\section{TABLE 13}

A SUMMARY OF THE ENTHALPIC AND ENTROPIC VALUES FOR BENZOIC ACID IN THE SOLVENT UTILIZED

DETERMINED BY GRAPHICAI MEANS

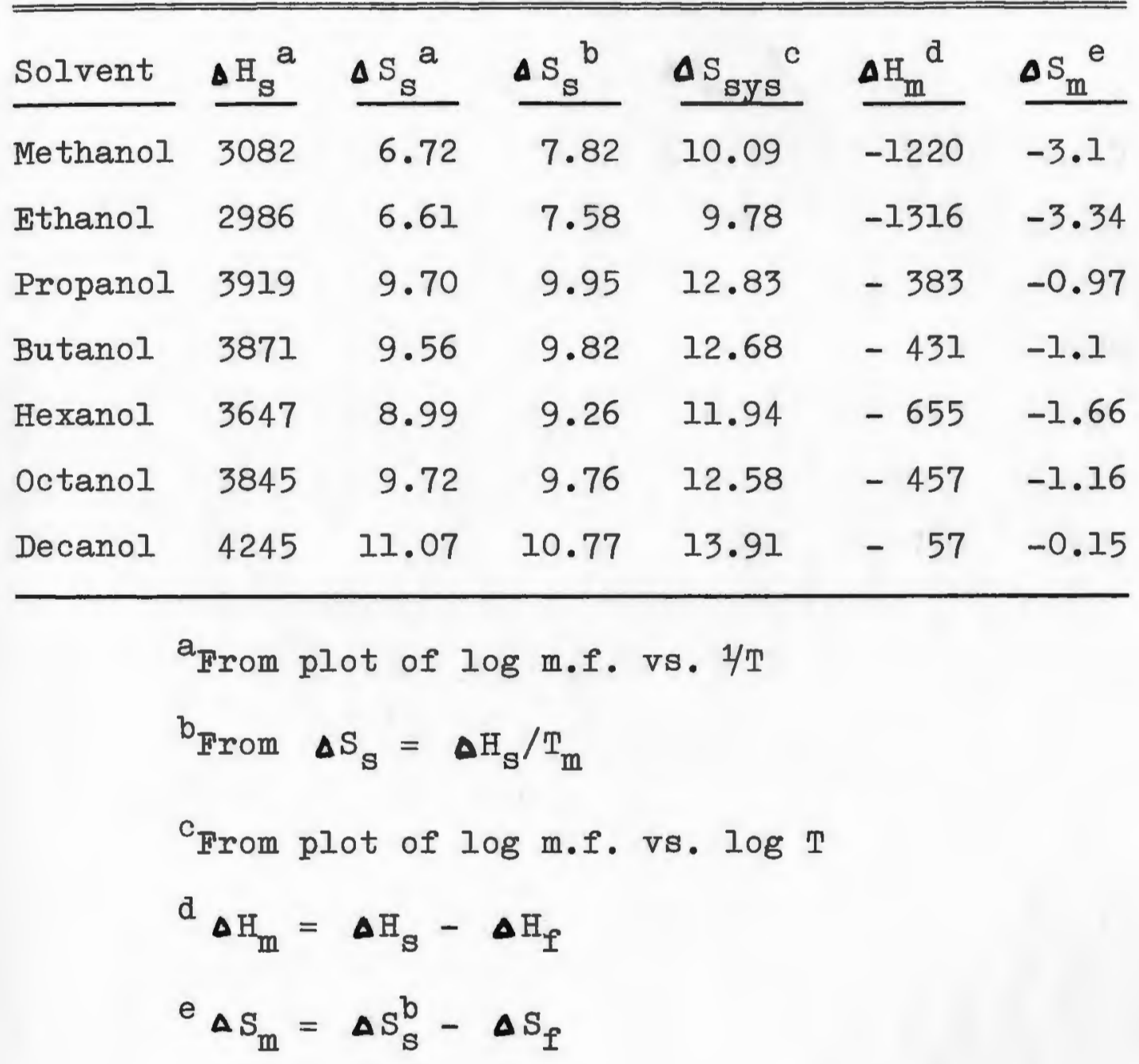


TABIE 14

A SUMMARY OF THE ENTHALPIC AND ENTROPIC VALUES FOR PARA-HYDROXYBENZOIC ACID IN THE SOLVENTS UTILIZED DETERMINED BY GRAPHICAL MEANS

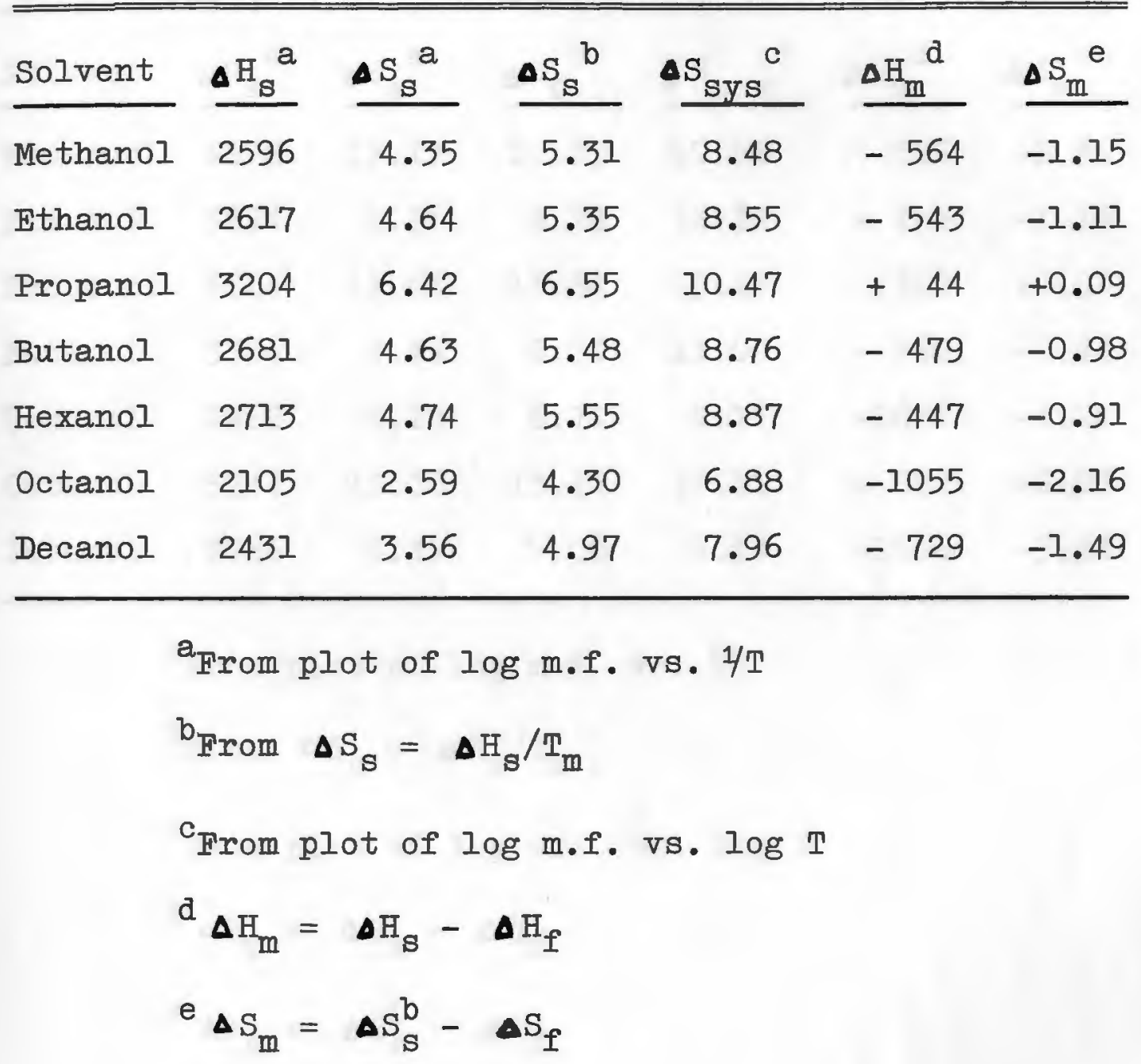


TABLE 15

A SUMMARY OF THE ENTHALPIC AND ENTROPIC VALUES FOR METHYL PARABEN IN THE SOLVENTS UTILIZED

DETERMINED BY GRAPHICAL MEANS

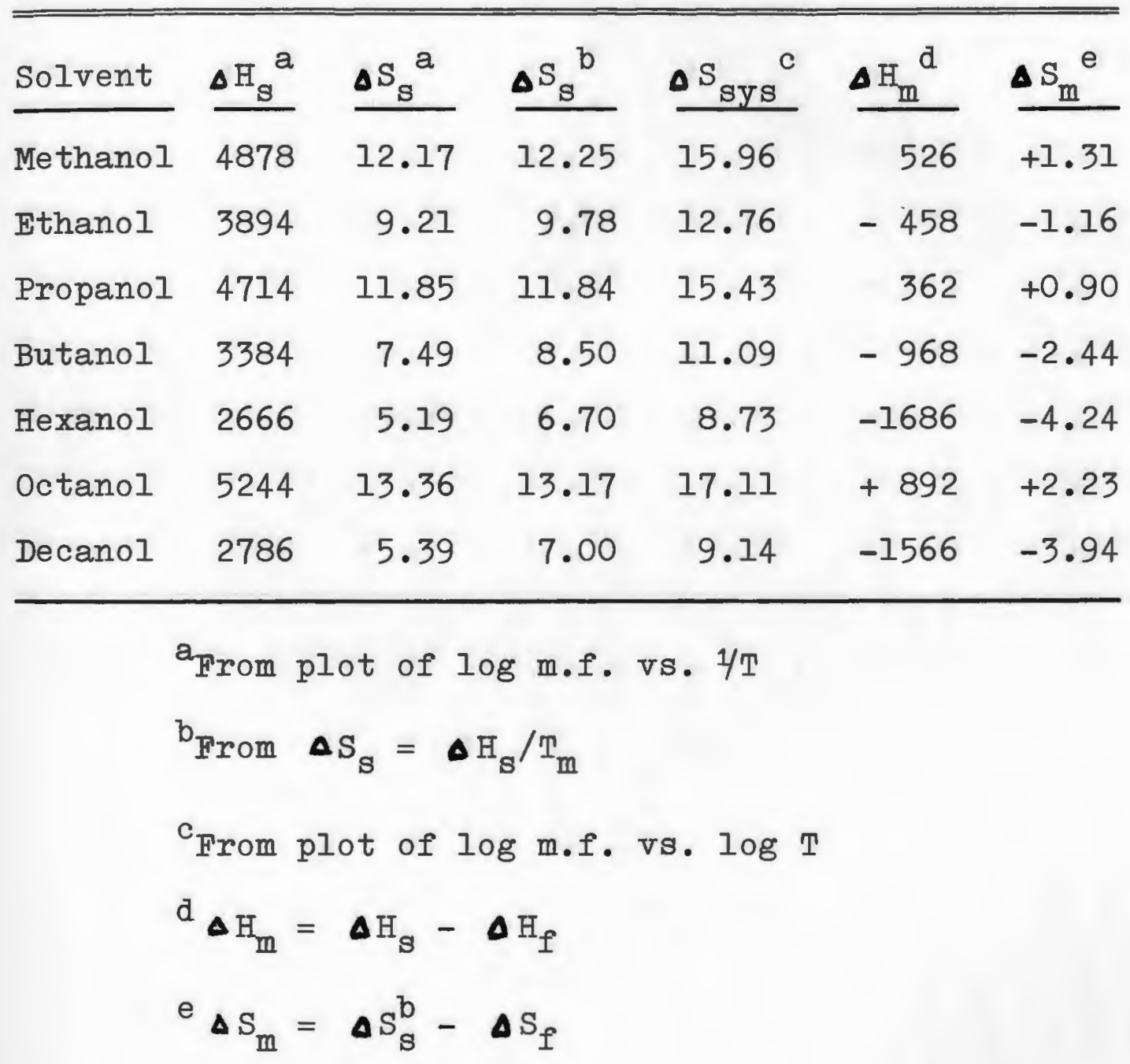


TABIE 16

A SUIMMARY OF THE ENTHALPIC AND ENTROPIC VALUES FOR ETHYI PARABEN IN THE SOLVENTS UTILIZED DETERMINED BY GRAPHICAL MEANS

\begin{tabular}{|c|c|c|c|c|c|c|}
\hline Solvent & $\Delta \mathrm{H}_{\mathrm{S}}{ }^{\mathrm{a}}$ & $\Delta S_{S}{ }^{a}$ & $\Delta S_{S}{ }^{b}$ & $\Delta S_{\text {sys }}{ }^{c}$ & $\Delta H_{m}^{d}$ & $\Delta \mathrm{S}_{\mathrm{m}}{ }^{\mathrm{e}}$ \\
\hline Methanol & 5420 & 14.20 & 13.96 & 17.73 & +1177 & +3.02 \\
\hline Ethanol & 3856 & 9.38 & 9.94 & 12.60 & -387 & -1.00 \\
\hline Propanol & 3428 & 8.03 & 8.83 & 11.22 & -815 & -2.11 \\
\hline Butanol & 3545 & 8.41 & 9.14 & 11.62 & -698 & -1.80 \\
\hline Hexanol & 2415 & 4.76 & 6.22 & 7.91 & -1828 & $-4 \cdot 72$ \\
\hline Octanol & 4514 & 11.48 & 11.63 & 14.76 & +271 & +0.69 \\
\hline Decanol & 7346 & 20.52 & 18.93 & 23.98 & +3103 & +7.99 \\
\hline
\end{tabular}

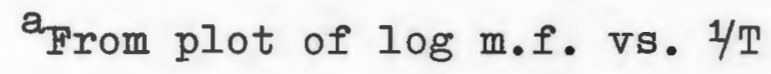

brom $\Delta S_{S}=\Delta H_{S} / T_{m}$

${ }^{C}$ From plot of log m.f. Vs. log T

d

$\Delta \mathrm{H}_{\mathrm{m}}=\Delta \mathrm{H}_{\mathrm{s}}-\Delta \mathrm{H}_{\mathrm{f}}$

${ }^{e} \Delta S_{m}=\Delta S_{s}^{b}-\Delta S_{f}$ 


\section{TABLE 17}

A SUMIMARY OF THE ENTHALPIC AND ENTROPIC VALUES FOR PROPYI PARABEN IN THE SOLVENTS UTILIZED

DETERMINED BY GRAPHICAI MEANS

\begin{tabular}{|c|c|c|c|c|c|c|}
\hline Solvent & $\Delta H_{s}{ }^{a}$ & $\Delta \mathrm{S}_{\mathrm{S}}^{\mathrm{a}}$ & $\Delta S_{S}{ }^{b}$ & $\Delta S_{\text {sys }}{ }^{c}$ & $\Delta H_{m}^{d}$ & $\Delta \mathrm{S}_{\mathrm{m}}{ }^{\mathrm{e}}$ \\
\hline Methanol & 5823 & 16.05 & 15.80 & 19.05 & 1797 & 4.88 \\
\hline Ethanol & 5592 & 15.55 & 15.17 & 18.28 & 1566 & 4.25 \\
\hline Propanol & 5102 & 13.93 & 13.84 & 16.68 & 1076 & 2.92 \\
\hline Butanol & 5232 & 14.43 & 14.19 & 17.11 & 1206 & 3.27 \\
\hline Hexanol & 4798 & 12.99 & 13.02 & 15.69 & 772 & 2.10 \\
\hline Octanol & 5078 & 13.83 & 13.76 & 16.61 & 1052 & 2.84 \\
\hline Decanol & 6295 & 17.70 & 17.08 & 20.56 & 2269 & 6.16 \\
\hline
\end{tabular}

From plot of $\log$ m.f. vs. $1 / T$

$b_{\text {From } \Delta S_{S}}=\Delta H_{s} / T_{m}$

From plot of $\log$ m.f. vs. $\log \mathrm{T}$

$\mathrm{d}_{\Delta \mathrm{H}_{\mathrm{m}}}=\Delta \mathrm{H}_{\mathrm{s}}-\Delta \mathrm{H}_{\mathrm{f}}$

${ }^{e} \Delta S_{m}=\Delta s_{s}^{b}-\Delta S_{f}$ 


\section{TABIE 18}

A SUMMARY OF THE ENTHALPIC AND ENTROPIC VALUES FOR BUTYL PARABEN IN THE SOLVENTS UTILIZED

DETERMINED BY GRAPHICAL MEANS

\begin{tabular}{|c|c|c|c|c|c|c|}
\hline Solvent & $\Delta \mathrm{H}_{\mathrm{s}}^{\mathrm{a}}$ & $\Delta S_{S}^{a}$ & $\Delta S_{S}{ }^{b}$ & $\Delta S_{\text {sys }}{ }^{c}$ & $\Delta \mathrm{H}_{\mathrm{m}}^{\mathrm{d}}$ & $\Delta S_{m}^{e}$ \\
\hline Methanol & 5005 & 14.60 & 14.67 & 16.38 & 1268 & 3.71 \\
\hline Ethanol & 4020 & 11.43 & 11.79 & 13.57 & 283 & 0.83 \\
\hline Propanol & 4347 & 12.53 & 12.75 & 14.23 & 610 & 1.79 \\
\hline Butanol & 4017 & 11.42 & 11.78 & 13.17 & 280 & 0.82 \\
\hline Hexanol & 3959 & 11.26 & 11.61 & 12.97 & 222 & 0.65 \\
\hline Octanol & 5077 & 14.83 & 14.88 & 16.61 & 1340 & 3.92 \\
\hline Decanol & 6266 & 18.63 & 18.38 & 20.47 & 2529 & 7.42 \\
\hline
\end{tabular}

arom plot of log m.f. vs. $1 / T$

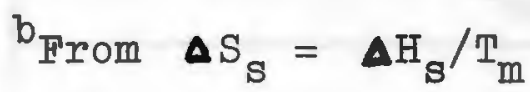

${ }^{C_{F r o m}}$ plot of $\log$ m.f. vs. $\log T$

$\mathrm{d}_{\Delta \mathrm{H}_{\mathrm{m}}}=\Delta \mathrm{H}_{\mathrm{S}}-\Delta \mathrm{H}_{\mathrm{f}}$

${ }^{e} \Delta S_{m}=\Delta S_{s}^{b}-\Delta S_{f}$ 


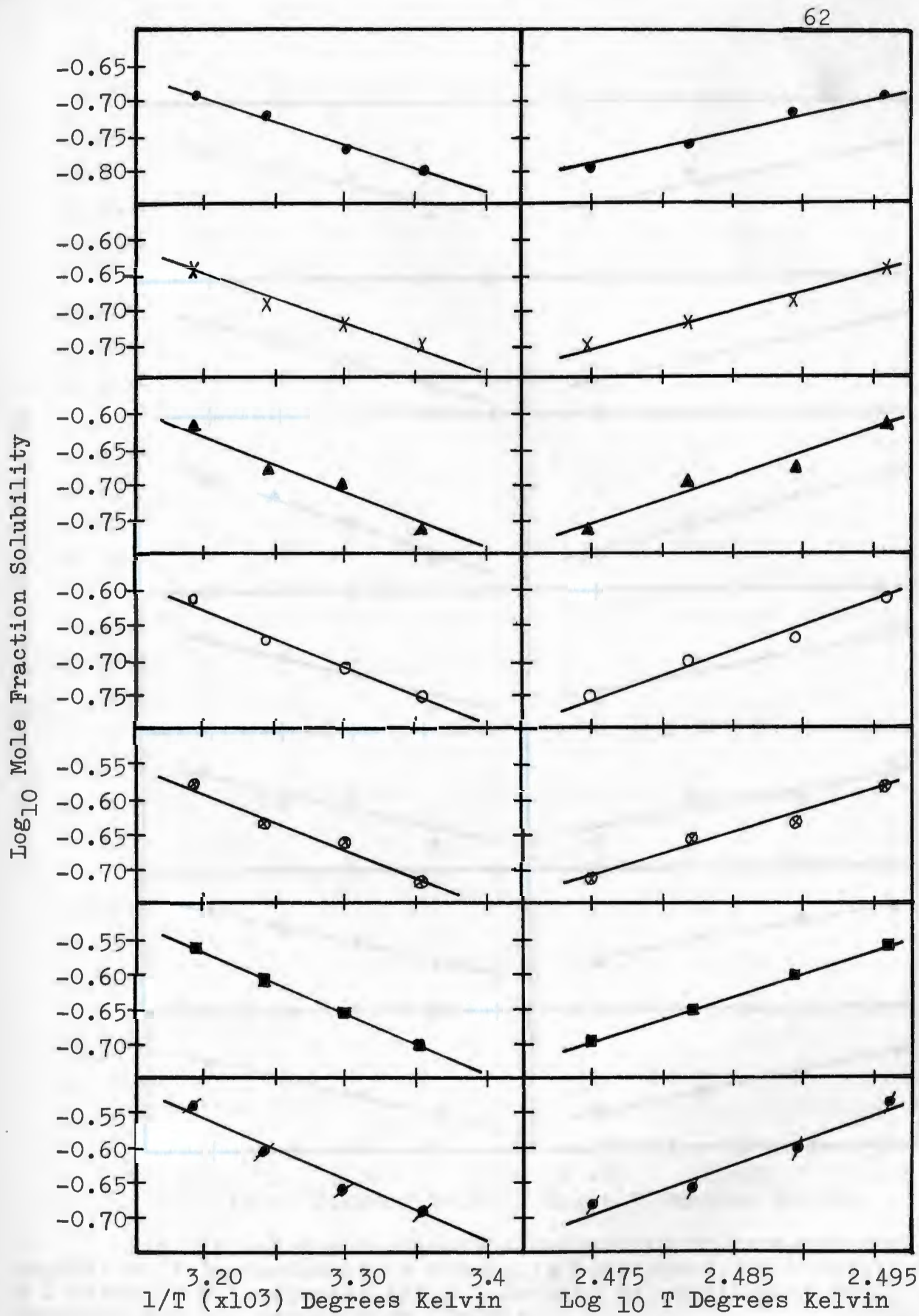

Fig. 8.-- Log mole fraction solubility of benzoic acid in - methanol; x ethanol; $\wedge$ l-propanol; 1 -butanol; 1 -hexanol; temperature; (Kelvin)-decanol vs. reciprocal temperature and log 
63

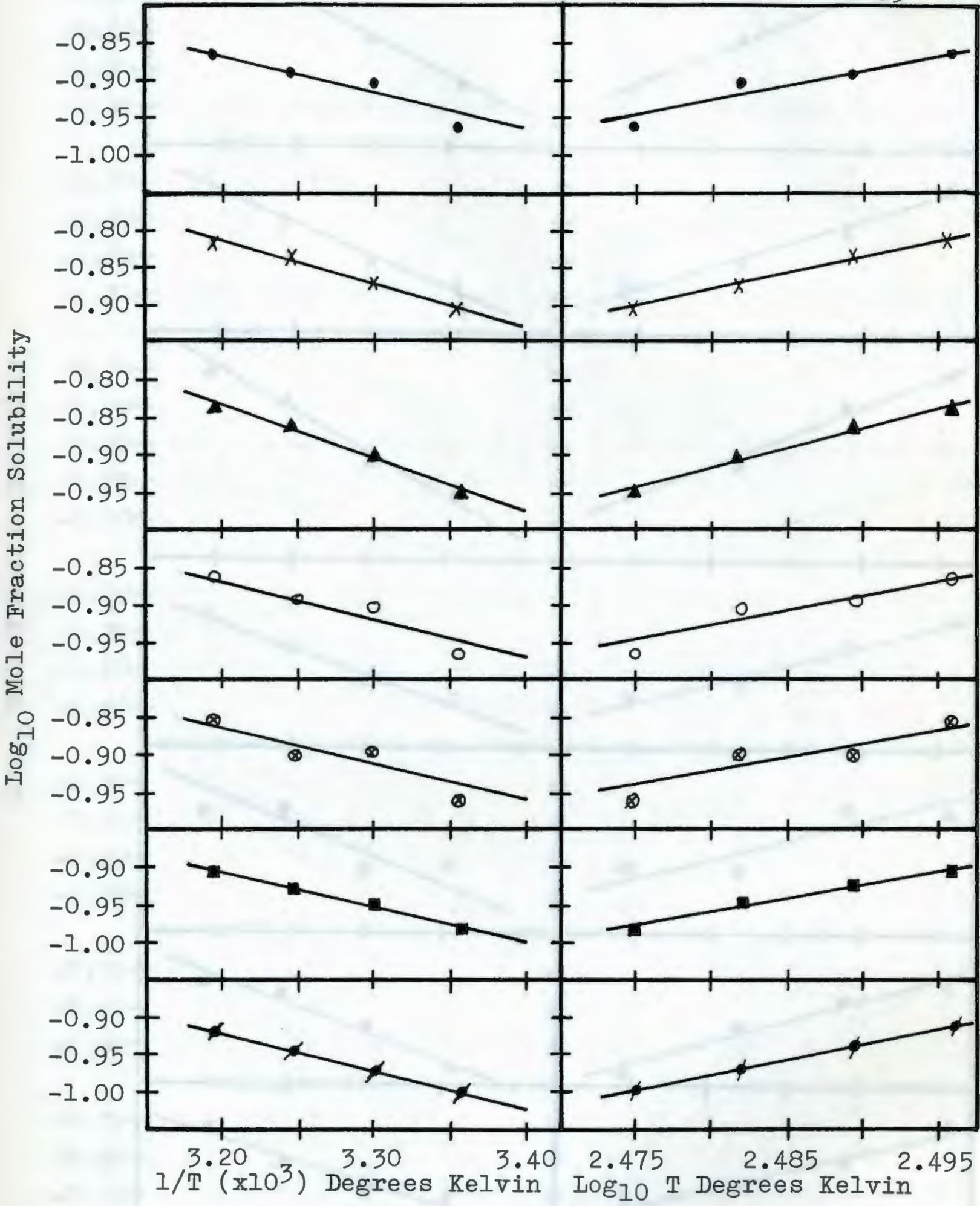

Fig. 9.--Iog mole fraction solubility of para-hydroxybenzoic acid in methanol; x ethanol; $\Delta$ l-propanol; : I-butanol; I-hexanol; l-octanol; and l-decanol vs. reciprocal temperature and log temperature (Kelvin) 


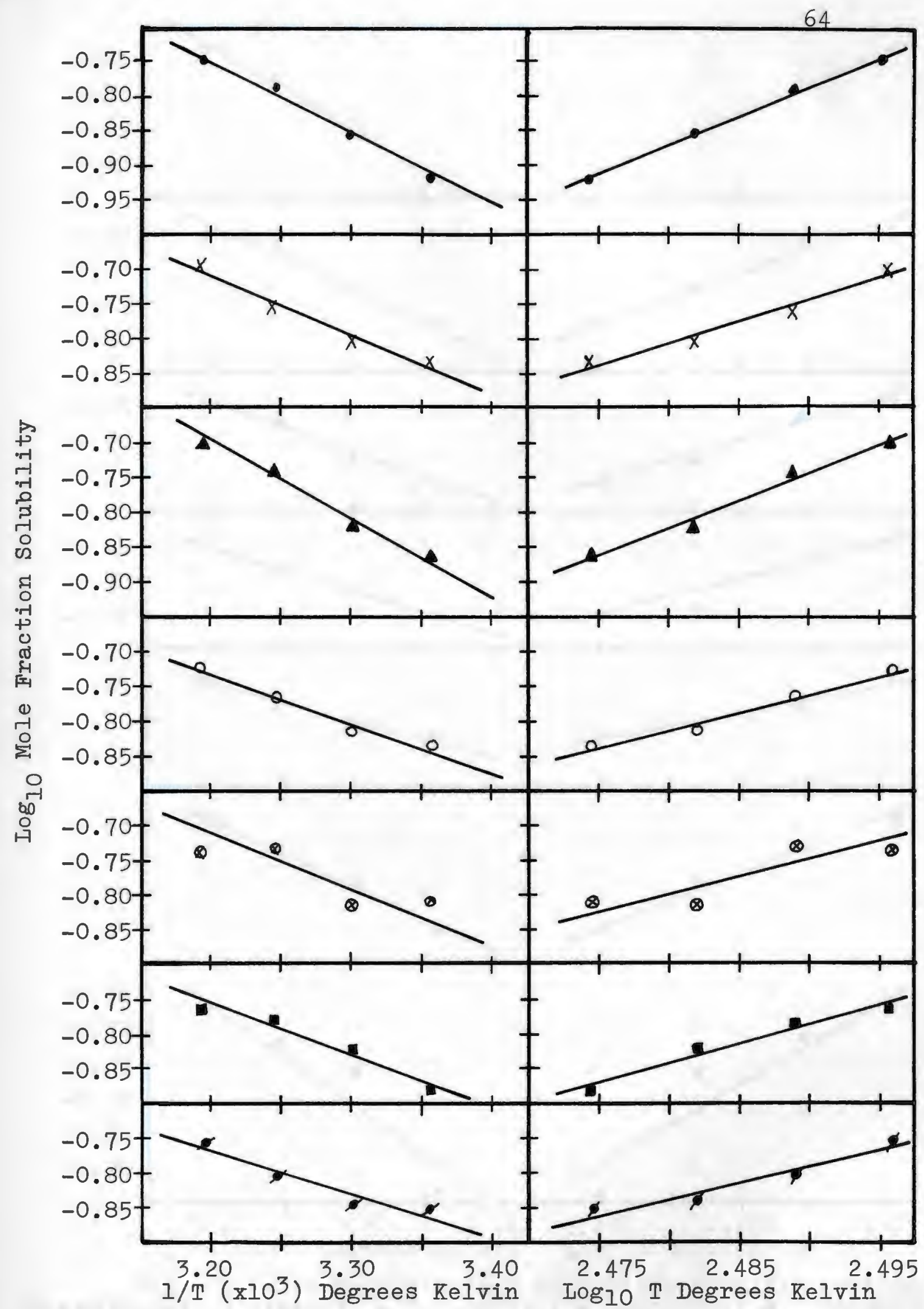

Fig. 10.-- Iog mole fraction solubility of methyl paraben in - methanol; $x$ ethanol; $\Delta$ l-propanol; 0 l-butanol; 1 I-hexanol; I-octanol; and I-decanol vs. reciprocal temperature and log temperature (Kelvin) 


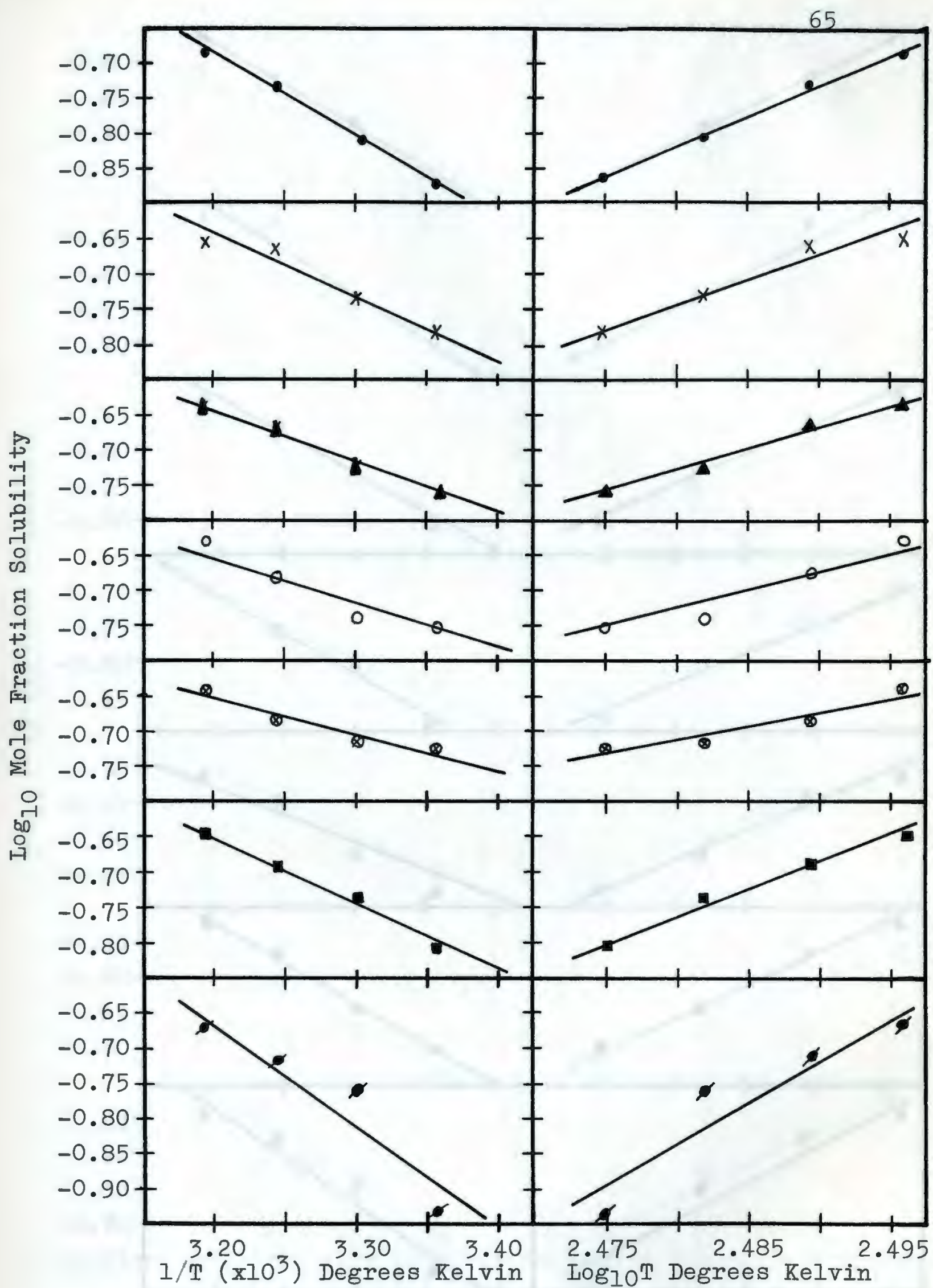

Fig. Il.--Iog mole fraction solubility of ethyl paraben in -methanol; $x$ ethanol; 4 -propanol; - l-butanol; - l-hexanol; 1-octanol; and l-decanol vs. reciprocal temperature and log temperature (Kelvin) 


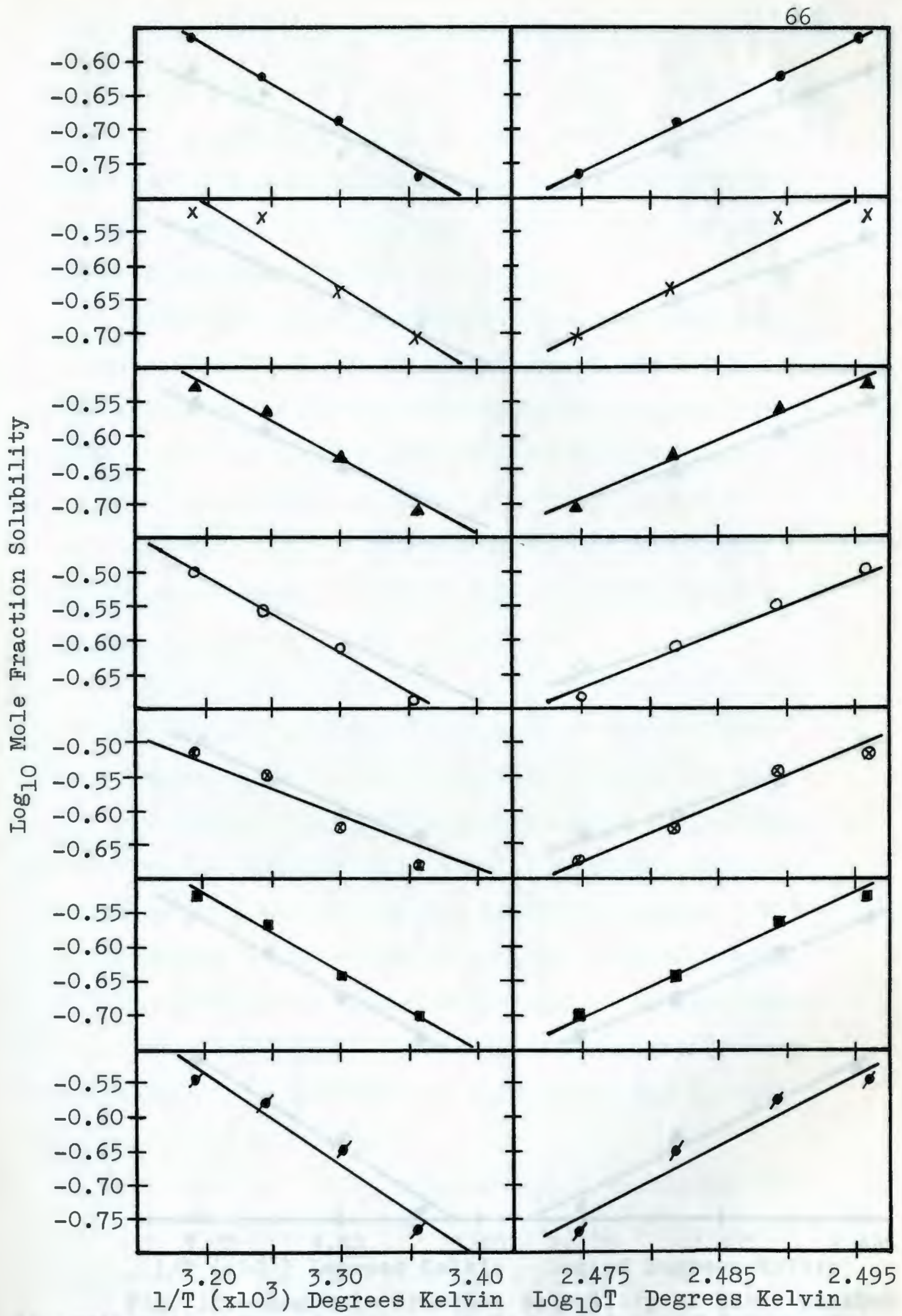

Fig. 12.--Iog mole fraction solubility of propyl paraben in - methanol; $x$ ethanol; $A$ l-propanol; 1 -butanol; 1 l-hexanol; l-octanol; and l-decanol vs. reciprocal temperature and log temperature (Kelvin) 


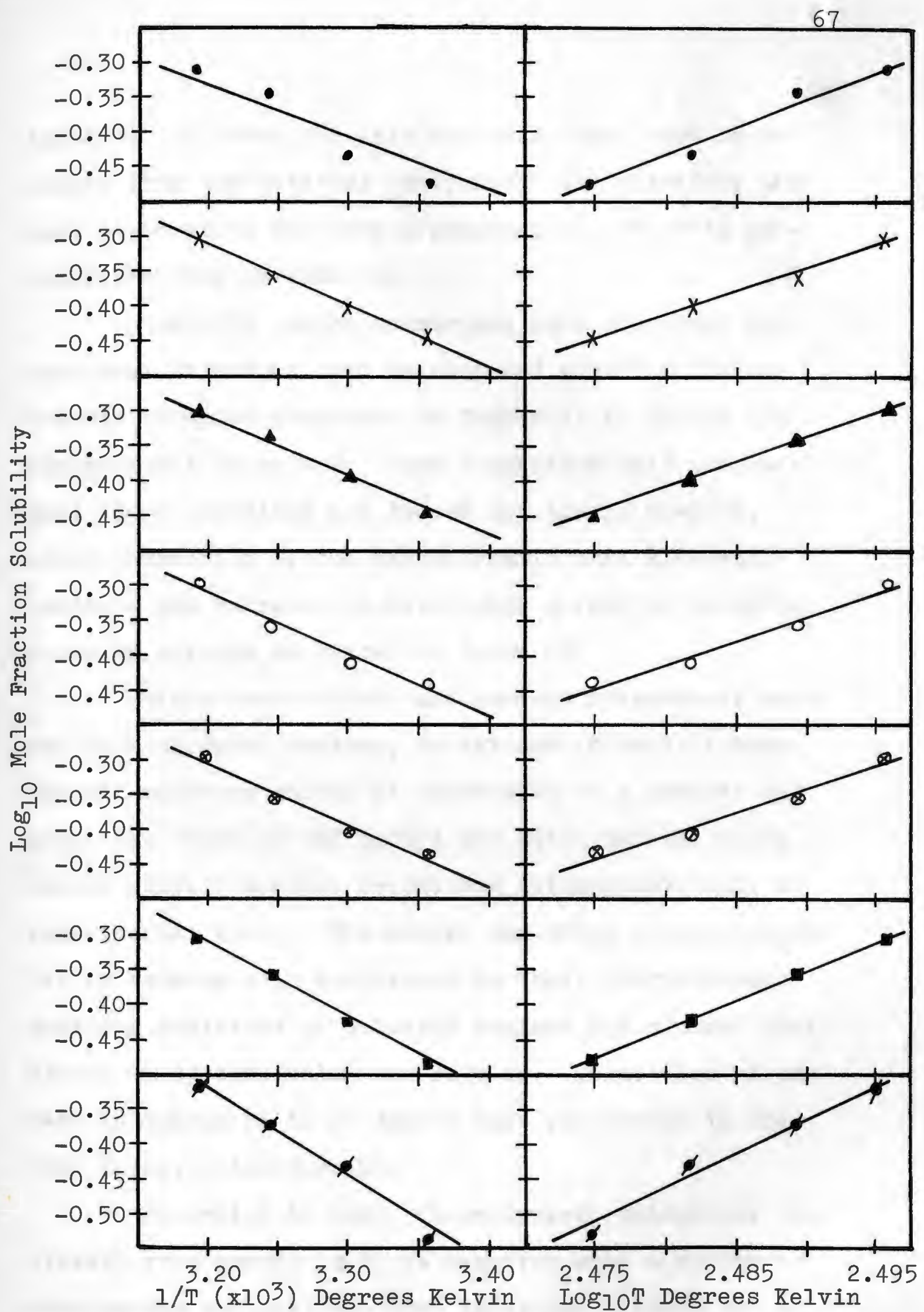

Fig. 13.--Iog mole fraction solubility of butyl paraben in -methanol; $x$ ethanol; $\triangle 1$-propanol; 0 l-butanol; 1 -hexanol; - l-octanol; and l-decanol vs. reciprocal temperature and log temperature (Kelvin) 
tainers. In order for this to occur, heat must be absorbed from the external environment and therefore $\Delta \mathrm{H}_{\mathrm{S}}$ must be positive for such a phenomenon. The data substantiate this observation.

Table 19 which summarizes data for ideal and non-ideal solutions, can be compared with the thermodynamic elements presented in Tables 13 to 18 for the experimental solutions. Such comparison will indicate that these solutions are indeed non-ideal; however, close inspection of the thermodynamic data also will indicate the category in which each solute in solution actually belongs as listed in Table 20.

Since benzoic acid and para-hydroxybenzoic acid are both solvated systems, deviations in their thermodynamic spectrum should be observable to a greater degree than those of the propyl and butyl esters, which should exhibit minimal deviations attributable only to experimental error. The methyl and ethyl esters should lie in between with deviations in their thermodynamic spectrum exhibited in solvated systems and minimal deviations in systems which are regular. Inspection of the data in Tables 21 to 26 depict this phenomenon in the free energy relationships.

According to basic thermodynamic principles the overall free energy $(\Delta F)$ is negative when a system is spontaneous and positive when it is not. Since the ex- 
TABLE 19

SUMMARY OF IDEAL AND NON-IDEAI SOLUTIONS ${ }^{a}$

\begin{tabular}{|c|c|c|c|}
\hline Class of Solution & $\begin{array}{l}\text { Heat } \\
\text { of } \\
\text { Mixing } \\
\end{array}$ & $\begin{array}{c}\text { Entropy } \\
\text { of } \\
\text { Mixing } \\
\end{array}$ & $\begin{array}{l}\text { Deviation } \\
\text { from } \\
\text { Raoult's Law } \\
\end{array}$ \\
\hline Ideal & 0 & $-R \ln x$ & none \\
\hline & & & \\
\hline \multicolumn{4}{|l|}{ Non-Ideal } \\
\hline Regular & + & $-R \ln x$ & + \\
\hline Solvated & - & $\Delta s<-R \ln x$ & - \\
\hline $\begin{array}{l}\text { (interaction of } \\
\text { solute and solvent) }\end{array}$ & & & \\
\hline $\begin{array}{l}\text { One component } \\
\text { associated }\end{array}$ & + & $\Delta s)-R \ln x$ & + \\
\hline
\end{tabular}

$a_{\text {Hildebrand, J.H. and Scott, R.I., The Solubility }}$ of Non-Electrolytes, Reinhold Publishing Co., New York, 1950, p. 47. 


\section{TABLE 20}

CLASSIFICATION OF THE INVESTIGATIONAL SOLUTES BY THEIR NON-IDEAL BEHAVIOR AS DEFINED IN TABIE 19

\begin{tabular}{|c|c|c|c|}
\hline Compound & $\Delta H_{m}$ & $\Delta S_{m}$ & Class of Solution \\
\hline Benzoic Acid & - & $-R T \ln x$ & Solvated \\
\hline $\begin{array}{l}\text { p-Hydroxybenzoic } \\
\text { Acid }\end{array}$ & - & $-R T \ln x$ & Solvated \\
\hline Methyl Paraben & - or + & [A Mixed & Solvated or \\
\hline Ethyl Paraben & - or + & System & Regular \\
\hline Propyl Paraben & + & $-\mathrm{RT} \ln \mathrm{x}$ & Regular \\
\hline Butyl Paraben & + & $-\mathrm{RT} \ln \mathrm{x}$ & Regular \\
\hline
\end{tabular}


perimental systems yield positive $\Delta F$ values, energy is required for the system to reach equilibrium. This statement is in agreement with the findings for $\Delta \mathrm{H}_{\mathrm{S}}$ values determined for the systems as discussed previously. In Tables 21 to 26 several types of free energy relationships are reported. The term $\Delta \overline{\mathrm{F}}_{2}^{i^{a}}$ (ideal partial free energy) was determined by the use of Eq. 26 and is compared with $\Delta \bar{F}_{2}^{a^{b}}$ (actual partial free energy) derived from the expression

$$
\Delta \bar{F}_{2}^{a}=\Delta H_{S}-T \Delta S_{S}
$$

in which the graphically determined values for $\mathrm{AH}_{\mathbf{s}}$ and $\mathrm{AS}_{\mathrm{S}}$ were used. Since this is a partial term, it can only be said that $\Delta \bar{F}_{2}^{a}$ approaches $\Delta \bar{F}_{2}^{i}$ in such systems which in themselves approximate the ideal solution. The partial excess free energy $\left(\Delta \bar{F}{ }_{2}^{E}\right)$ was determined by the use of the equation

$$
\Delta \overline{\mathrm{F}}_{2}^{\mathrm{E}}=\Delta \overline{\mathrm{F}}_{2}^{\mathrm{a}}-\Delta \overline{\mathrm{F}}_{2}^{\mathrm{i}}
$$

These values are also presented in the tables. The overall free energy ( $\Delta \mathrm{F}^{i}$ ) was determined by the use of Eq. 27; it is compared with the actual overall free energy ( $\Delta \mathrm{F}^{\mathrm{a}}$ ) obtained by the use of $\mathrm{Eq} .28$. This comparison again reveals the nature of each system with respect to the ideal state. The excess free energy terms were determined from Eq. 30 for $F^{E g}$ and Eq. 31 for $F^{E^{f}}$. The deviations in excess free energy observed with ben- 
TABLE 21

A SUMMARY OF THE FREE ENERGIES INCLUDING PARTIAL, OVERALI AND EXCESS FREE ENERGY DETERMINED IN CALORIES/MOLE FOR BENZOIC ACID IN THE SOLVENT SYSTEMS STUDIED

\begin{tabular}{|c|c|c|c|c|c|c|c|}
\hline & $\Delta \bar{F}^{i^{a}}$ & $\Delta \bar{F}^{\mathrm{a}^{\mathrm{b}}}$ & $\underline{\bar{F}}^{E^{C}}$ & $\Delta \mathrm{F}^{\mathrm{i}^{\mathrm{d}}}$ & $\Delta F^{a^{e}}$ & $\underline{\mathrm{F}^{\mathrm{E}^{\mathrm{f}}}}$ & $\mathrm{F}^{\mathrm{E}^{\mathrm{g}}}$ \\
\hline Methanol & 992 & 1045 & 53 & 294 & 284 & +10 & -13.2 \\
\hline Ethanol & 992 & 982 & 10 & 294 & 297 & -3.0 & -8.6 \\
\hline Propanol & 992 & 978 & 14 & 294 & 304 & -10.0 & -7.3 \\
\hline Butanol & 992 & 920 & 72 & 294 & 300 & -6.0 & -11.6 \\
\hline Hexanol & 992 & 922 & 70 & 294 & 319 & -25 & -9.0 \\
\hline Octanol & 992 & 899 & 93 & 294 & 321 & -27 & -16.7 \\
\hline Decanol & 992 & 904 & 88 & 294 & 319 & -25 & -19.6 \\
\hline
\end{tabular}

$$
\begin{aligned}
& a_{\Delta \bar{F}^{i}}=\Delta H_{f}-T \Delta S_{f} \\
& { }_{\Delta \Delta F^{a}}^{a}=\Delta H_{s}-T_{\Delta} S_{S} \\
& c_{\bar{F}} E=\Delta \bar{F}^{i}-\Delta \bar{F}^{a} \\
& \mathrm{~d}_{\Delta \mathrm{F}^{i}}=\left(\mathrm{x}_{1}{ }^{{ }^{1}} \log \mathrm{x}_{1}^{i}+\mathrm{x}_{2}{ }^{i} \log \mathrm{x}_{2}^{i}\right)(2.303 \mathrm{RT})=\mathrm{Eq} 27 \\
& { }_{\Delta F^{a}}^{a}=2.303 R T\left(x_{1}^{a} \log x_{1}+x_{2}^{a} \log x_{2}\right) \\
& f_{F} E=\Delta F^{i}-\Delta F^{a} \\
& g_{F} E=2.303 R T\left(x_{1}^{a} \log \gamma_{1}+x_{2}^{a} \log \gamma_{2}\right)
\end{aligned}
$$


TABLE 22

A SUMMARY OF THE FREE ENERGIES INCLUDING PARTIAL, OVERALI AND EXCESS FREE ENERGY DETERMINED IN CALORIES/MOLE FOR PARA-HYDROXYBENZOIC ACID IN THE SOLVENT SYSTEMS STUDIED

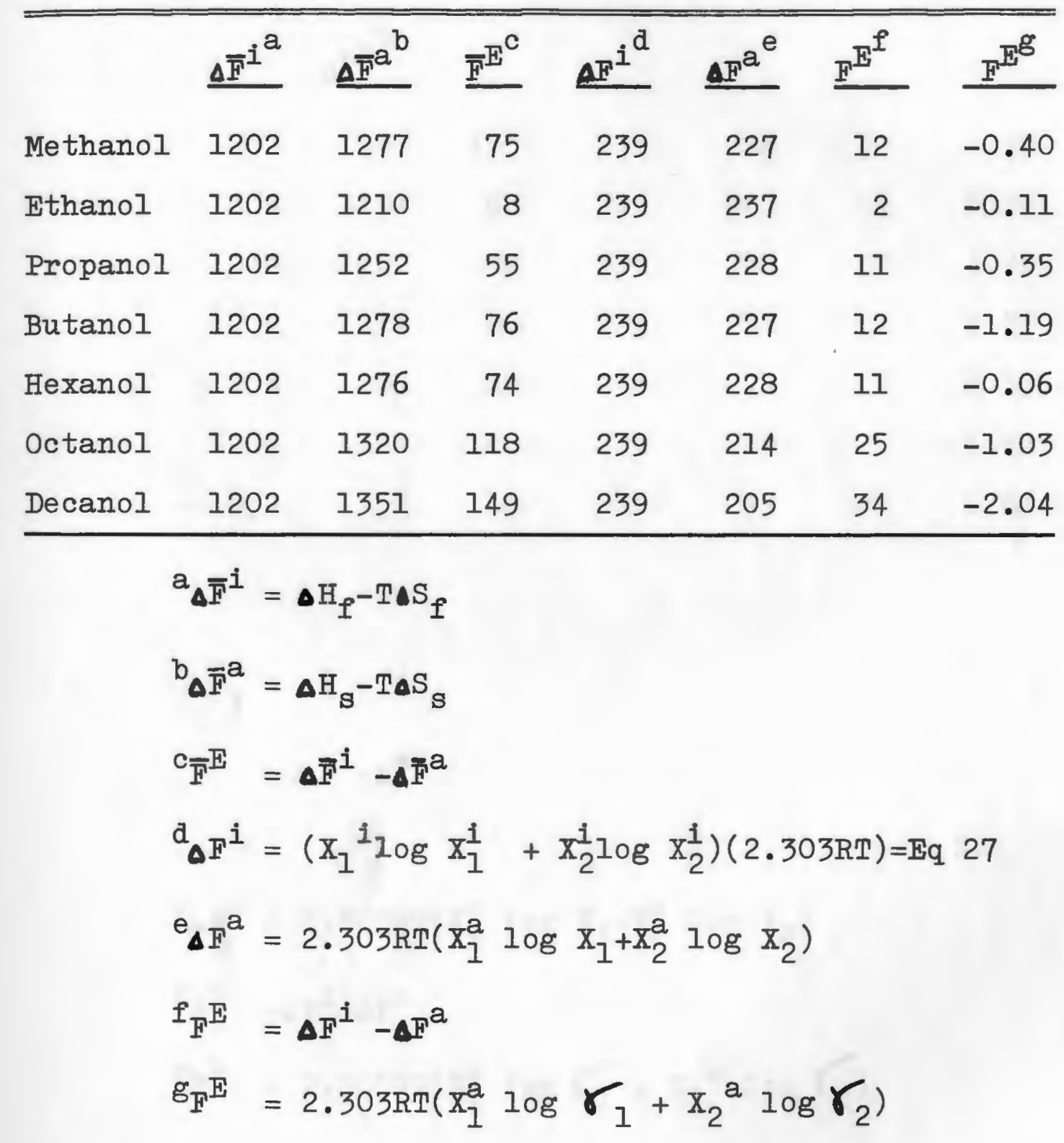


TABLE 23

A SUMMARY OF THE FREE ENERGIES INCLUDING PARTIAI, OVERALL AND EXCESS FREE ENERGY DETERMINED IN CALORIES/MOLE FOR METHYL PARABEN IN THE SOLVENT SYSTEMS STUDIED

\begin{tabular}{|c|c|c|c|c|c|c|c|}
\hline & $\Delta F^{i^{a}}$ & $\Delta \bar{F}^{a^{b}}$ & $\underline{\overline{\mathrm{F}}^{\mathrm{E}}}$ & $\Delta F^{i^{d}}$ & $\Delta F^{a^{e}}$ & $\underline{\mathrm{F}^{\mathrm{E}}}$ & $\mathrm{F}^{\mathrm{E}^{\mathrm{g}}}$ \\
\hline Methanol & 1034 & 1189 & 155 & 276 & 246 & 30 & 2.96 \\
\hline Ethanol & 1034 & 1102 & 68 & 276 & 261 & 5 & 5.26 \\
\hline Propanol & 1034 & 1122 & 88 & 276 & 256 & 20 & 4.95 \\
\hline Butanol & 1034 & 1114 & 80 & 276 & 259 & 17 & 5.23 \\
\hline Hexanol & 1034 & 1093 & 59 & 276 & 271 & 5 & 3.15 \\
\hline Octanol & 1034 & 1194 & 160 & 276 & 255 & 21 & 3.48 \\
\hline Decanol & 1034 & 1152 & 118 & 276 & 247 & 29 & 5.66 \\
\hline \multicolumn{8}{|c|}{$a_{\Delta \bar{F}^{i}}=\Delta H_{f}-T \Delta S_{f}$} \\
\hline \multicolumn{8}{|c|}{${ }_{\Delta}^{b} \bar{F}^{a}=\Delta H_{s}-T \Delta S_{S}$} \\
\hline \multicolumn{8}{|c|}{$c_{\bar{F}} \bar{E}=\Delta \bar{F}^{i}-\Delta \bar{F}^{a}$} \\
\hline \multicolumn{8}{|c|}{$\mathrm{d}_{\Delta \mathrm{F}^{i}}=\left(\mathrm{x}_{1}{ }^{i} \log \mathrm{x}_{1}^{i}+\mathrm{X}_{2}^{i} \log \mathrm{x}_{2}^{i}\right)(2.303 \mathrm{RT})=\mathrm{Eq} 27$} \\
\hline \multicolumn{2}{|c|}{$e_{\Delta F^{a}}^{a}=$} & $.303 R$ & $c_{1}^{a} 1 c$ & $\mathrm{x}_{1}+\mathrm{x}_{2}^{\mathrm{a}}$ & $\log x_{2}$ & & \\
\hline \multicolumn{2}{|c|}{$f_{F}^{E}$} & $\dot{i}-\Delta F^{a}$ & & & & & \\
\hline \multicolumn{2}{|c|}{$g_{F} E$} & 3031 & $a$ & & a & & \\
\hline
\end{tabular}


TABLE 24

A SUMMARY OF THE FREE ENERGIES INCLUDING PARTIAI, OVERALI AND EXCESS FREE ENERGY DETERMINED IN CALORIES/MOLE FOR ETHYL PARABEN IN THE SOLVENT SYSTEMS STUDIED

\begin{tabular}{|c|c|c|c|c|c|c|c|}
\hline & $\underline{\Delta \bar{F}^{i^{a}}}$ & $\underline{\underline{F^{2}}} \mathrm{a}^{\mathrm{b}}$ & $\underline{\bar{F}^{E^{C}}}$ & $\Delta F^{i^{d}}$ & $\Delta F^{\mathrm{a}^{\mathrm{e}}}$ & $\underline{\mathrm{F}^{\mathrm{E}^{f}}}$ & $\mathrm{~F}^{\mathrm{E}^{\mathrm{g}}}$ \\
\hline Methanol & 926 & 1115 & 189 & 312 & 261 & 51 & -6.16 \\
\hline Ethanol & 926 & 1012 & 86 & 312 & 288 & 24 & -1.44 \\
\hline Propanol & 926 & 993 & 67 & 312 & 295 & 17 & -0.81 \\
\hline Butanol & 926 & 995 & 69 & 312 & 287 & 25 & -1.35 \\
\hline Hexanol & 926 & 972 & 46 & 312 & 297 & 15 & -0.74 \\
\hline Octanol & 926 & 1034 & 108 & 312 & 287 & 25 & -1.85 \\
\hline Decanol & 926 & 1125 & 199 & 312 & 279 & 33 & -2.48 \\
\hline
\end{tabular}

$$
\begin{aligned}
& a_{\Delta \bar{F}^{i}}=\Delta H_{f}-T \Delta S_{f} \\
& \mathrm{~b}_{\Delta} \overline{\mathrm{F}}^{\mathrm{a}}=\Delta \mathrm{H}_{\mathrm{s}}-\mathrm{T}_{\Delta} \mathrm{S}_{\mathrm{S}} \\
& c_{\overline{\mathrm{F}}} \mathrm{E}=\Delta \overline{\mathrm{F}}^{\mathrm{i}}-\Delta \overline{\mathrm{F}} \mathrm{a} \\
& \mathrm{d}_{\Delta \mathrm{F}^{i}}=\left(\mathrm{x}_{1}{ }^{i_{\log }} \mathrm{x}_{1}^{i}+\mathrm{x}_{2}^{i} \log \mathrm{x}_{2}^{i}\right)(2.303 \mathrm{RT})=\mathrm{Eq} 27 \\
& { }_{\Delta F^{a}}^{a}=2.303 R T\left(x_{1}^{a} \log x_{1}+X_{2}^{a} \log x_{2}\right) \\
& f_{F} E=\Delta F^{i}-\Delta F^{a} \\
& g_{F} E=2.303 R T\left(x_{1}^{a} \log \gamma_{1}+x_{2}^{a} \log \gamma_{2}\right)
\end{aligned}
$$


TABIE 25

A SUMMARY OF THE FREE ENERGIES INCLUDING PARTIAL, OVERALI AND EXCESS FREE ENERGY DETERMINED IN CALORIES/MOLE FOR PROPYI PARABEN IN THE SOLVENT SYSTEMS STUDIED

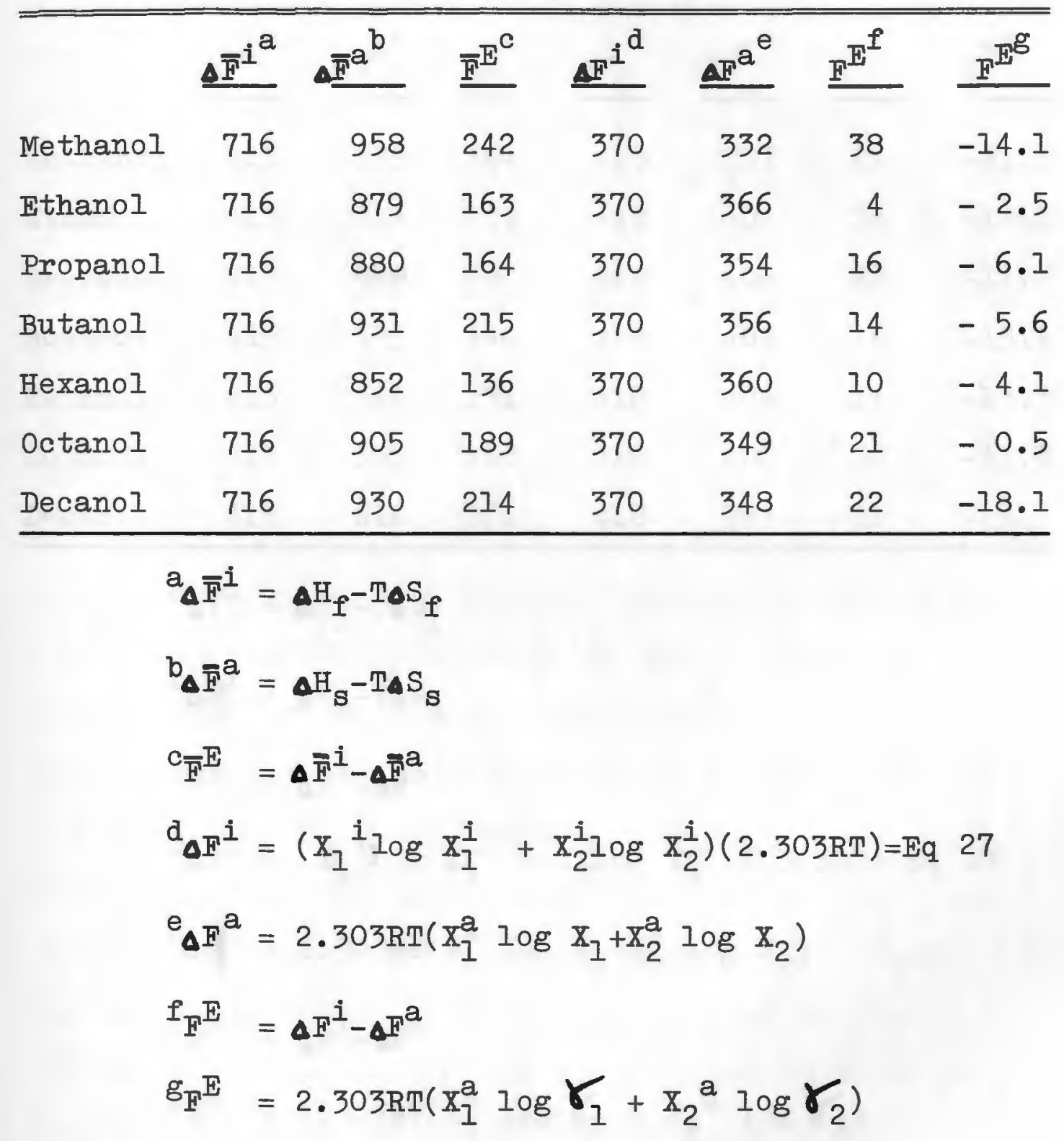


TABIE 26

A SUMMARY OF THE FREE ENERGIES INCLUDING PARTIAL, OVERALL AND EXCESS FREE ENERGY DETERMINED IN CALORIES/MOLE FOR BUTYL PARABEN IN THE SOLVENT SYSTEMS STUDIED

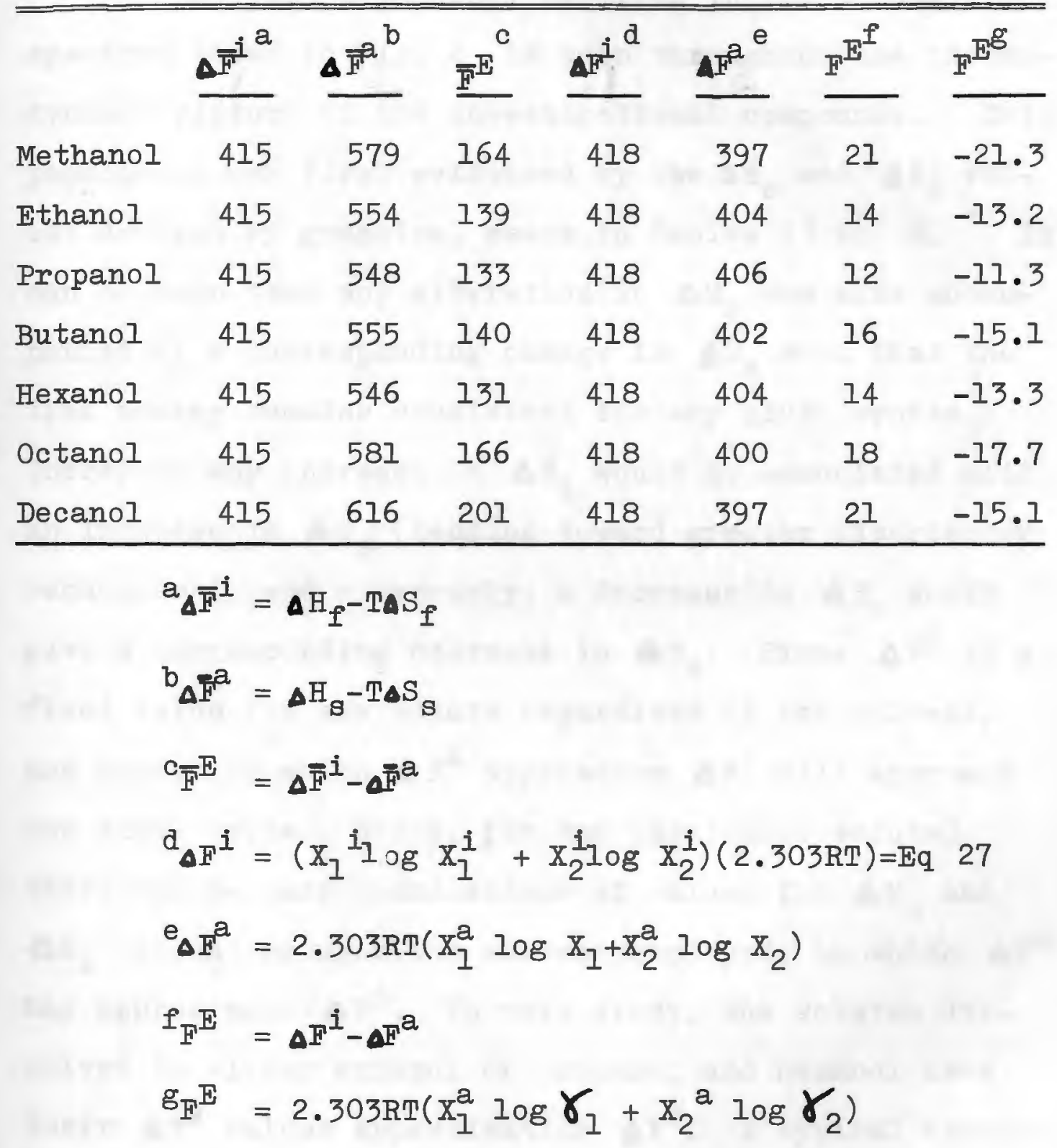


zoic acid, para-hydroxybenzoic acid, methyl and ethyl paraben as seen in the tables can be associated with the solvation process; therefore, it may be said that energy can be either liberated or consumed with this secondary process.

The twin peak array observed in the solubility spectrum shown in Fig. 6 is seen throughout the thermodynamic picture of the investigational compounds. This phenomenon was first evidenced by the $\Delta \mathrm{H}_{\mathbf{S}}$ and $\Delta \mathrm{S}_{\mathrm{S}}$ values derived by graphical means in Tables 13 to 18. It can be seen that any alteration in $\Delta \mathrm{H}_{\mathrm{S}}$ was also accompanied by a corresponding change in $\Delta \mathrm{S}_{\mathrm{S}}$ such that the free energy remains consistent for any given system. Therefore any increase in $\Delta \mathrm{H}_{\mathrm{S}}$ would be associated with an increase in $\Delta \mathrm{S}_{\mathrm{S}}$ (tending toward greater disorder or randomness); and conversely, a decrease in $\Delta \mathrm{H}_{\mathrm{S}}$ would give a corresponding decrease in $\Delta S_{S}$. Since $\Delta F^{i}$ is a fixed value for any solute regardless of the solvent, any system in which $\Delta \mathrm{F}^{\mathrm{a}}$ approaches $\Delta \mathrm{F}^{i}$ will approach the ideal state. Hence, for any particular solute, there may be many combinations of values for $\Delta H_{S}$ and $\Delta S_{S}$, depending upon the solvent employed, in which $\Delta F^{a}$ may approximate $\Delta \mathrm{F}^{i}$. In this study, the solutes dissolved in either ethanol or propanol and hexanol have their $\Delta \mathbb{F}^{\mathrm{a}}$ values approximating $\Delta \mathrm{F}^{i}$. A typical example is shown in Fig. 14. This can be further shown by the 


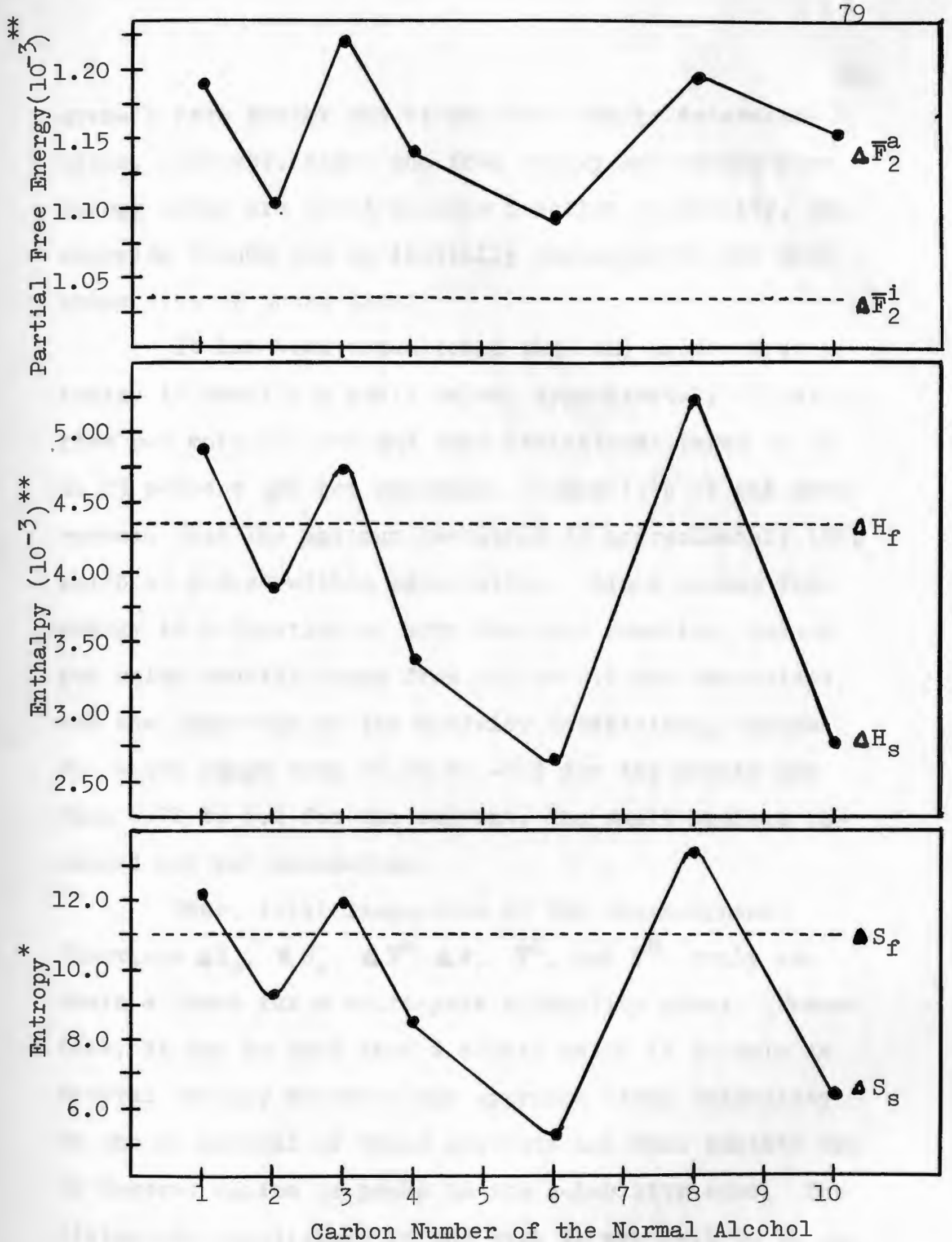

Fig.14.--Comparison of the ideal and actual partial free energy, enthalpy and entropy values for methyl paraben vs. the carbon number of the normal alcohol. *calories/degree-mole **alories/mole 
overall free energy and excess free energy determinations. However, since the free energy and excess free energy terms are based on mole fraction solubility, the emerging trends can be initially perceived by the mere inspection of these data.

It has been established that the excess free energy is usually a small value, approximately 50 calories per mole or less and that deviational terms of 20 to 25 percent are not uncommon. Inspection of the data reveals that the maximum deviation is approximately $15 \%$, which is indeed within expectation. Since excess free energy is a function of both the mole fraction, values for which usually range from 0.1 to 0.3 for the solute, and the logarithm of the activity coefficient, values for which range from -0.75 to -0.9 for the solute and from 0.01 to 0.1 for the solvent, the small numbers obtained are not unexpected.

Thus, total inspection of the thermodynamic functions $\Delta \mathrm{H}_{\mathrm{S}}, \Delta \mathrm{S}_{\mathrm{S}}, \Delta \overline{\mathrm{F}}^{\mathrm{a}}, \Delta \mathrm{F}, \overline{\mathrm{F}}^{\mathrm{E}}$, and $\mathrm{F}^{\mathrm{E}}$ truly reveals a trend for a multi-peak solubility array. Therefore, it can be said that a solute which is soluble in several or many solvents may approach ideal solubility in one or several of these solvents and thus exhibit one or several maxima or peaks in its solubility scan. The dielectric requirement of one peak is now felt to be related to the thermodynamics of the total system; hence, 
81

a multi-peak system should signify that ideal solubility is being approximated in that particular solvent-solute system. 
BOOK II

MOLECULAR ORBITAI CONSIDERATIONS 


\section{INTRODUCTION}

During the past ten years, the mechanics of interaction between drugs and receptor sites have been intensively scrutinized in the hope of describing these interactions, their nature, rate, and steric dependence in quantitative terms by an estimation of chemical and physical parameters occurring in a viable system. Molecular parameters of a single molecule, such as bond length, bond order, charge distribution, electron density and energy levels, are based on simple overall, summed, molecular perturbations in which the effects of neighboring electrons and nuclei upon the ground state are measured.

Several workers have attempted to relate molecular parameters and drug action (activity), notably Kier (1-3), Pullman (4, 5), Dewar (6), Streitweisser (7), Roberts (8), Purcell (9), and Martin (10). Because these systems are extremely complex a simplistic uniparameter correlation between activity and some scaling of molecular parameters has not yet been found; however, correlations of this kind are useful in the estimation of "actual." molecular ground states, which are relatively 
self-consistent for like molecules.

With the knowledge and background of quantum theory, it is possible via simplifying assumptions and appropriate programs to envision the steric and shape characteristics within the constraints of the direction, shape and neighboring distance of atomic orbitals contributing to the overall molecular parameters.

Efforts were restricted to molecular orbital calculations of the simpler members of the series: benzoic acid, para-hydroxybenzoic acid, methyl and ethyl paraben, since all characteristic trends of the entire series are demonstrated by these members. The computer programs were derived from the Iterated Extended Huckel Theory (IEHT), which is based upon assumptions of various kinds but which, for any related series of molecules are self consistent such that comparisons can be made directly.

The approach taken in this portion of the study is to characterize these systems in terms of atomic charge distributions, effect of hydroxy $(-\mathrm{OH})$ and ester groups (both sterically and electronically), preferred molecular conformations, and distinguishing features of the molecular orbitals. Since no previous molecular orbital calculations have been carried out on this series of preservatives, it is hoped that this initial effort will spur subsequent investigations into other theoretical approaches 
85 to the mechanistic aspects of their action at the molecular level. 


\section{STRUCTURE ACTIVITY RELATIONSHIPS}

OF ANTIMICROBIAL AGENTS

In viable systems molecules serve many purposes which require special sets of properties that result from their unique configurations. The physical and chemical properties of any organic molecule may result from ( 1 ) the carbon skeleton, the number and arrangement of carbon atoms; (2) the nature and position of the atoms attached to the carbon chain; (3) the nature of the functional groups (carboxyl, hydroxyl, amino, sulfhydryl, ether, ester, etc.); (4) the nature of the bonds between the various atoms of the molecule; and (5) the three dimensional arrangements of the atoms within the molecule. Whether a molecule is planar or non-planar, and if non-planar, whether in one or another conformation, has a profound effect on its chemical properties. Therefore, in molecules of biological interest, the configurational and conformational aspects are of considerable importance.

Just as important is the principle that fitting a molecule into a specific macromolecule may well underlie the stringent requirements for biological activity 
of many small molecules, such that the relative suitability of small molecules for particular biological tasks depends upon how well they fit into the basic machinery of the living cell. Thus, it is both the fit per se and its chemical nature that makes the small molecule active.

All molecules must traverse biological membranes before they can exert their specific action; therefore, the biochemistry of membranes is indeed important. A membrane may be defined in terms of its properties: (I) a closed vesicular or tubular system with a structured rim and a fluid interior; (2) a structured rim, a mosaic of nesting repeating particles one layer thick and lipoprotein in nature; and (3) the presence of structural protein as a major, intrinsic component of the repeating units. In this definition there are no structural elements other than the repeating units and subunits. A membrane's most important feature is that it is a closed system, which may be tubular (a pipe), vesicular (a hollow ball), bulbar (light bulb), or disc shaped (flattened duct).

Each membrane has its own type of repeating unit, distinctive with respect to shape and size. The various parts of a repeating unit are bound together by relatively weak forces. The subunits are chemically and functionally distinct; each subunit is composed of dif- 
ferent proteins arranged in distinctive patterns. The repeating units of a given membrane appear to be identical in respect to form and size, although they are not all chemically identical. Experience has shown that there are multiple species of repeating units in a given membrane, each of which has a characteristic complement of proteins and spectrum of enzymatic activity, all of which share the same geometrical form, and all of which are outwardly indistinguishable from one another. The particular geometric form assumed by a membrane system is the one by which the system of repeating units will satisfy the principle of minimal free energy of conformation. Further, it is the one in which the interlocking parts are most stable under physiological conditions. The basis function of a membrane is the integration of the functions of the individually oriented repeating units which make it up. Therefore all membrane properties can be reduced to the properties of the individual units. Iipids, in the form of phospholipid, sulfolipid or glycelipid, are an inherent part of all membranes. They are joined to the membrane protein by chemical links that are predominately hydrophobic. The hydrocarbon chains of phospholipids penetrate deeply into hydrophobic faces of proteins, while the polar sectors of these phospholipid molecules confer water-solubility and a charge on the protein faces. The particular way in which lipids 
and proteins are packed together constitutes the very basis for the properties of the membrane system. Further, mounting evidence of a continuity among all the phospholipid molecules in a membrane suggest that a lipid soluble molecule may be able to move in any direction through the entire membrane continuum without leaving the phospholipid phase.

When phospholipids are removed from the membrane by solvent extraction, essentially all the characteristic, functional properties of the intact membrane system are lost and the proteins in the membrane tend to form polymers. Proteins having this capacity are often referred to as hydrophobic proteins. They constitute some $50 \%$ of the total protein of membrane systems in the form of structural protein. The structural protein portion of a given organism is distinctive; however, it shares the following properties, regardless of the membrane or organism: (I) the tendency to form insoluble polymers in aqueous media; (2) the capacity to bind phospholipid hydrophobically; (3) the capacity to interact with other membrane proteins to form water-soluble complexes; the capacity to bind small molecules; (5) the tendency of the polymeric form to disintegrate when exposed to certain chemical agents, e.g., dodecyl sulfate, $66 \%$ acetic acid, and dilute alkali.

Membranes are not static systems. The integrity 
of the membrane requires the constant input of energy to counterbalance environmental changes. Energy is also required for the work performed by the membrane. The molecular structure of a membrane determines its permeability to ions and polar molecules. The structure of the repeating unit governs the tightness of fit between one repeating unit and its nesting neighbor, thus regulating the permeability. The association of certain metabolic processes with membranes is so general that it can be best considered a universal attribute of cells. The apparent invariability of the chemistry of these major metabolic sequences is associated with the special organization of the membranes within the framework of repeating units and subunits. Such a framework imposes so rigid a requirement on the three-dimensional fit of enzymes and coenzymes which participate in these metabolic sequences that the degree of permissible structural change and innovation is severely limited.

The cells of multicellular organisms have both general and specialized membrane systems, the former in all cells, the latter in specialized cells. Unicellular protozoa or plants have multiple membrane systems, both general and specialized, all within one cell. The bacteria, however, have essentially one membrane system, which is a composite of almost all the membrane systems found in the more complex forms of life. The important 
consideration, then, is not the number of membrane systems, but the full compliment of repeating units and the functions fulfilled by these repeating units. Indeed, if the various segments of the bacterial membrane could be dissected, extensive variation with respect to repeating units and function might well be found.

The bacterial cell wall is a strong and rigid structure that protects and supports the weaker and biochemically more active parts of the cell. The rigidity of bacterial walls is attributed to glucosamino peptides (compounds containing amino sugars and amino acids). The basic structure consists of alternating residues of amino sugars, $\mathbb{N}$-acetyl muramic acid and $\mathbb{N}$-acetyl glucosamine, attached to the peptide, as shown in Figure 15. The bacterial protoplast (plasma) membrane consists of three layers: a bimolecular "leaflet" of lipid between protein or other hydrophilic layers. It is composed largely of lipoprotein and contains enzymes, especially those concerned in biological oxidations, by which the cell secures energy. Therefore, the plasma membrane regulates the passage of materials into and out of the cell. Low molecular weight substances such as urea, glycine and glycerin rapidly enter bacterial cells, whereas the electrolytes $\mathrm{NaCl}$ and $\mathrm{KCl}$ and larger organic molecules, e.g., glucose and sucrose, traverse the membrane very slowly. The membrane is essentially imper- 

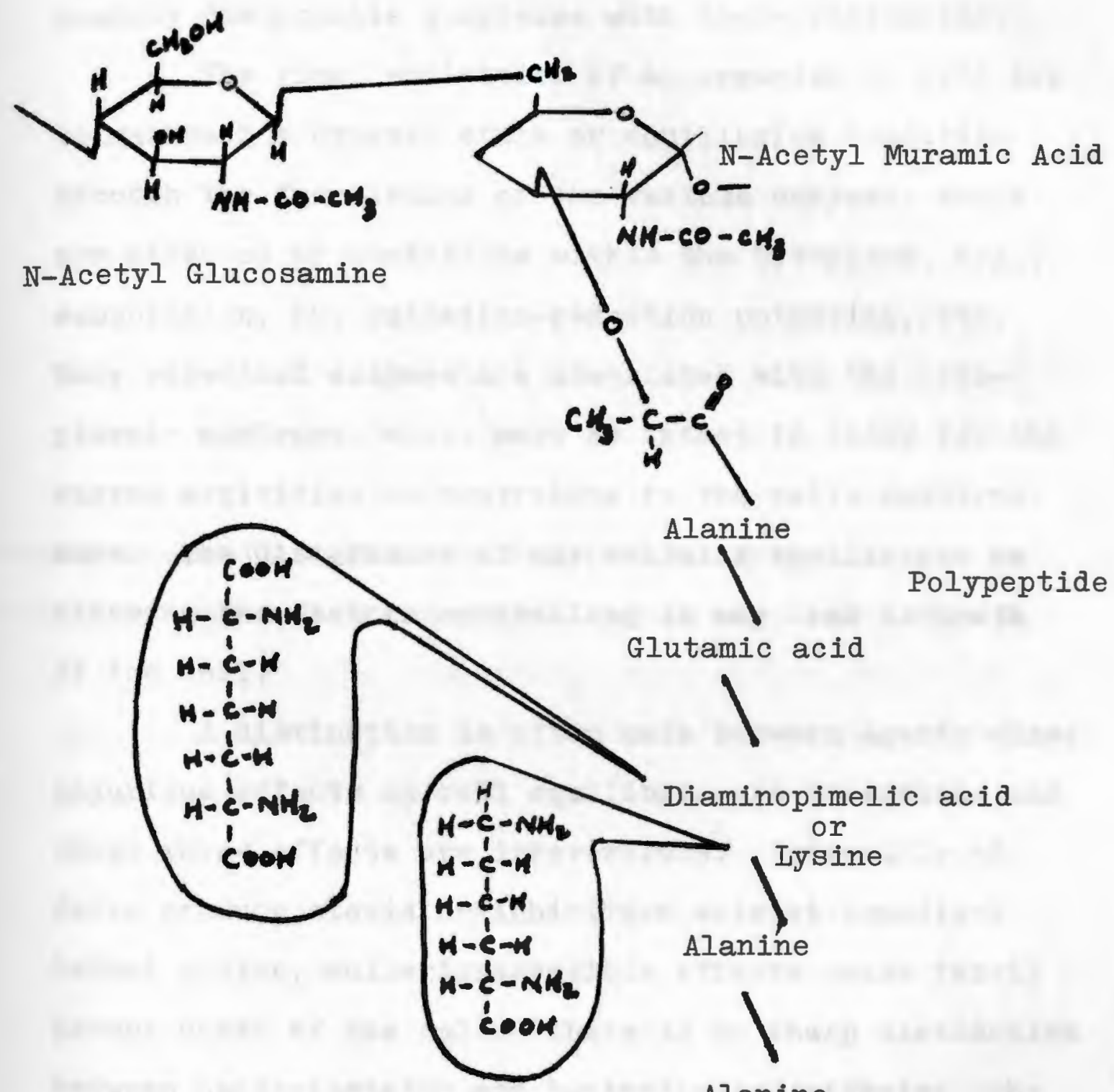

Fig.15.--Part of the proposed glycosaminopeptide "backbone" that contributes to the rigidity of the bacterial cell wall. Diaminopimelic acid is found only in certain bacteria and the blue-green algae. 
meable to polar organic substances because of its high lipid content. Enzymes called permeases transport particular materials or groups of materials by forming readily dissociable complexes with these substances. The vital activities of an organism or cell are to maintain a dynamic state or equilibrium condition through the functioning of the various enzymes, which are affected by conditions within the cytoplasm, e.g., composition, $\mathrm{pH}$, oxidation-reduction potential, etc. Many essential enzymes are associated with the cytoplasmic membrane, which must be intact in order for the enzyme activities to contribute to the cells maintenance. The disturbance of any cellular equilibrium by altering the factors controlling it may lead to death of the cell.

A distinction is often made between agents whose injurious effects on cell equilibria are reversible and those whose effects are irreversible. Reversible effects produce stasis or inhibition without immediate lethal action, while irreversible effects cause fairly prompt death of the cell. There is no sharp distinction between bacteriostatic and bacteriocidal effects: the difference is quantitative rather than qualitative. Nevertheless, the terms "bacteriostatic" and "bacteriocidal" are useful with reference to the action of various agents in the concentrations or under the conditions 
in which they are ordinarily employed. Bacteriostatic or bacteriocidal action may be of three types: (1) injury to cell membranes; (2) injury to cell nucleus and genes; (3) inhibition of enzymes. Any agent that alters the permeability of cell membranes interferes with either the intake of essential substances or the excretion of waste materials or else permits the entrance of toxic substances or the loss of essential cell components. Detergents, for example, break the osmotic barrier and allow leakage of metabolically active components such as nitrogen and phosphorous compounds. Some chemicals dissolve or remove the cell membranes and destroy the equilibria that maintain constant composition and osmotic pressure. Penicillin damages amino acid transport mechanisms of the cells of sensitive species, bringing about virtual starvation because essential nutrients fail to pass the cell membranes.

Certain agents have a particular affinity for nuclei or genes. Basic dyes, e.g., crystal violet, react strongly with the nucleic acids of nucleoproteins, presumably by salt formation. Dilute solutions are bacteriostatic, while more concentrated solutions are bacteriocidal. Heavy metals may react with the sulfhydryl (-SH) groups of nucleoproteins. Any damage to genes is reflected in inhibition of the enzymes they 
control. If the enzyme is essential, growth will cease. However, some enzymes are not essential; that is, suitable alternate substrates may be supplied or some other mechanism may be available to form the required product. The inhibition of enzymes may be effected by other means. Enzymes are proteins and as such are denatured by alcohols, phenols, heavy metals in high concentration, surface active substances and other active agents. Denaturation is more or less irreversible. Low concentrations of heavy metals and mild oxidizing agents form inactive compounds by reversible reactions with - SH groups, which are essential for the activity of certain enzymes and coenzymes. Stronger oxidizing agents irreversibly oxidize - $\mathrm{SH}$, phenol, indol, and amino radicals of enzymes or coenzymes. Enzyme inhibition can also be accomplished by competition or antagonism between either the substrate or the enzyme and the inhibitor substance as illustrated in Figure 16. Competitive inhibition can best be illustrated by the behavior of sulfonamide drugs in their inhibition of folic acid production. Paraaminobenzoic acid ( $P A B A$ ) is a constituent of folic acid; and if the chemically related substance sulfanilamide is present, it may replace $\mathrm{PABA}$ and prevent the formation of folic acid. This is shown in Figure 17. Folic acid is a coenzyme essential to the synthesis of amino acids, purines and pyrimidines. 

A. Enzyme + Inhibitor 1
Enzyme-Inhibitor 1 complex
B. Enzyme + Substrate
Enzyme-Substrate
Enzyme + Product
C. Inhibitor $2+$ Substrate
Inhibitor 2-Substrate Complex

tion.

Figure 16.--Inhibition of enzyme action by chemical competi-

The normal reaction is depicted in B; where the enzyme and substrate interact to form a product or products and the enzyme is released for further activity. At $A$, an inhibitor that is chemically related to the normal substrate reacts with the enzyme, thus blocking the enzyme from reacting with the usual substrate. At $c$, a different inhibitor reacts with the normal substrate and forms a compound that cannot react with the enzyme. 

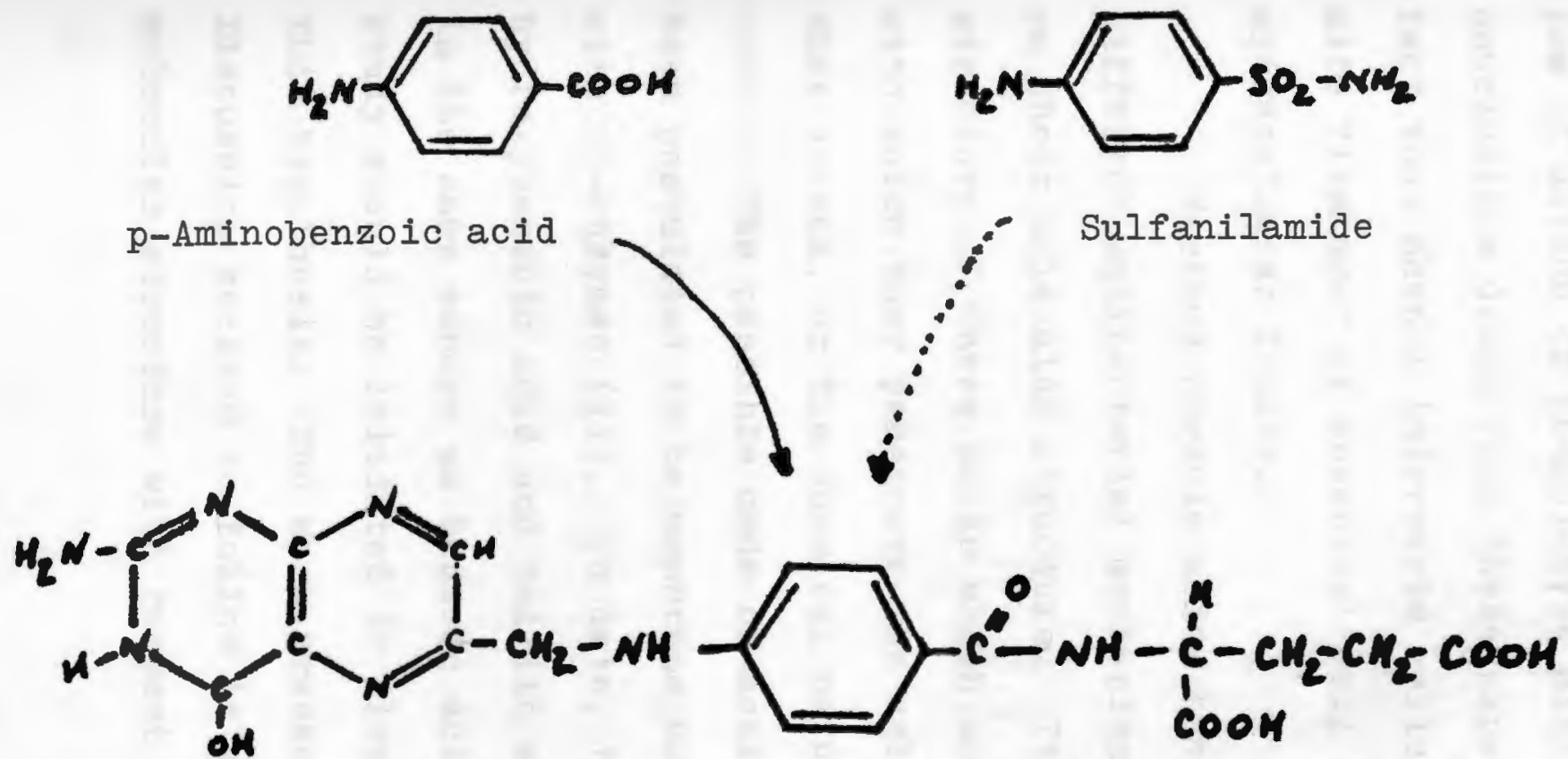

Pteridine Nudeus

p-Aminobenzoic Acid

Glutamic Acid

Folic Acid

Fig. 17.--Competitive inhibitor as depicted by the replacement of para-aminobenzoic, an essential part of folic acid, by sulfanilamide to prevent folic acid formation. 
Studies were initiated to elucidate the mechanism of action of phenol-type disinfectants (7-9). The conclusions drawn from these experiments point to the fact that phenol interrupts cellular transport and permits "leakage" of essential cell constituents into the extracellular fluids.

Various organic acids have been shown to elicit different antibacterial mechanisms of action depending on their molecular structure. It is the molecular structure of these acids which would influence the ease with which they penetrate the cell, the part of the cell they attack, or the chemical nature of their attack (10).

The possible mode of action of benzoic acid has been postulated to be membrane action and competition with co-enzymes (II). To date, the esters of parahydroxybenzoic acid and vaillic acid are thought to act in the same manner as benzoic acid, however, further study should be initiated to clarify or substantiate this hypothesis. The work presented in the Results and Discussion section to follow is an attempt to elaborate molecular structure with respect to mode of action. 
EXPER IMENTAL

The Iterated Extended Huckel Theory (IEHT) molecular orbital theory program was executed on an IBM 360/50 computer. The program, a modification of Hoffmann's Extended Huckel Theory (EHT) program (1), was designed to iterate until charge consistency was attained. In this study we chose input parameters that have been widely used in the application of semi-empirical ICAO methods. This choice gave our calculations a relevance not obtainable with other, less well recognized parameters. These input parameters included the molecular cartesian coordinates; Slater-type orbital exponents; atomic charges and valence state ionization potentials, (VSIP's); a test limit of 0.002 (in units of charge distribution) to define a converged charge distribution; a weighting factor of $9 / 10$ to control the charge correction with each iteration; and the number of iterations to be carried out.

Cartesian coordinates were calculated by use of the computer program CORCAI (2), for which the input data included the molecular geometry in terms of bond angles, bond lengths, bond attachments and dihedral 
angles. The crystal-morphological, $\mathbf{x}$-ray data used to generate these terms were obtained for benzoic acid from the work by Sim (3); for aniline from the work of Hulme (4); for phenol from the work of Giller-Pandraud (5) and Scheringer (6); for para-hydroxybenzoic acid from the work of Manjlovic (7); and for para-aminobenzoic acid from the work by Alleaume (8) and Lai (9). Estimates of corresponding data for esters of para-hydroxybenzoic acid were based upon previously established crystallographic work for esters of various types, such that bond angles and bond lengths represent typical values. These bond length and bond angle values for the experimental compounds gave cartesian coordinates as listed in Tables $A$ to $Q$, in the appendix.

Values for the orbital exponents, derived from Slater's Rules, were as follows: Carbon 2 s and 2p, 1.625; nitrogen $2 \mathrm{~s}$ and $2 \mathrm{p}, 1.95$; oxygen $2 \mathrm{~s}$ and $2 \mathrm{p}, 2.275$; and for hydrogen 1s, 1.2. As already noted, the value of 1.2 for the hydrogen $1 s$ is more applicable to this type of calculation.

VSIP's were used to generate values for coulomb integrals, which are charge dependent and which, in turn, were used to obtain resonance integrals. However, since a given set of input VSIP's leads to MO's which, from a Mulliken population analysis, produce a charge distribution different from that assumed in the original evalua- 
tion of VSIP values, these input VSIP's had to be adjusted for the new charge distribution; and the calculation had to be repeated until the calculated charge distribution coincided within a preset limit to that used to evaluate VSIP's. The VSIP's were obtained from the work of Cusacks (10), and Basch, Viste and Gray (11, 12) and are listed in Table 27. 
TABIE 27

ATOMIC ORBITAL VALENCE STATE IONIZATION POTENTIALS ${ }^{a}$

$$
\operatorname{VSIP}=A \mathrm{q}^{2}+\mathrm{Bq}+\mathrm{C}
$$

\begin{tabular}{|c|c|c|c|}
\hline Orbital & A & $\mathrm{B}$ & $\mathrm{C}$ \\
\hline $\mathrm{H} I \mathbf{s}$ & 13.60 & 27.18 & 13.62 \\
\hline C $2 s$ & 19.41 & 17.56 & 3.47 \\
\hline C $2 p$ & 10.64 & 14.65 & 3.47 \\
\hline$N 2 s$ & 25.56 & 20.11 & 3.49 \\
\hline$N 2 p$ & 13.19 & 16.51 & 3.49 \\
\hline $02 s$ & 32.33 & 22.89 & 3.47 \\
\hline $02 p$ & 15.80 & 18.57 & 3.46 \\
\hline
\end{tabular}

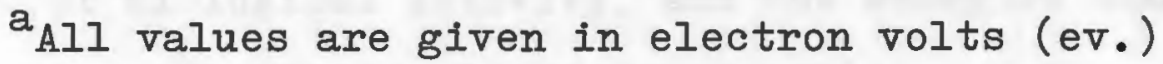
Note: The net atomic charge is represented by $q$. 
IV

RESULTS AND DISCUSSION OF THE MOLECULAR

ORBITAL CAICULATIONS AND CONSIDERATIONS

OF MECHANISMS OF ACTION OF THE PARABENS

A search of the recent literature reveals that a growing number of scientists are employing theoretical chemistry to probe biological events at the molecular level. Therefore, experiments designed to elucidate mechanisms at the drug-receptor site must be directed toward the fundamental process controlling these biological events. Hence, the experimenter must understand the structural features of the molecules imparting chemical and/or biological activity, and the energies and distribution of valence electrons as well.

Molecular Orbital Theory characteristically depicts the electrons of a molecule as being delocalized over the entire molecular framework; however, in some instances these molecular orbitals (MO's) are significantly localized on one or two atoms, e.g., Ione pairs or carbonyl pi $(\pi)$ systems. Because of mathematical complexity, the use of rigorous, self-consistent-field molecular orbital theory, was severely limited, except for simple molecules, until the development of high 
speed digital computers. The success of MO theory in predicting chemical and physical events, however, has been very encouraging: there has been a steady increase in its use, and concurrently, there has been a development of semiempirical molecular orbital theories applicable to large molecules. Since most medicinal chemists and pharmacologists are interested in large molecules, it is necessary to apply semiempirical molecular orbital theory which can be used in a practical manner to treat such molecules. These methods have been described by Kier (1) in great detail. It must be pointed out that it is one thing to utilize MO theory to calculate an activity index for a series of molecules, but it is another matter to relate this index realistically to a reaction a drug may undergo in a biological environment. Therefore, an index must be plausible, and high energy reactions such as spectral transitions would be excluded because their MO indices are comparatively meaningless. Other combinations of indices that exhibit certain types of high energy bond-forming reactions would also have little bearing on a biological event. Where the correlation between a biological action and an MO index represents an improbable reaction, it is likely that there are other relationships within the index that are more directly related to the possible chemical event. Thus, a correlation between activity and an index re- 
flecting an electron transition may in fact be correlating activity within $\mathrm{E}_{\text {HOMO}}$, with a relatively constant $\mathrm{E}_{\text {LEMO }}$ - This index would then be more realistically interpreted as implying a relationship with charge transfer donation rather than an electronic transition. Therefore, classical chemical intuition and experience must serve as a guide and check on MO-calculated predictions.

The quantum mechanical treatment of charge transfer complex formation first described by Mulliken (2), depicts an intimate relationship between two molecules in which there exists a mutual tendency for the partial exchange of an electron from the donor to the acceptor. To effect a complete transfer of an electron from the donor to the acceptor molecule in the complex, sufficient energy must be put into the system to promote the various participants to an excited state. In the biological medium, sources of energy are not readily identified or comparable with those obtained in vitro. Therefore, in vivo, the energy levels of both donor and acceptor are so disposed that a minimum expenditure of energy is necessary for the transfer of an electron. The donor molecules must have a very high-lying Hомо (Highest Occupied Molecular Orbital) energy, and the acceptor molecule a very low-lying LEMO (Lowest Empty Molecular Orbital). When these conditions are met, the 
need for significant amounts of external energy are obviated and electron exchange becomes relatively easy. Therefore, attention may then be focused on the HOMO energy as a calculatable index of the spontaneous donor ability of a molecule.

The formation of charge transfer complexes among drugs and biologically important molecules may have a significant consequence in itself or may lead to a subsequent event important in the action of the molecule. A complex may lead to the creation of a new conformation not present in the donor or acceptor, imparting biological activity. An allosteric effector may engage the appropriate site in a charge transfer complex. The formation of a complex may influence reactivity resulting in altered chemical stability. The complex may bring together two molecules in sufficient intimacy so that hydrogen or electron transfer may ensue. Further bonding in the form of covalent or hydrogen bonding may be a consequence of the complex. Therefore, the indices usually examined for the charge transfer phenomena have been the $\mathrm{E}_{\text {HOMO }}$ and $\mathrm{E}_{\text {LEMO }}$.

If we can accept the premise that a pattern of essential atoms and groups in a drug molecule must bear some distinct relationship to complementary features on a receptor molecule, then it follows that we must understand the spatial relationships of these essential moie- 
ties in order to relate structural to biological activity. Therefore, with an understanding of the electron distribution on the various atoms and groups of the drug moiety and an understanding of the drug molecule stereochemistry, one is in a position to deduce something of the nature of the topology of the receptor. The importance of the stereochemistry of pharmacologically active molecules is well known, as is also the high degree of receptor specificity for active substrates. Some MO methods, including the Extended Huckel Theory (EHT) (3), Iterated Extended Huckel Theory (IEHT) (4), and the Pople-Segal CNDO/2, SCF method (5), are capable of treating all-valence electrons and leading to a total energy as a function of geometry. Important also is the relationship between the MO-calculated conformation, the X-ray crystallographicdetermined conformation and that conformation of a substance in solution. The Mo calculations are determined on a single isolated molecule and do not consider the pertinent perturbations introduced by the neighboring molecules or solvent; the crystal studies are done on a molecule frozen into an array of its kind; while the solution-derived conformations are those of a molecule surrounded by solvent.

A recent question regarding MO-calculated conformations has been raised as to whether drug molecules 
treated in such a manner can be used to map complementary features of a receptor. One working hypothesis, which has been used in MO studies, is that these molecules engage the receptor in their preferred conformations. An alternative hypothesis is that the receptor is capable of a significant perturbing influence on a drug molecule within its vicinity, and that a nonpreferred conformation engages the receptor. This is not in violation of the concept that optimum stereochemistry maximizes efficacy, since the perturbed conformation would arise from an initial presentation of the drug molecule in its preferred conformation.

In this study, Iterated Extended Huckel Theory (IEHT) semiempirical molecular orbital calculations have been carried out on aniline, phenol, benzoic acid, parahydroxybenzoic acid, and the methyl and ethyl esters of para-hydroxybenzoic acid. The results are considered from the point of view of HOMO and LEMO energies as well as charge distributions and molecular conformation energies.

The computer calculated Cartesian-Coordinates for the investigational compounds utilizing CORCAL (6) are given in Tables $A$ to $Q$. The graphic representation of these various configurations for the molecules are seen in Figures 18 to 34 .

Tables 28 and 29 illustrate the charge distribu- 
tion within the various compounds and the conformations studied.

Tables 30 and 31 show the total energy in electron volts within the molecules and the HOMO and LEMO Energies of the molecular conformations of the substances under investigation.

The HOMO and LEMO basis set orbital coefficients for para-Hydroxybenzoic acid and conformer are given in Table 32; for Methyl para-Hydroxybenzoate and conformers in Table 33; and for Ethyl para-Hydroxybenzoate and conformers in Tables 34 and 35.

Resonance forms, which can lead to molecular stabilization, can be shown to exist in the various compounds investigated. A summary of the resonance forms are as follows:

1) Phenol

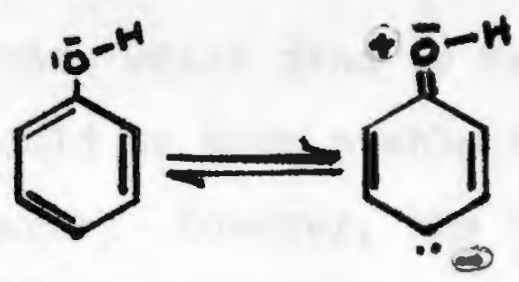

2) Aniline

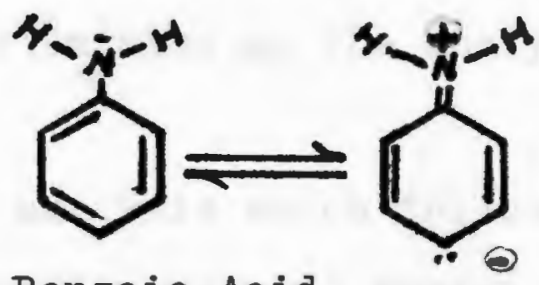

3) Benzoic Acid

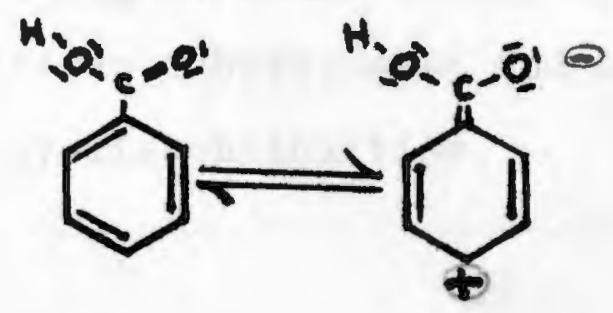


4) para-Hydroxybenzoic Acid

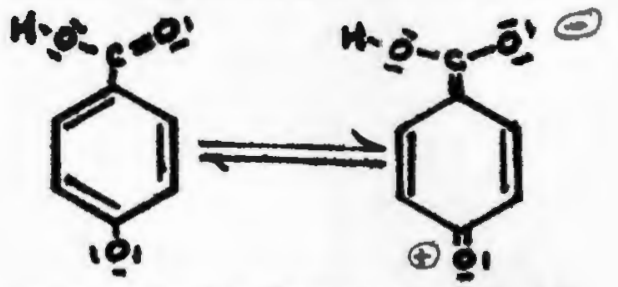

5) para-Aminobenzoic Acid

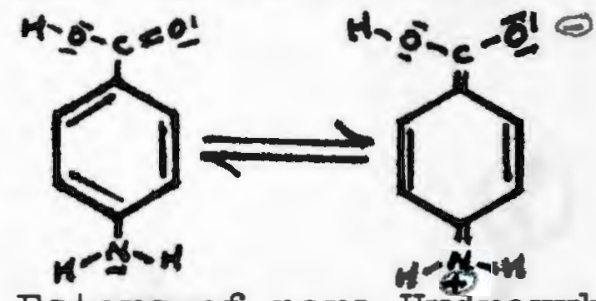

6) Esters of para-Hydroxybenzoic Acid

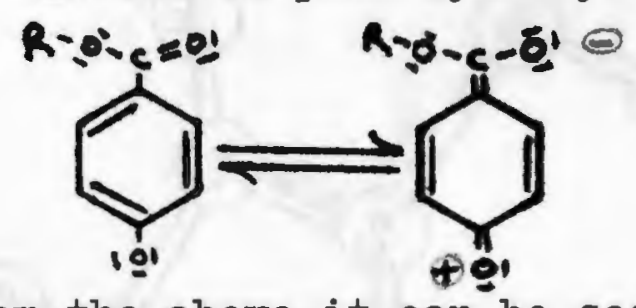

From the above it can be seen that para-hydroxy and para-aminobenzoic acid, as well as their esters, form more stable resonance structures than do benzoic acid, phenol or aniline. Hence, we should see that molecular conformers which tend to retain these resonance structures would be more stable than conformers which restrict resonance. However, the relationship of MO theory, $\mathrm{X}$-ray crystallography, solution and biological conformers must be kept in mind as the analysis of the data progresses.

The analysis which follows will use a charge/ HOMO/LEMO/configurational energy approach to study effects of various substituents and conformers, both by trends and by discontinuities. 


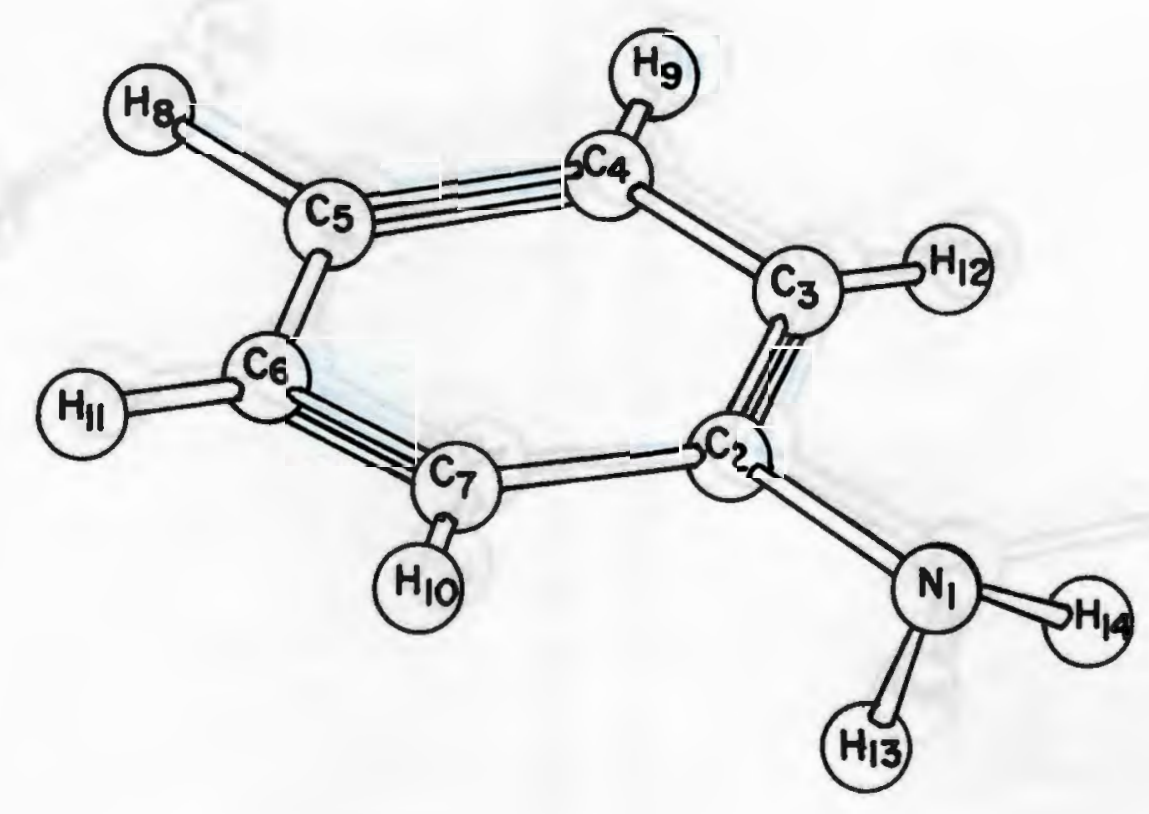

Fig. 18.--Aniline Molecular Conformation

Conformational energy: $-13058 \mathrm{Kcal}$ 


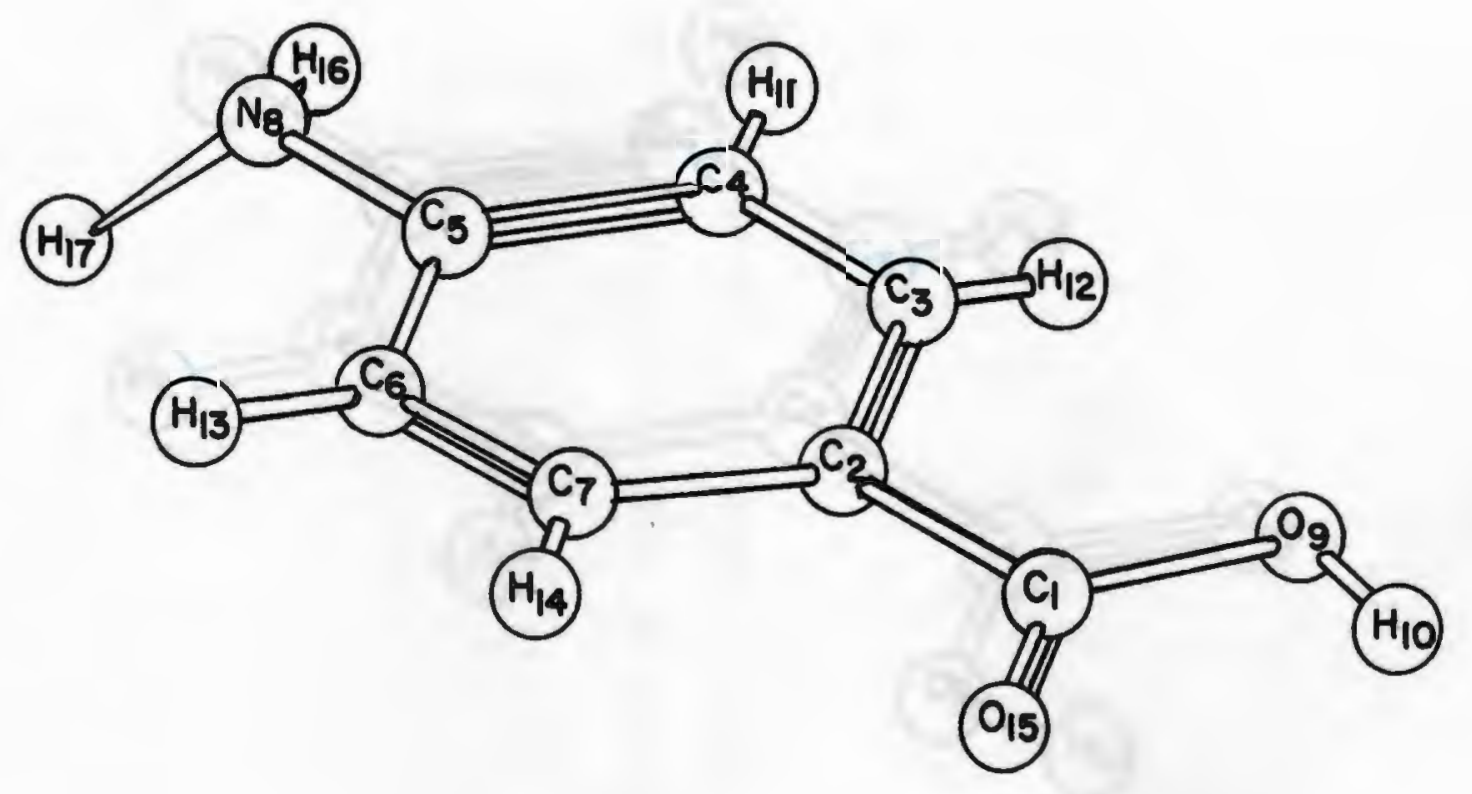

Fig. 19.--para-Aminobenzoic Acid: carboxyl group coplanar with the phenyl ring

Conformational energy: $-19535 \mathrm{Kcal}$ 


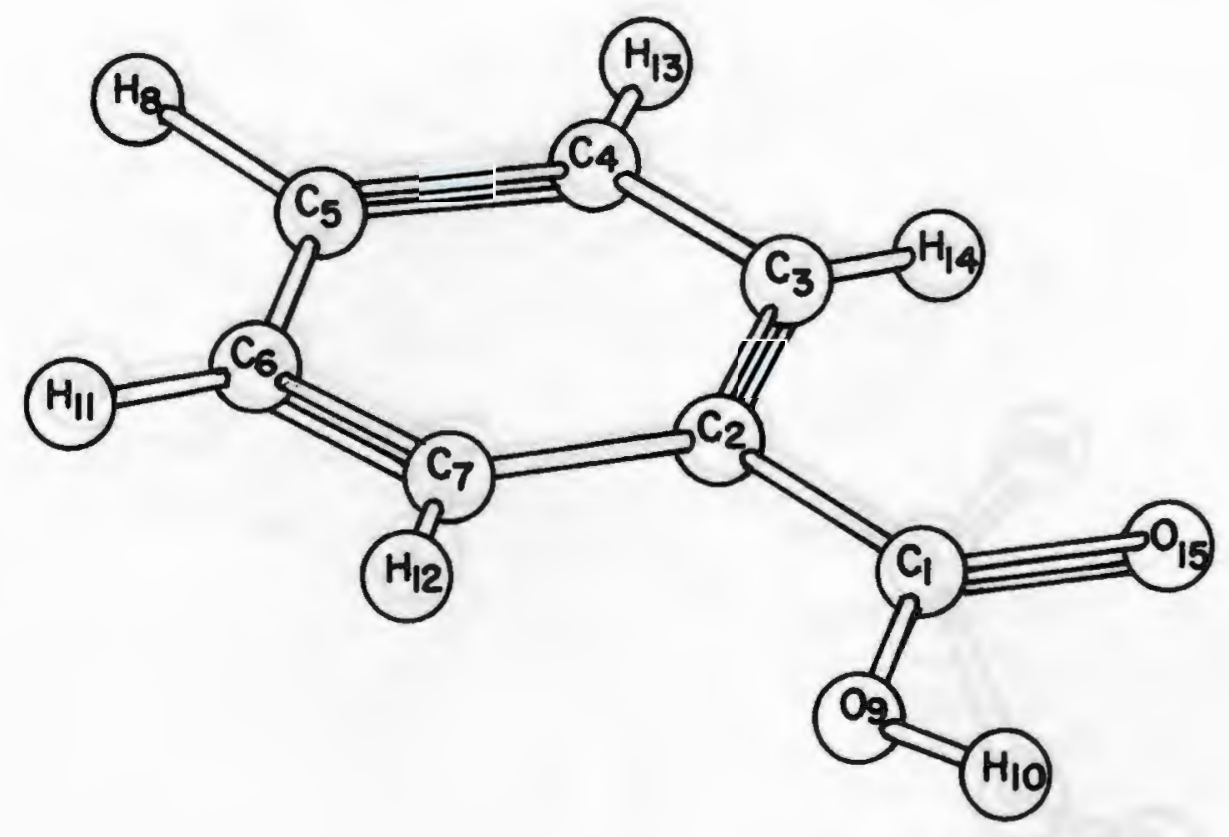

Fig.20.--Benzoic acid: carboxyl group coplanar with the phenyl ring. Conformational energy: -17261 Kcal 


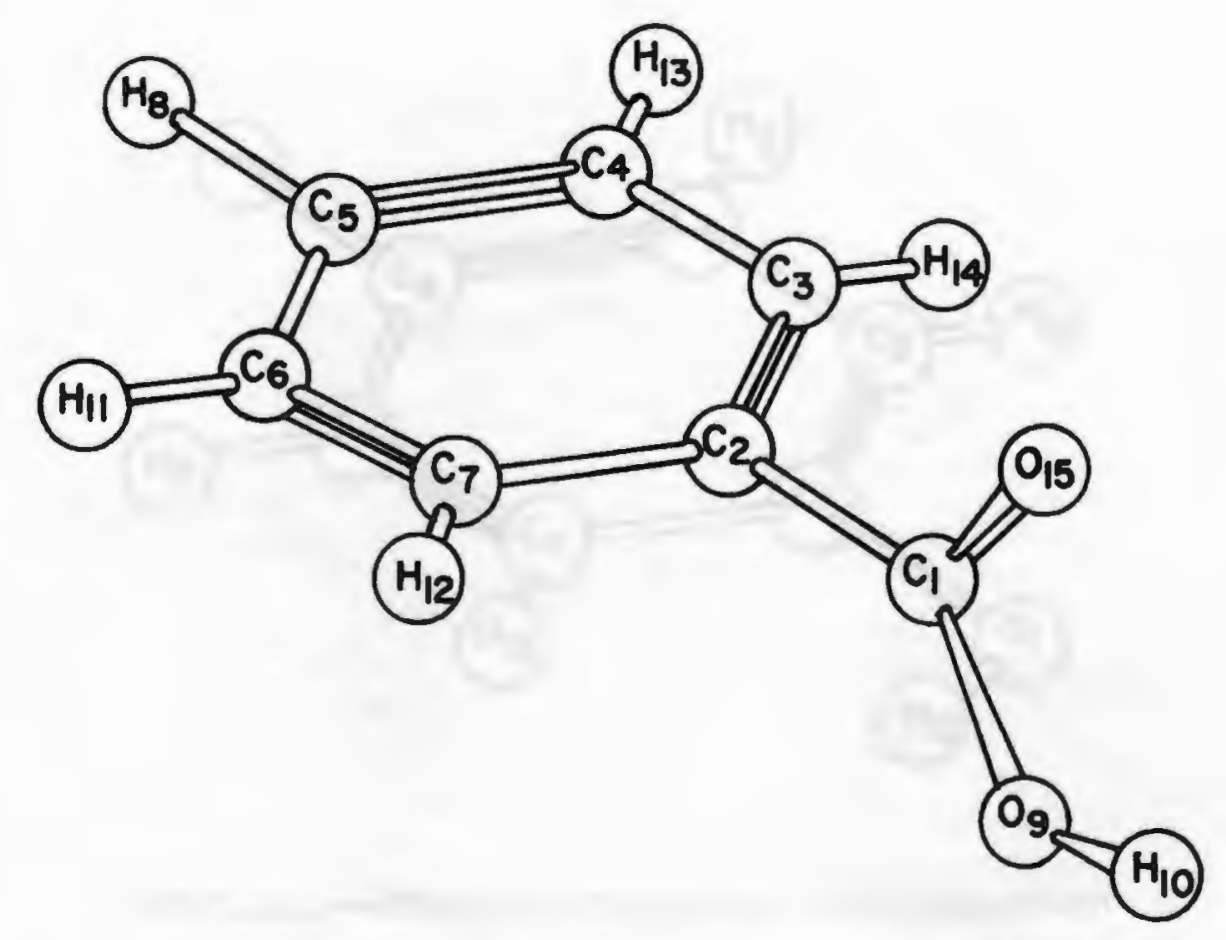

Fig. 2l.--Benzoic acid: carboxyl group perpendicular to the plane of the phenyl ring. Conformational energy: -17264 Kcal 


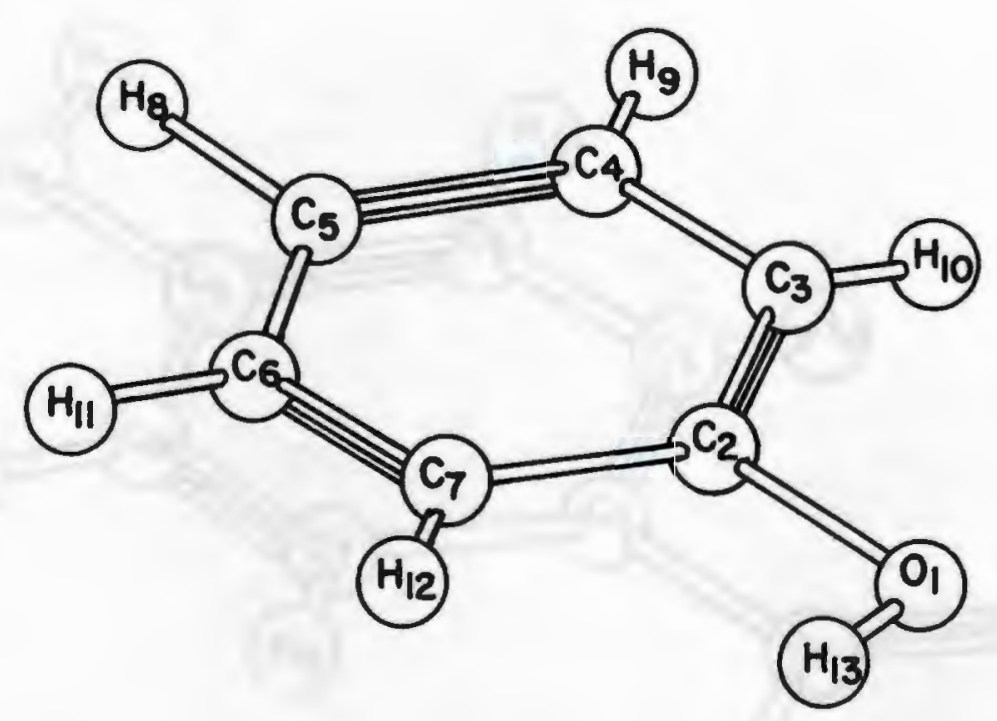

Fig.22.--Phenol molecular conformation Conformational energy: -13360 Kcal 


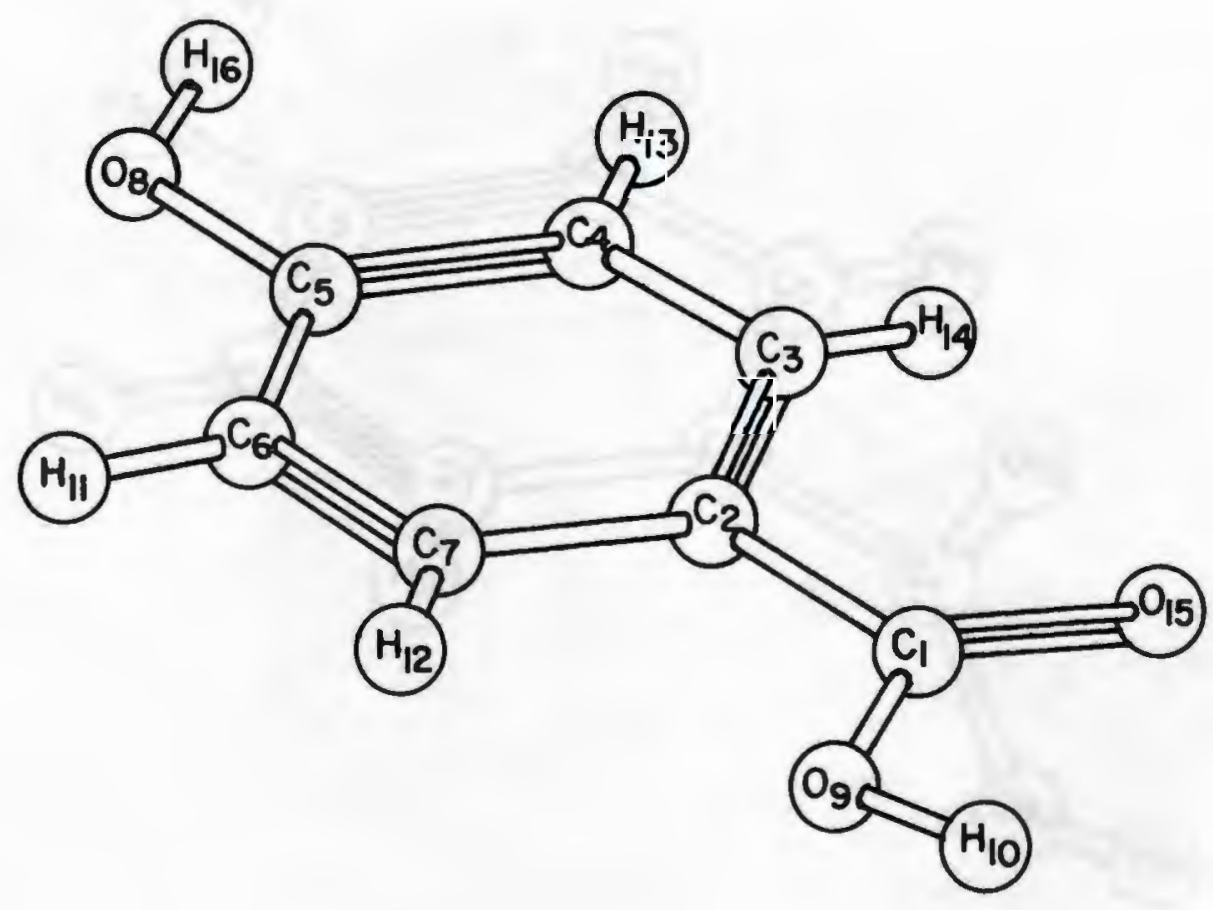

Fig. 23.--para-Hydroxybenzoic acid: carboxyl group coplanar with the phenyl ring.

Conformational energy: $-19883 \mathrm{Kcal}$ 


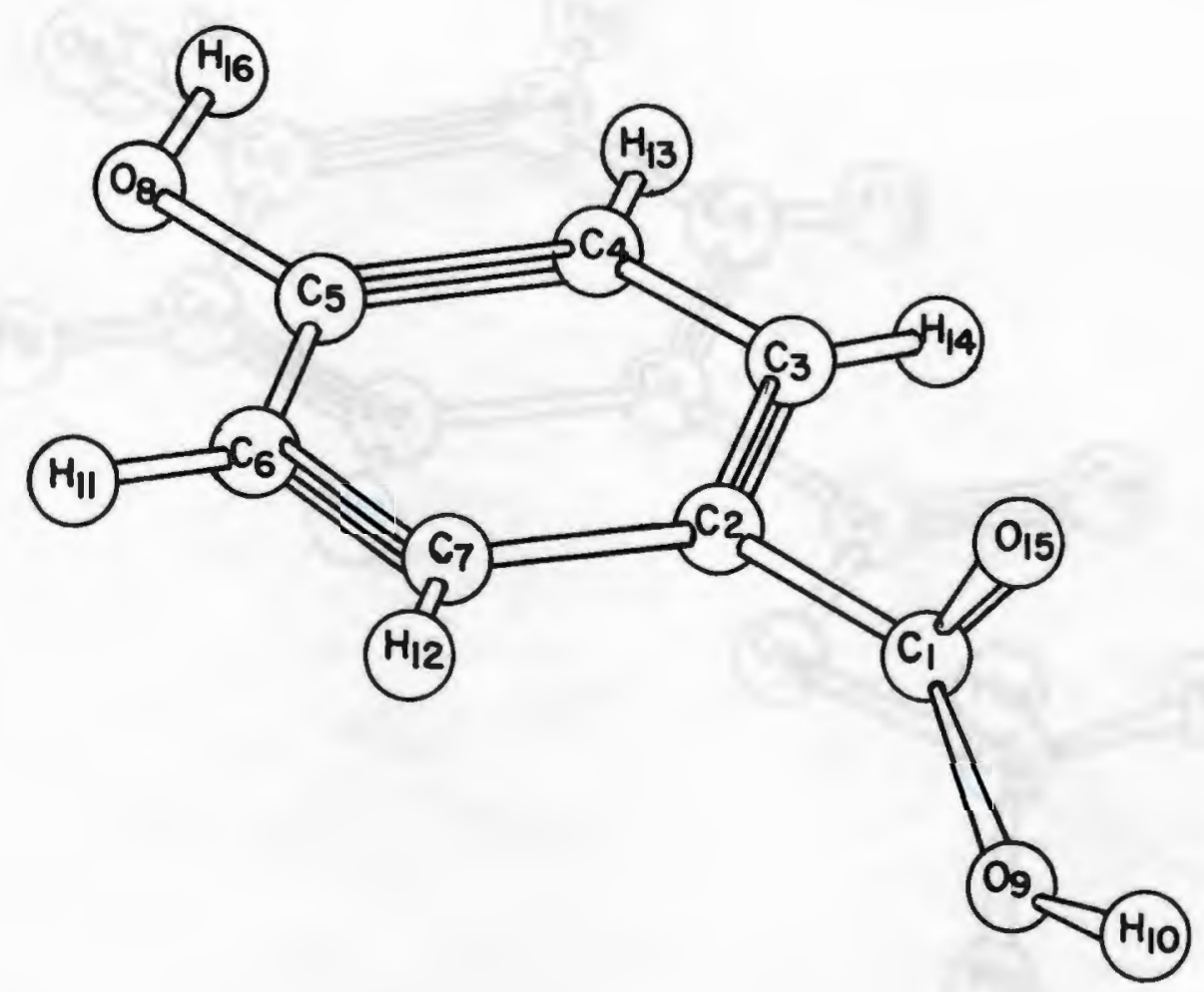

Fig. 24.--para-Hydroxybenzoic acid: carboxyl group perpendicular to the plane of the phenyl ring.

Configurational energy: $-19859 \mathrm{Kcal}$ 


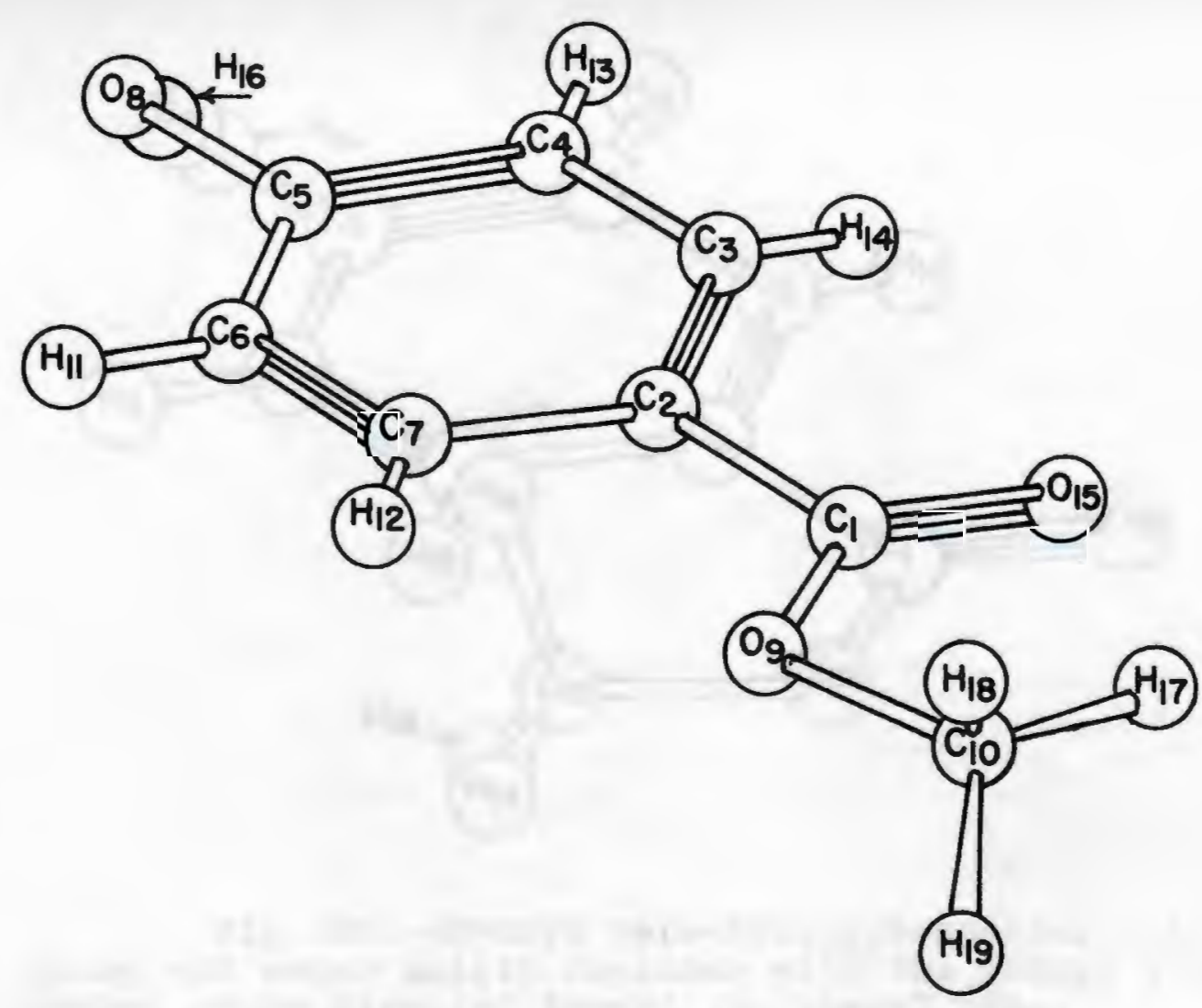

Fig. 25.--Methyl para-hydroxybenzoate: carboxyl group and ester moiety coplanar with the phenyl ring; methyl group directed toward the carbonyl oxygen.

Conformational energy: $-21993 \mathrm{Kcal}$ 


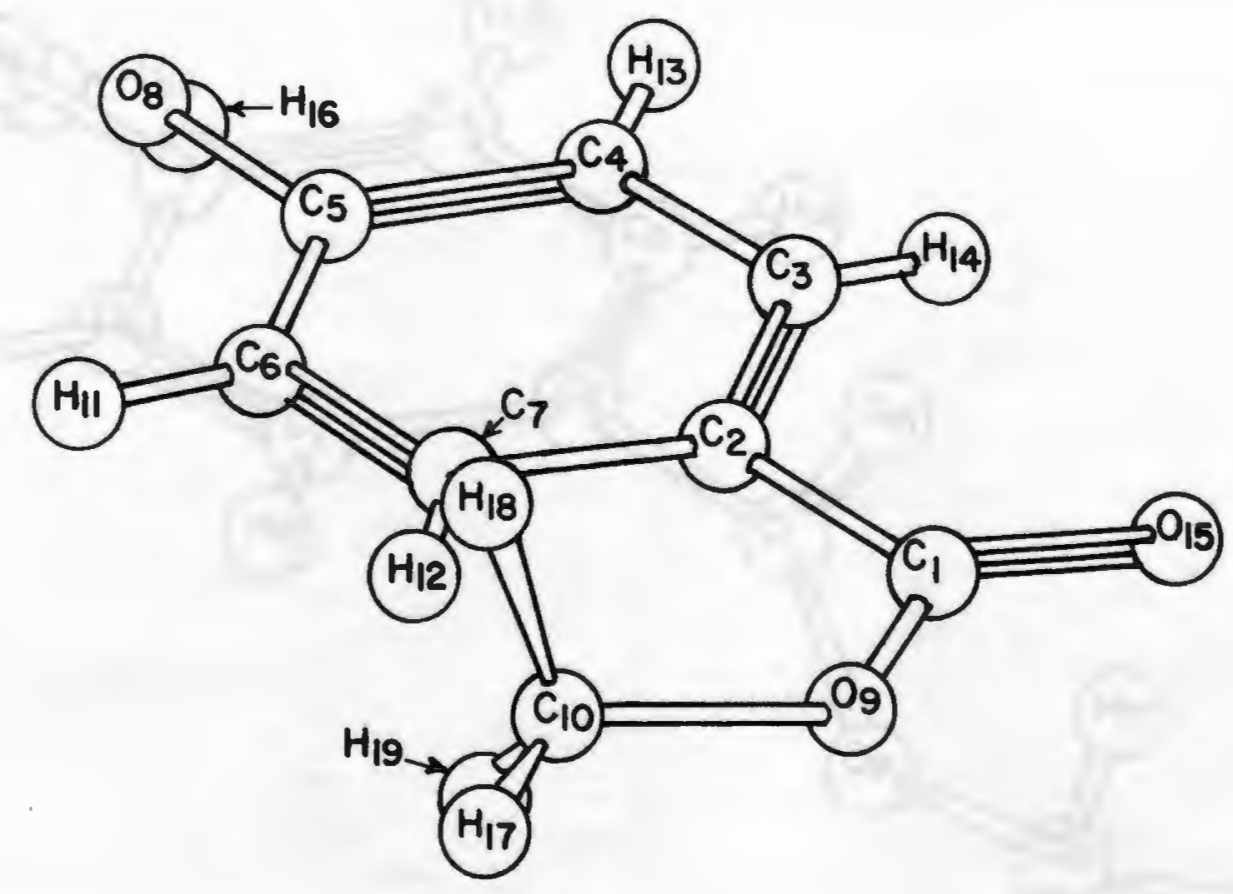

Fig. 26.--Methyl para-hydroxybenzoate: carboxyl group and ester moiety coplanar with the phenyl ring; methyl group directed toward the phenyl ring.

Conformational energy: Computer program did not converge. 


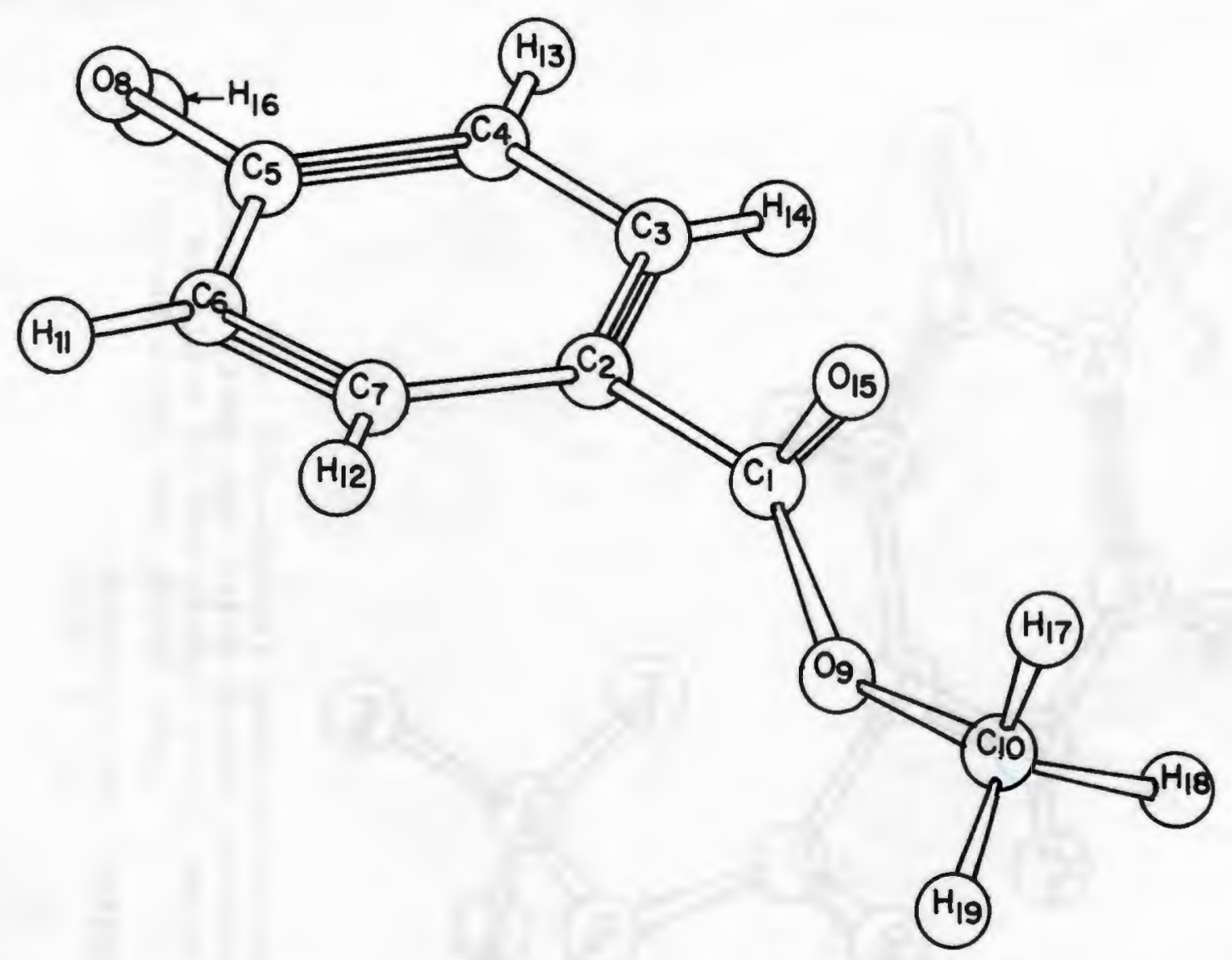

Fig. 27.--Methyl para-hydroxybenzoate: carboxyl group and ester moiety perpendicular to the plane of the phenyl ring; methyl group directed toward the carbonyl oxygen.

Conformational energy: -21835 Kcal 


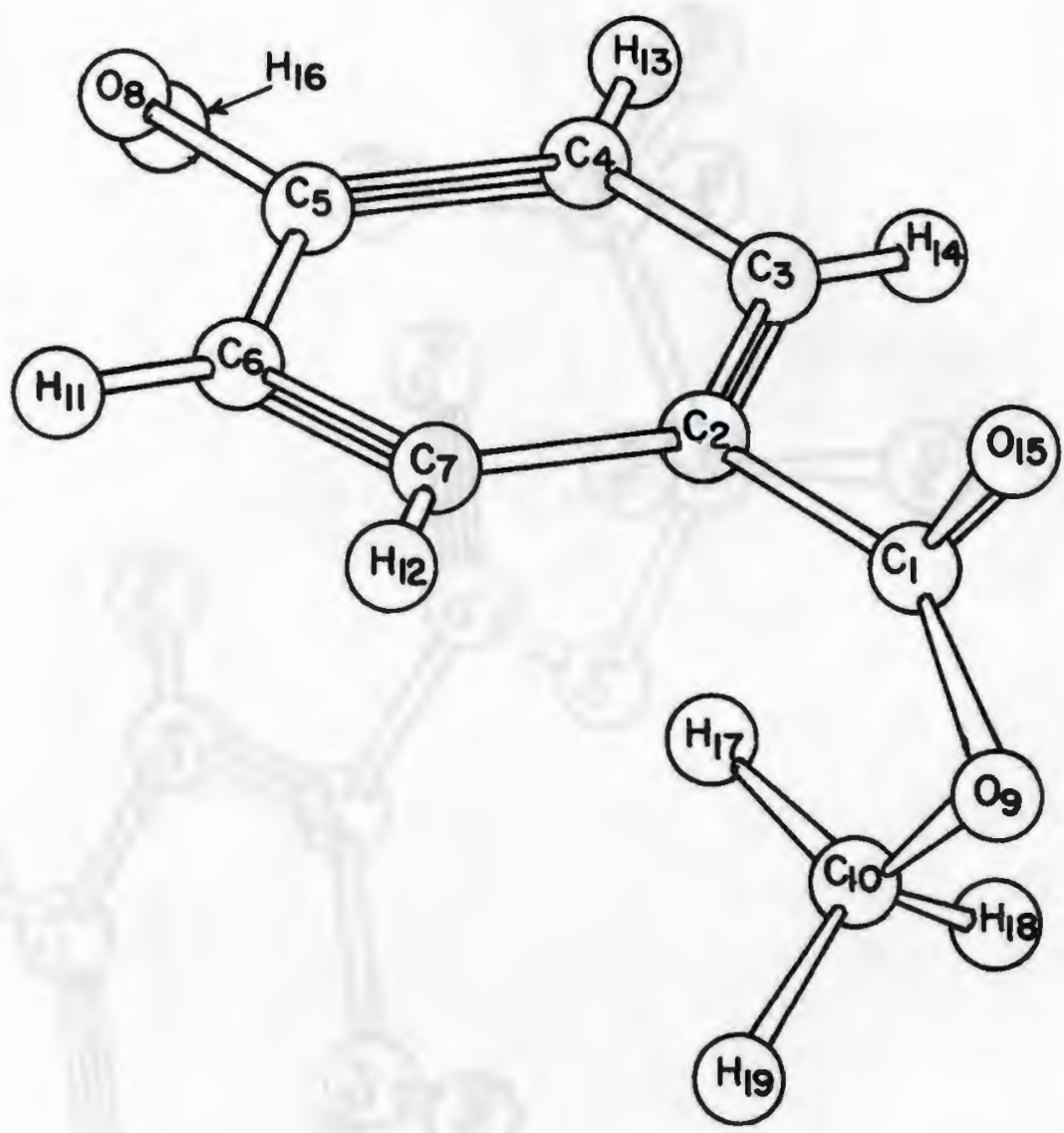

Fig. 28.--Methyl para-hydroxybenzoate: carboxyl group and ester moiety perpendicular to the plane of the phenyl ring; methyl group directed under the phenyl ring.

Conformational energy: $-21940 \mathrm{~K}$ cal 


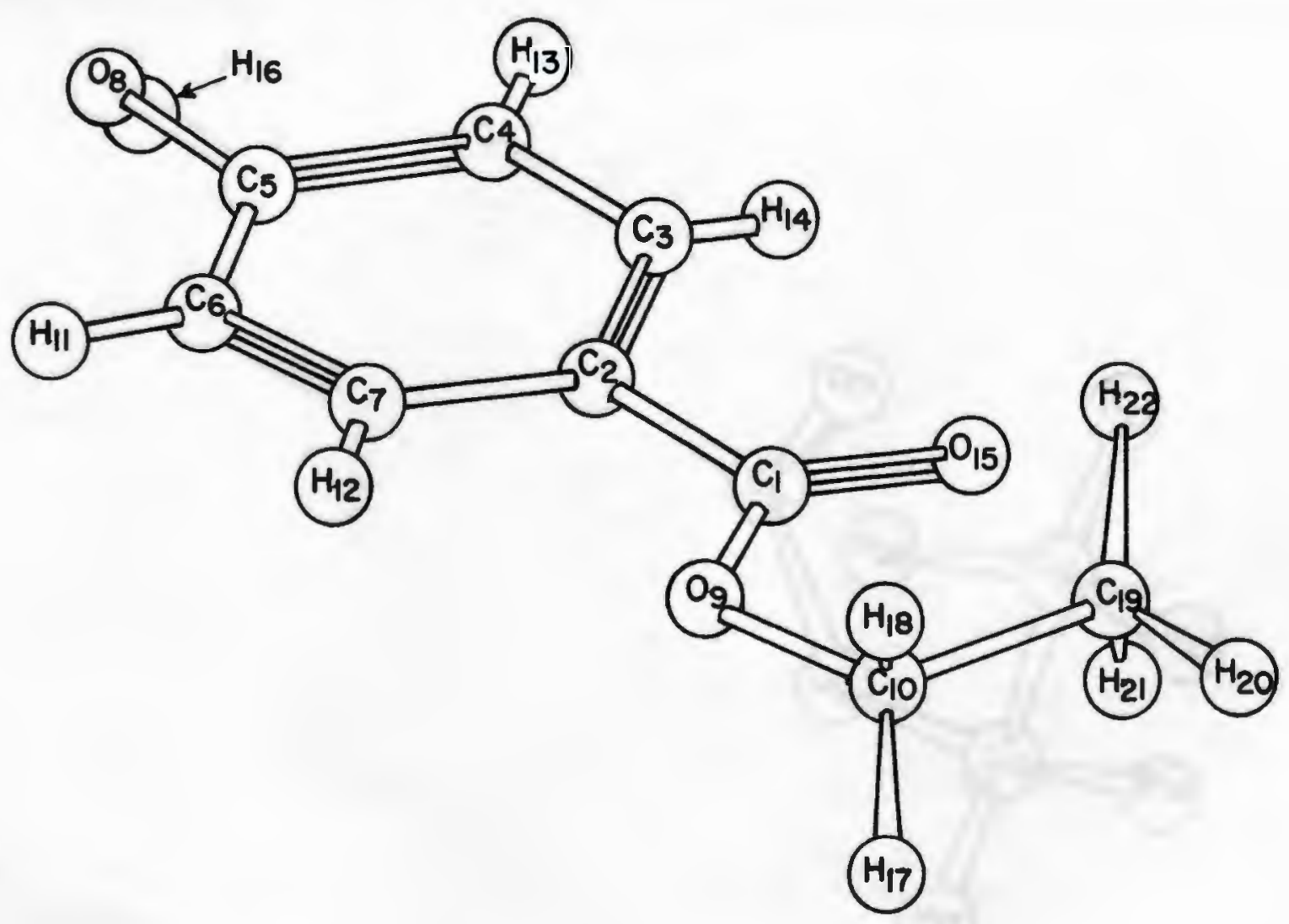

Fig. 29.--Ethyl para-hydroxybenzoate: carboxyl group and ester moiety coplanar with the phenyl ring; ethyl group in a hooked position directed toward the carbonyl oxygen.

Conformational energy: -24099 Kcal 


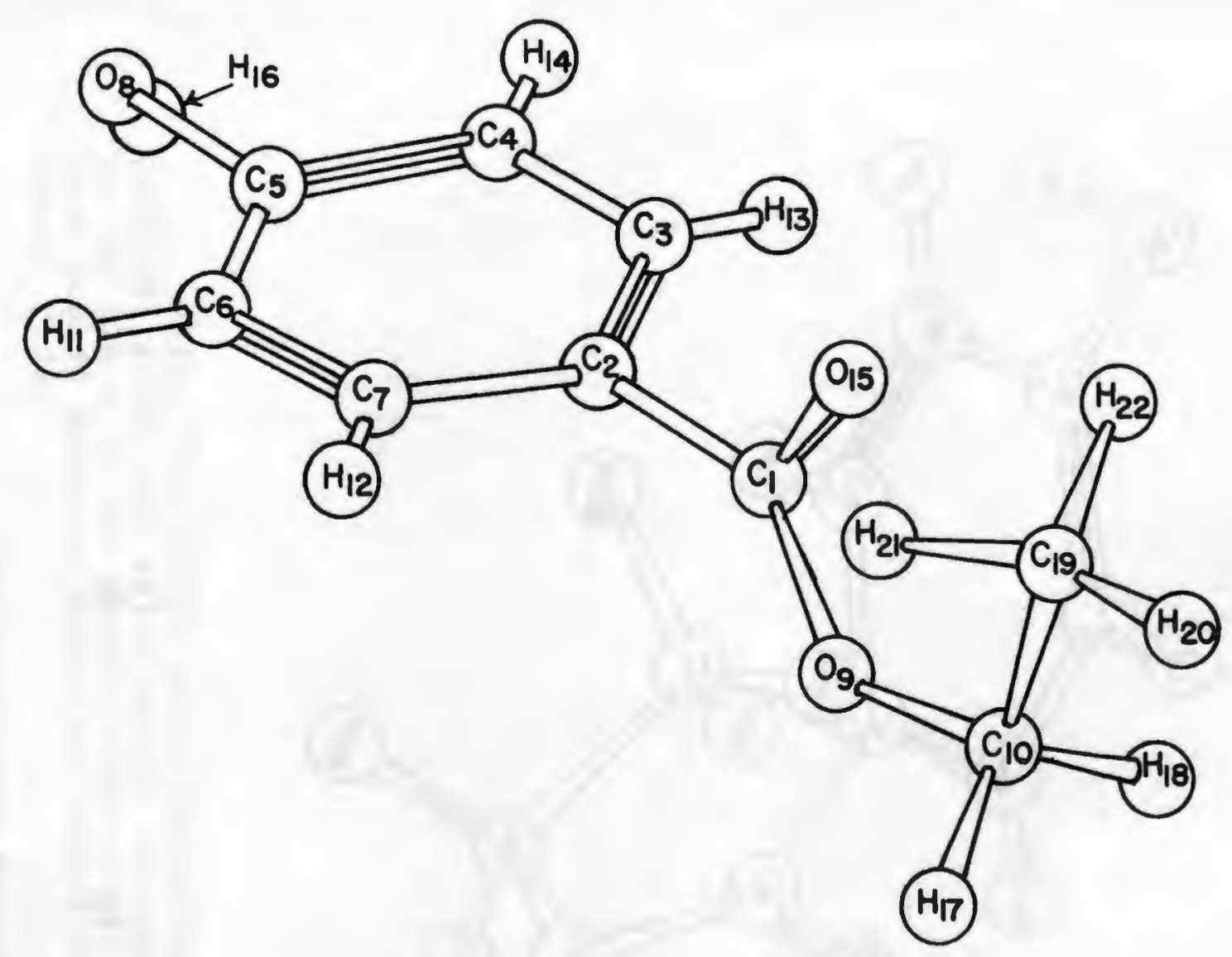

Fig. 30.--Ethyl para-hydroxybenzoate: carboxyl group and ester moiety perpendicular to the plane of the phenyl ring; ethyl group in a hooked position directed toward the carbonyl oxygen.

Conformational energy: $-24040 \mathrm{Kcal}$ 


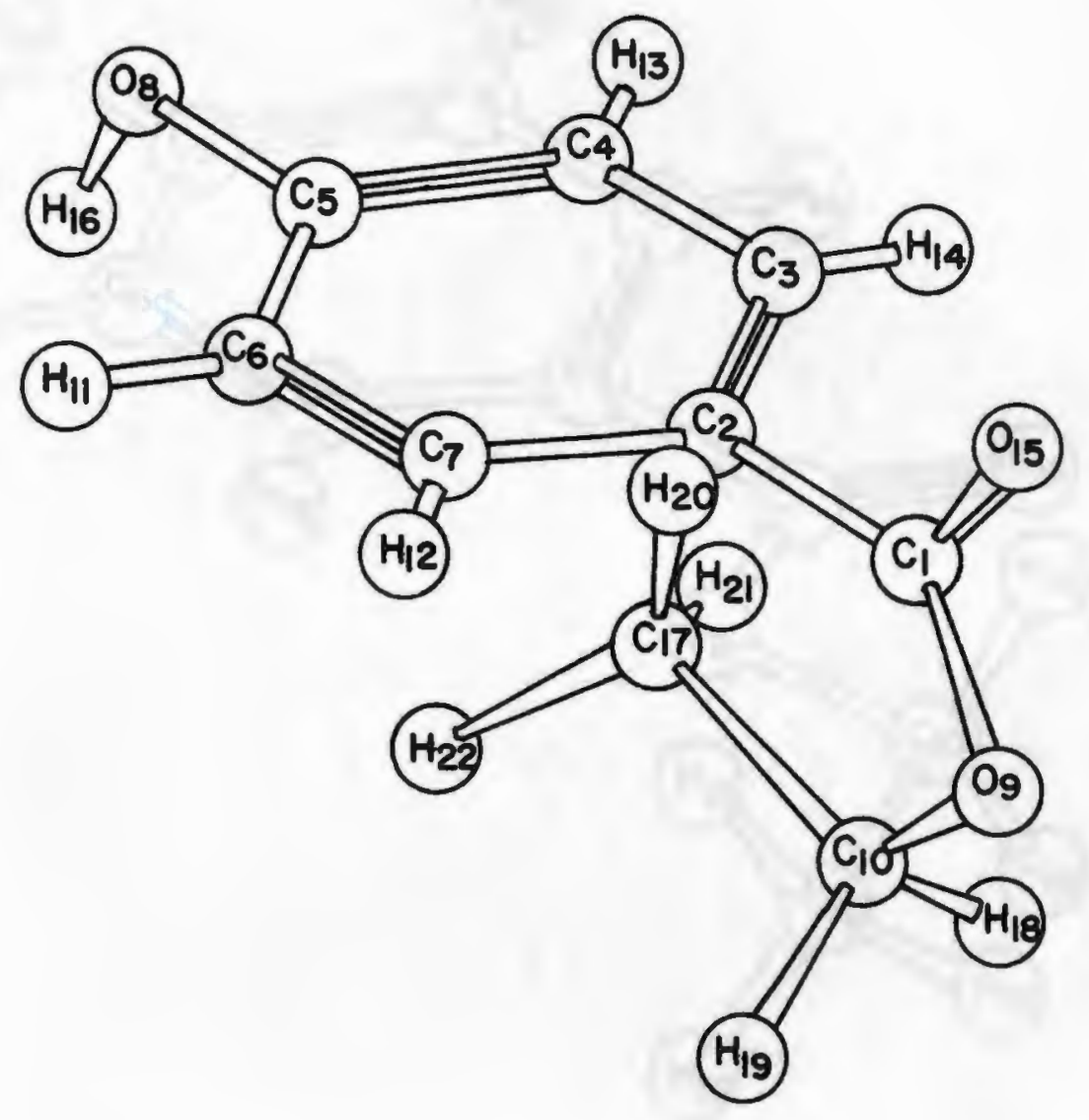

Fig. 31.--Ethyl para-hydroxybenzoate: carboxyl group and ester moiety perpendicular to the plane of the phenyl ring; ethyl group in a hooked position directed toward the phenyl ring.

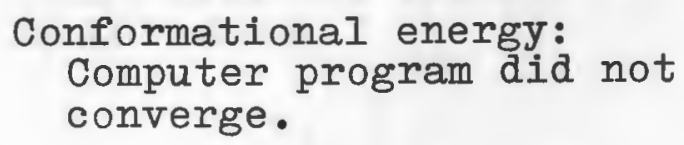




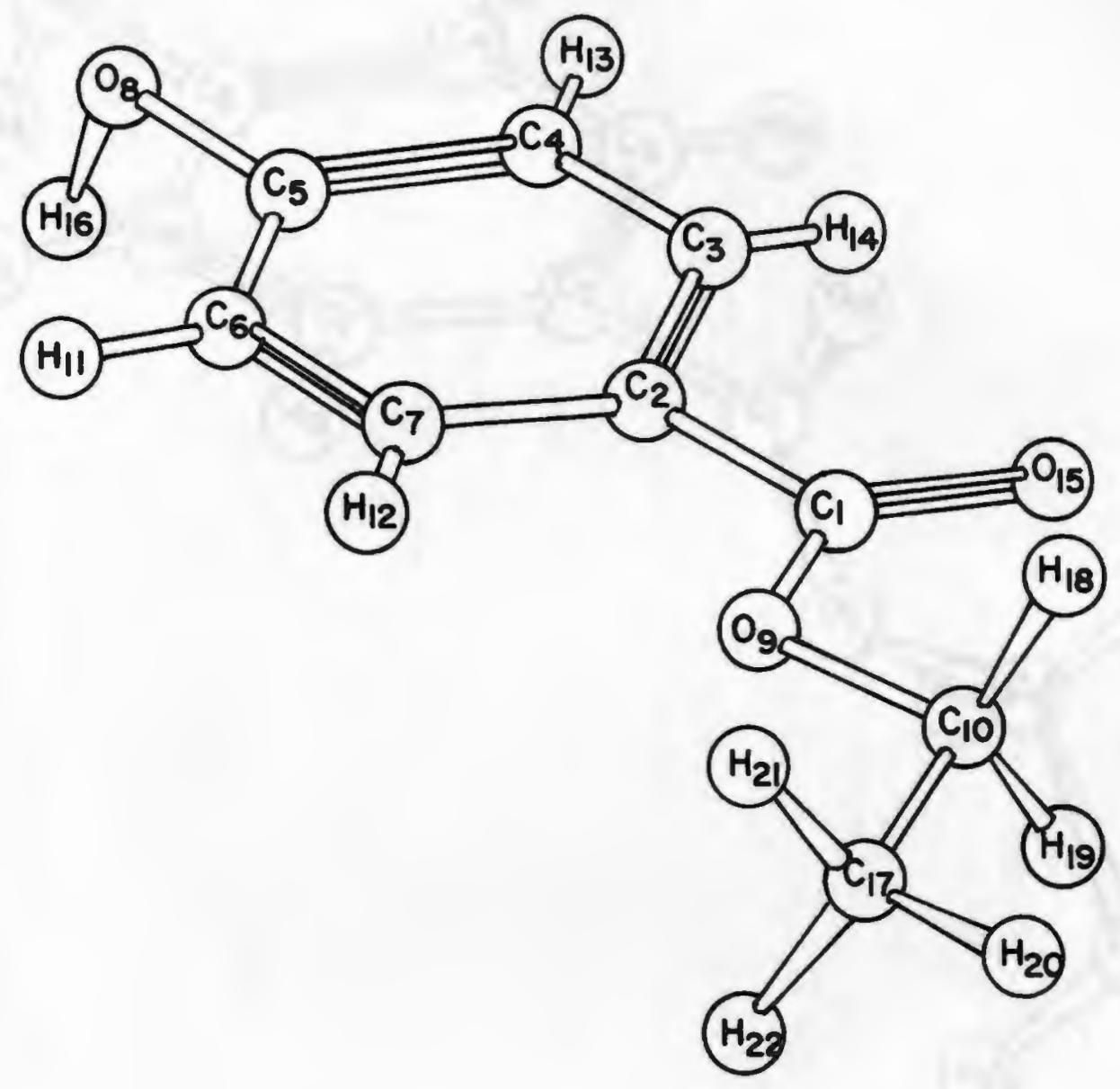

Fig. 32.--Ethyl para-hydroxybenzoate: carboxyl group and ester moiety coplanar with the phenyl ring; methyl group directed away from the carbonyl oxygen.

Conformational energy:

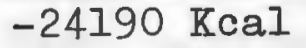




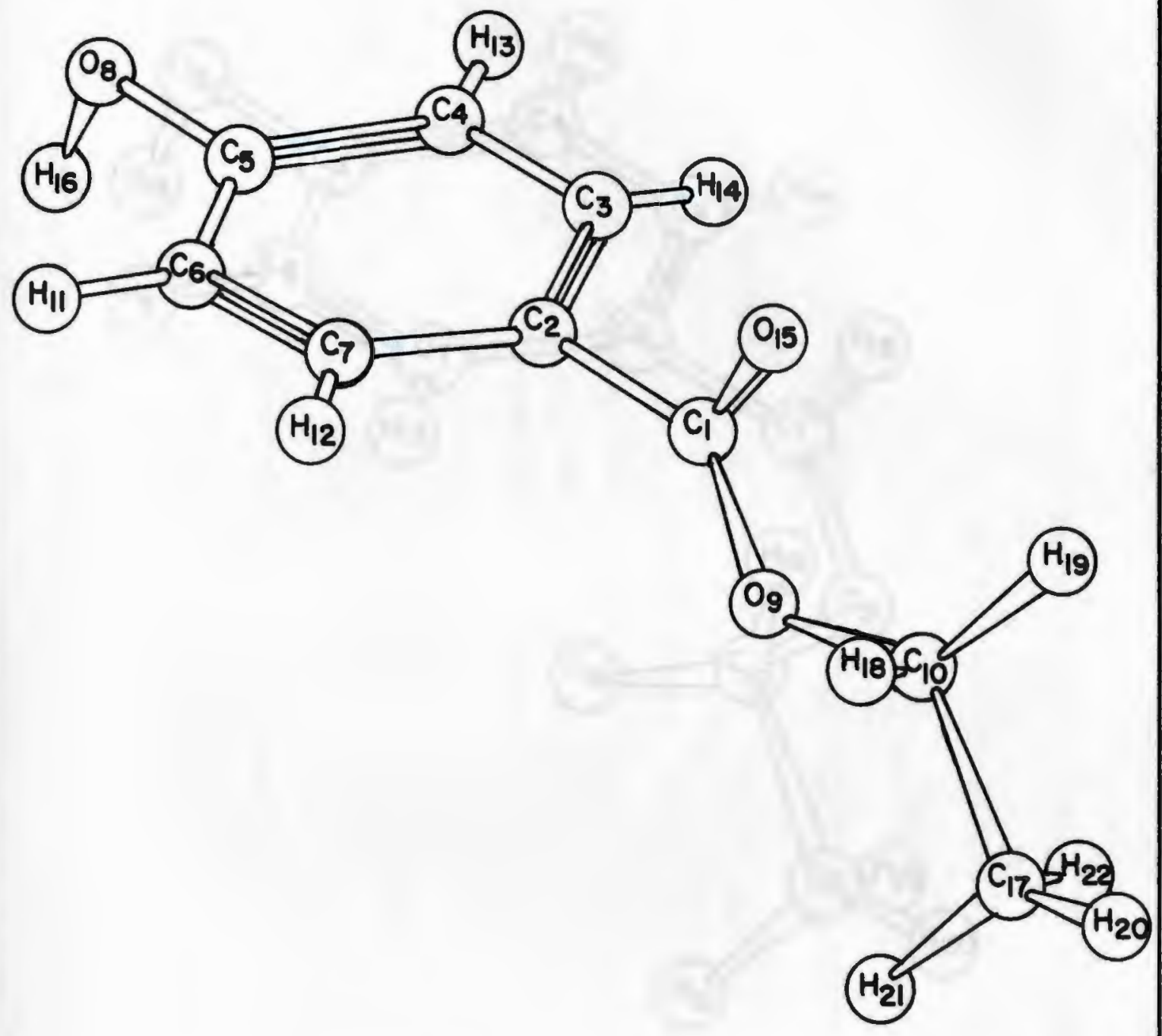

Fig. 33.--Ethyl para-hydroxybenzoate: carboxyl group and ester moiety perpendicular to the plane of the phenyl ring; methyl group directed away from the carbonyl oxygen.

Conformational energy: -24080 Kcal 


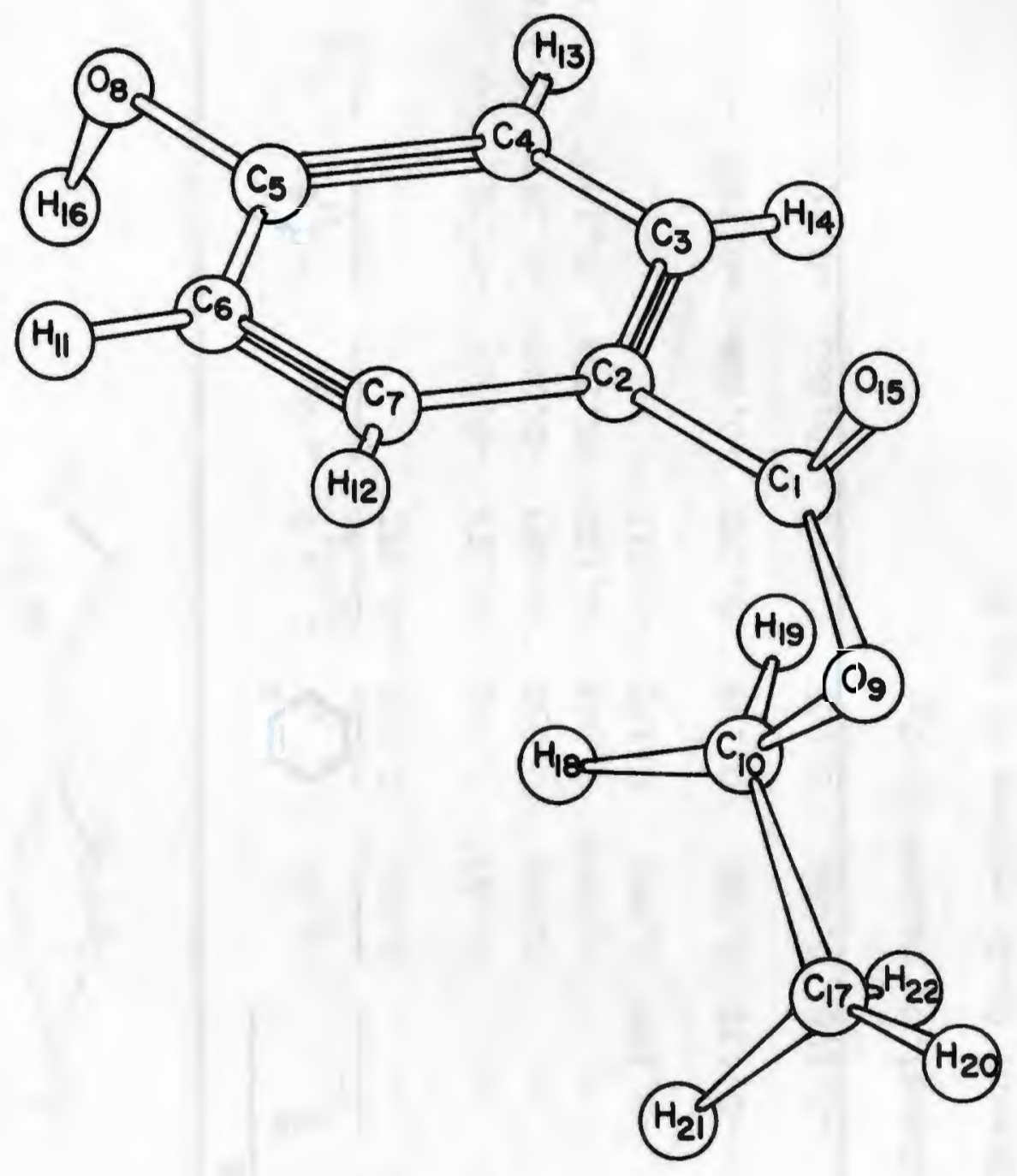

Fig. 34.--Ethyl para-hydroxybenzoate: carboxyl group and ester moiety perpendicular to the plane of the phenyl ring; methyl group directed away from the phenyl ring; methylene group directed under the phenyl ring.

Conformational energy: -24116 Kcal 
TABLE 28

CHARGE DISTRIBUTION WITHIN THE MOLECULES OF THE TYPE

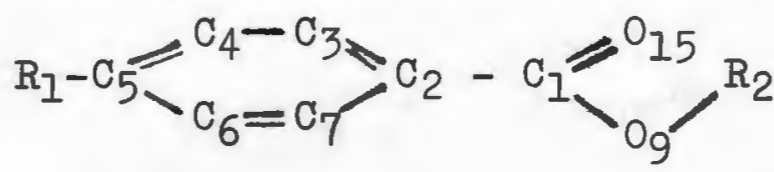

\begin{tabular}{|c|c|c|c|c|c|c|c|c|c|c|}
\hline \multirow[b]{2}{*}{ Compound } & \multicolumn{3}{|c|}{$\underline{R}$} & \multirow{2}{*}{$\mathrm{C}_{5}{ }^{\mathrm{a}}$} & \multirow{2}{*}{ 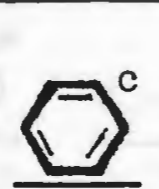 } & \multirow{2}{*}{$\mathrm{C}_{2}-\mathrm{C}_{1}^{\mathrm{b}}$} & \multirow{2}{*}{$=\mathrm{O}_{15}$} & \multirow{2}{*}{$-C_{0}^{0} R_{2}$} & \multirow[b]{2}{*}{$\mathrm{O}_{9}^{\prime}$} & \multirow[b]{2}{*}{$\mathrm{R}_{2}$} \\
\hline & Fig & $\mathrm{H}^{\prime}$ & b- & & & & & & & \\
\hline Aniline & 18 & 0.0026 & - & 0.050 & 0.051 & -0.031 & - & - & - & - \\
\hline $\begin{array}{l}\mathrm{p}-\mathrm{NH}_{2}^{-} \\
\text {Benzoic Acid }\end{array}$ & 19 & 0.0837 & - & 0.063 & 0.062 & 0.124 & -0.304 & -0.261 & -0.192 & 0.110 \\
\hline Benzoic Acid & 20 & - & - & 0.004 & 0.050 & 0.183 & -0.285 & -0.183 & -0.172 & 0.125 \\
\hline Benzoic Acid & 21 & - & - & 0.0006 & 0.048 & 0.184 & -0.286 & -0.180 & -0.171 & 0.128 \\
\hline Phenol & 22 & - & -0.149 & 0.081 & 0.129 & -0.011 & - & - & - & - \\
\hline $\begin{array}{l}\mathrm{p}-\mathrm{OH} \\
\text { Benzoic Acid }\end{array}$ & 23 & - & -0.132 & 0.088 & 0.189 & 0.178 & -0.286 & -0.195 & -0.178 & 0.125 \\
\hline $\begin{array}{c}\mathrm{p}-\mathrm{OH} \\
\text { Benzoic Acid }\end{array}$ & 24 & - & -0.176 & 0.084 & 0.205 & 0.194 & -0.281 & -0.168 & -0.170 & 0.129 \\
\hline
\end{tabular}

${ }^{a}$ In Aniline and Phenol $C_{5}$ refers to $C_{2}$

${ }^{\mathrm{b}}$ In Aniline and Phenol $\mathrm{C}_{2}-\mathrm{C}_{1}$ refers to $\mathrm{C}_{5} \mathrm{H}_{8}$

${ }^{c_{T h e}}$ hydrogens attached to the ring have been ignored 


\section{TABLE 29}

CHARGE DISTRIBUTION WITHIN THE MOLECULES OF THE TYPE

$$
{ }_{16}{ }^{\mathrm{H}}-\mathrm{O}_{8}-\mathrm{C}_{5}{ }_{\mathrm{C}_{6}}^{\mathrm{C}_{4}-\mathrm{C}_{7}} \mathrm{C}_{3} \mathrm{C}_{2}-\mathrm{C}_{1}{ }_{\mathrm{O}_{9}}^{\mathrm{O}_{15}}
$$

\begin{tabular}{|c|c|c|c|c|c|c|c|c|c|}
\hline Compound & Fig & ${ }^{\mathrm{H}} \mathrm{O}$ & $\mathrm{C}_{5}$ & 11 & $\mathrm{C}_{2}-\mathrm{C}_{1}$ & $11^{0} 15$ & $-C_{0-R}^{R}$ & & $\mathrm{R}$ \\
\hline Methyl Paraben & 25 & -0.172 & 0.086 & 0.192 & 0.270 & -0.293 & -0.156 & -0.208 & 0.210 \\
\hline Methyl Paraben & 27 & -0.186 & 0.081 & 0.184 & 0.166 & -0.296 & -0.157 & -0.213 & 0.220 \\
\hline Methyl Paraben & 28 & -0.186 & 0.077 & 0.201 & 0.192 & -0.299 & -0.146 & -0.207 & 0.220 \\
\hline Ethyl Paraben & 29 & -0.157 & 0.087 & 0.184 & 0.167 & -0.278 & -0.142 & -0.217 & 0.218 \\
\hline Ethyl Paraben & 30 & -0.180 & 0.080 & 0.180 & 0.178 & -0.274 & -0.131 & -0.210 & 0.207 \\
\hline Ethyl Paraben & 32 & -0.158 & 0.086 & 0.180 & 0.159 & -0.299 & -0.153 & -0.218 & 0.236 \\
\hline Ethyl Paraben & 33 & -0.180 & 0.083 & 0.198 & 0.184 & -0.291 & -0.154 & -0.206 & 0.196 \\
\hline Ethyl Paraben & 34 & -0.184 & 0.077 & 0.182 & 0.176 & -0.300 & -0.128 & -0.210 & 0.247 \\
\hline
\end{tabular}

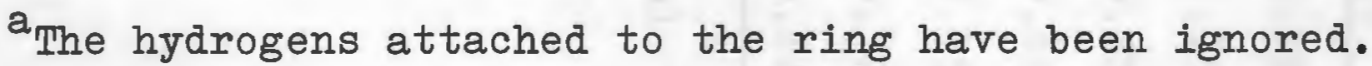


TABLE 30

TOTAL ENERGY WITHIN THE MOLECULES AND

THEIR HOMO AND LEMO ENERGIES

\begin{tabular}{|c|c|c|c|c|}
\hline Compound & Fig. & $\begin{array}{l}\text { Total } \\
\text { Energy } \\
\text { eV } \\
\end{array}$ & $\begin{array}{l}\text { HOMO }^{a} \\
\text { Energy } \\
\text { eV }\end{array}$ & $\begin{array}{c}\text { LEMO }^{b} \\
\text { Energy } \\
\text { eV } \\
\end{array}$ \\
\hline Aniline & 18 & -566 & -10.847 & -7.530 \\
\hline $\mathrm{p}-\mathrm{NH}_{2}$ Benzoic Acid & 19 & -847 & -10.154 & -8.924 \\
\hline Benzoic Acid & 20 & -748 & -10.453 & -8.796 \\
\hline Benzoic Acid & 21 & -748 & -10.416 & -7.925 \\
\hline Phenol & 22 & -579 & -11.152 & -7.653 \\
\hline p-OH Benzoic Acid & 23 & -862 & -10.394 & -8.610 \\
\hline p-OH Benzoic Acid & 24 & -861 & -10.449 & -7.801 \\
\hline
\end{tabular}

a Highest occupied molecular orbital

$\mathrm{b}_{\text {Lowest empty molecular orbital }}$ 
TABLE 31

TOTAL ENERGY WITHIN THE MOLECULES AND

THEIR HOMO AND IEMO ENERGIES

\begin{tabular}{|c|c|c|c|c|}
\hline Compound & Fig. & $\begin{array}{c}\text { Total } \\
\text { Energy } \\
\text { eV } \\
\end{array}$ & $\begin{array}{c}\text { HOMO }^{a} \\
\text { Energy } \\
\text { eV } \\
\end{array}$ & $\begin{array}{c}\text { IEMO } \\
\text { Energy } \\
\text { eV } \\
\end{array}$ \\
\hline Methyl Paraben & 25 & -953 & -10.203 & -8.598 \\
\hline Methyl Paraben & 27 & -947 & -10.117 & -7.658 \\
\hline Methyl Paraben & 28 & -951 & -10.158 & -7.597 \\
\hline Ethyl Paraben & 29 & -1045 & -8.642 & -8.590 \\
\hline Ethyl Paraben & 30 & -1042 & -8.680 & -7.722 \\
\hline Ethyl Paraben & 32 & -1049 & -10.146 & -8.521 \\
\hline Ethyl Paraben & 33 & -1044 & -10.157 & -7.694 \\
\hline Ethyl Paraben & 34 & -1045 & -10.125 & -7.636 \\
\hline
\end{tabular}

$a_{\text {Highest occupied molecular orbital }}$

$\mathrm{b}_{\text {Lowest empty molecular orbital }}$ 
TABLE 32

HOMO AND IEMO BASIS SET ORBITAL COEFFICIENTS FOR PARA-HYDROXYBENZOIC ACID

\begin{tabular}{|c|c|c|c|c|c|c|}
\hline \multicolumn{2}{|c|}{ Atom } & \multirow[b]{2}{*}{ Orbital } & \multicolumn{2}{|c|}{ HOMO } & \multicolumn{2}{|c|}{ IEMO } \\
\hline Number & Type & & Fig. 23 & Fig. 24 & Fig. 23 & Fig. 24 \\
\hline 1 & $C$ & $\begin{array}{l}2 p x \\
2 p y \\
2 p z\end{array}$ & $\begin{array}{c}-0.1 \\
- \\
-\end{array}$ & $\begin{array}{c}-0.11 \\
- \\
-\end{array}$ & $\begin{array}{c}- \\
-0.48\end{array}$ & -0.79 \\
\hline 2 & C & $\begin{array}{l}2 p x \\
2 p y \\
2 p z\end{array}$ & $\begin{array}{l}0.24 \\
- \\
-\end{array}$ & $\begin{array}{l}0.26 \\
- \\
-\end{array}$ & $\begin{array}{c}- \\
- \\
-0.31\end{array}$ & $0_{-}^{-}$ \\
\hline 3 & $\mathrm{C}$ & $\begin{array}{l}2 \mathrm{px} \\
2 \mathrm{py} \\
2 \mathrm{pz}\end{array}$ & $\begin{array}{l}- \\
- \\
-\end{array}$ & $\begin{array}{c}-0.1 \\
- \\
-\end{array}$ & $\begin{array}{c}- \\
0.34\end{array}$ & $\begin{array}{c}-0.1 \\
-0.1 \\
-\end{array}$ \\
\hline 4 & $\mathrm{C}$ & $\begin{array}{l}2 p x \\
2 p z\end{array}$ & $\begin{array}{l}- \\
-\end{array}$ & 0.1 & 0.1 & - \\
\hline 5 & $\mathrm{C}$ & $2 p z$ & - & - & -0.42 & - \\
\hline 6 & $C$ & $\begin{array}{l}2 \mathrm{px} \\
2 \mathrm{py}\end{array}$ & $\begin{array}{l}- \\
-\end{array}$ & 0.1 & 0.1 & $\begin{array}{l}- \\
-\end{array}$ \\
\hline 7 & $\mathrm{C}$ & $\begin{array}{l}2 p x \\
2 p y \\
2 p z\end{array}$ & $\begin{array}{l}- \\
- \\
-\end{array}$ & $\begin{array}{c}-0.1 \\
- \\
-\end{array}$ & $\begin{array}{c}- \\
0.36\end{array}$ & $\begin{array}{c}-0.1 \\
-0.1 \\
-\end{array}$ \\
\hline 8 & 0 & $\begin{array}{l}2 \mathrm{~s} \\
2 \mathrm{pz}\end{array}$ & $\begin{array}{l}- \\
-\end{array}$ & $\begin{array}{l}-0.1 \\
-0.21\end{array}$ & 0.26 & - \\
\hline 9 & 0 & 2 py & -0.22 & - & - & 0.43 \\
\hline 15 & 0 & $\begin{array}{l}2 \mathrm{px} \\
2 \mathrm{py} \\
2 \mathrm{pz}\end{array}$ & $\begin{array}{r}0.81 \\
-0.47 \\
-\end{array}$ & $\begin{array}{c}0.80 \\
- \\
-0.47\end{array}$ & $\begin{array}{c}- \\
\overline{0.61}\end{array}$ & $\begin{array}{c}- \\
0.75 \\
-\end{array}$ \\
\hline
\end{tabular}


TABIE 33

HOMO AND LEMO BASIS SET ORBITAL COEFFICIENTS

FOR METHYI-PARA-HYDROXYBENZOATE

\begin{tabular}{|c|c|c|c|c|c|c|c|c|}
\hline \multicolumn{2}{|c|}{ Atom } & \multirow[b]{2}{*}{ Orbital } & \multicolumn{3}{|c|}{ HOMO } & \multicolumn{3}{|c|}{ IEMO } \\
\hline Number & Type & & Fig.25 & Fig.27 & Fig.28 & Fig 25 & Fig 27 & Fig 28 \\
\hline 1 & C & $\begin{array}{l}2 p x \\
2 p y \\
2 p z\end{array}$ & $\begin{array}{l}- \\
-\end{array}$ & $\begin{array}{c}-0.1 \\
- \\
-\end{array}$ & $\begin{array}{c}0.11 \\
- \\
-\end{array}$ & $\begin{array}{c}\overline{-} \\
-0.45\end{array}$ & $\begin{array}{l}- \\
-\end{array}$ & 0.78 \\
\hline 2 & C & $\begin{array}{l}2 p x \\
2 p z\end{array}$ & -0.23 & 0.25 & $\begin{array}{c}-0.28 \\
-\end{array}$ & -0.35 & 0.66 & - \\
\hline 3 & C & $2 \mathrm{pz}$ & - & - & - & 0.34 & 0.25 & - \\
\hline 4 & C & $2 p z$ & - & - & - & 0.13 & -0.39 & - \\
\hline 5 & C & $2 p z$ & - & - & - & -0.45 & 0.65 & - \\
\hline 6 & C & $2 p z$ & - & - & - & 0.11 & -0.22 & - \\
\hline 7 & C & $2 p z$ & - & - & - & 0.36 & -0.44 & - \\
\hline 8 & 0 & $2 \mathrm{pz}$ & - & - & - & 0.14 & -0.16 & - \\
\hline 9 & 0 & $\begin{array}{l}2 \mathrm{px} \\
2 \mathrm{py} \\
2 \mathrm{pz}\end{array}$ & 0.13 & $\begin{array}{l}0.1 \\
-0.7 \\
-0.11\end{array}$ & $\begin{array}{c}-0.18 \\
0.20\end{array}$ & $\begin{array}{c}- \\
\overline{0.34}\end{array}$ & - & $\overline{-}$ \\
\hline 10 & C & $\begin{array}{l}2 p y \\
2 p z\end{array}$ & $\begin{array}{l}0.17 \\
-\end{array}$ & $\begin{array}{r}0.10 \\
-0.19\end{array}$ & $\overline{-}$ & - & - & $\begin{array}{l}0.46 \\
-\end{array}$ \\
\hline 15 & 0 & $\begin{array}{l}2 \mathrm{px} \\
2 \mathrm{py} \\
2 \mathrm{pz}\end{array}$ & $\begin{array}{c}-0.82 \\
0.46 \\
-\end{array}$ & $\begin{array}{r}0.80 \\
-0.45 \\
-\end{array}$ & $\begin{array}{c}-0.80 \\
0.45 \\
-\end{array}$ & $\begin{array}{c}- \\
\overline{-} \\
0.59\end{array}$ & $\overline{0.13}$ & -0.73 \\
\hline 16 & $\mathrm{H}$ & $2 s$ & - & - & - & -0.11 & 0.16 & - \\
\hline
\end{tabular}


TABLE 34

HOMO BASIS SET ORBITAI COEFFICIENTS

FOR ETHYI PARA-HYDROXYBENZOATE

\begin{tabular}{|c|c|c|c|c|c|c|c|}
\hline \multicolumn{2}{|c|}{ Atom } & \multirow[b]{2}{*}{ Orbital } & \multicolumn{5}{|c|}{ HOMO } \\
\hline Number & Type & & Fig.29 & Fig.30 & Fig 32 & Fig.33 & Fig.34 \\
\hline 1 & C & $2 \mathrm{px}$ & - & - & -0.1 & - & 0.12 \\
\hline 2 & C & $2 p x$ & - & -0.21 & 0.24 & -0.24 & -0.28 \\
\hline 9 & 0 & $\begin{array}{l}2 \mathrm{px} \\
2 \mathrm{py}\end{array}$ & $\begin{array}{c}0.13 \\
-\end{array}$ & $\begin{array}{c}-0.15 \\
-\end{array}$ & -0.21 & $\begin{array}{r}-0.15 \\
0.15\end{array}$ & $\begin{array}{r}-0.19 \\
0.21\end{array}$ \\
\hline 15 & 0 & $\begin{array}{l}2 \mathrm{~s} \\
2 \mathrm{px} \\
2 \mathrm{py}\end{array}$ & $\begin{array}{r}0.27 \\
0.84 \\
-0.27\end{array}$ & $\begin{array}{r}-0.27 \\
-0.83 \\
0.15\end{array}$ & $\begin{array}{r}- \\
0.81 \\
-0.48\end{array}$ & $\begin{array}{r}- \\
-0.78 \\
0.45\end{array}$ & $\begin{array}{r}-0.79 \\
0.44\end{array}$ \\
\hline 17 & C & $\begin{array}{l}2 \mathrm{px} \\
2 \mathrm{py} \\
2 \mathrm{pz}\end{array}$ & $\begin{array}{c}0.17 \\
-0.2 \\
-\end{array}$ & $\begin{array}{c}-0.17 \\
0.2 \\
-\end{array}$ & - & $\begin{array}{r}0.17 \\
-0.17 \\
0.15\end{array}$ & - \\
\hline 20 & $\mathrm{H}$ & $2 s$ & 0.32 & -0.32 & - & - & - \\
\hline 21 & $\mathrm{H}$ & $2 s$ & -0.29 & 0.29 & - & - & - \\
\hline 22 & $\mathrm{H}$ & $2 s$ & -0.29 & 0.28 & - & - & - \\
\hline
\end{tabular}




\section{TABIE 35}

IEMO BASIS SET ORBITAL COEFFICIENTS FOR ETHYI PARA-HYDROXYBENZOATE

\begin{tabular}{|c|c|c|c|c|c|c|c|}
\hline \multicolumn{2}{|c|}{ Atom } & \multirow[b]{2}{*}{ Orbital } & \multicolumn{5}{|c|}{ LEFMO } \\
\hline Number & Type & & Fig 29 & Fig.30 & Fig 32 & Fig. 33 & Fig.34 \\
\hline 1 & $C$ & $\begin{array}{l}2 p y \\
2 p z\end{array}$ & $0 . \overline{46}$ & 0.79 & $\overline{0.45}$ & -0.14 & 0.19 \\
\hline 2 & $c$ & $\begin{array}{l}2 \mathrm{py} \\
2 \mathrm{pz}\end{array}$ & 0.33 & $\begin{array}{c}-0.1 \\
-\end{array}$ & 0.35 & 0.65 & -0.66 \\
\hline 3 & C & $\begin{array}{l}2 \mathrm{px} \\
2 \mathrm{py} \\
2 \mathrm{pz}\end{array}$ & $\begin{array}{c}- \\
- \\
-0.33\end{array}$ & $\begin{array}{c}-0.1 \\
-0.1 \\
-\end{array}$ & $\begin{array}{c}- \\
- \\
-0.33\end{array}$ & $\begin{array}{c}\overline{-} \\
-0.26\end{array}$ & $\begin{array}{c}\overline{-} \\
0.21\end{array}$ \\
\hline 4 & C & $2 p z$ & -0.12 & - & -0.13 & -0.38 & 0.40 \\
\hline 5 & C & $2 \mathrm{pz}$ & 0.43 & - & 0.44 & 0.64 & -0.62 \\
\hline 6 & $\mathrm{C}$ & $2 p z$ & -0.1 & - & -0.1 & -0.22 & 0.17 \\
\hline 7 & C & $\begin{array}{l}2 p x \\
2 p y \\
2 p z\end{array}$ & $\begin{array}{c}- \\
- \\
-0.36\end{array}$ & $\begin{array}{l}0.1 \\
0.1 \\
-\end{array}$ & $\begin{array}{c}- \\
-0.37\end{array}$ & $\begin{array}{c}- \\
- \\
-0.43\end{array}$ & $\begin{array}{c}- \\
\overline{0.44}\end{array}$ \\
\hline 8 & 0 & $2 p z$ & -0.2 & - & -0.2 & -0.16 & 0.15 \\
\hline 9 & 0 & $\begin{array}{l}2 p y \\
2 p z\end{array}$ & -0.35 & $\begin{array}{c}-0.48 \\
-\end{array}$ & -0.33 & - & - \\
\hline 15 & 0 & $\begin{array}{l}2 p x \\
2 p y \\
2 p z\end{array}$ & $\begin{array}{c}- \\
- \\
-0.59\end{array}$ & -0.71 & $\begin{array}{c}- \\
-0.6\end{array}$ & $\begin{array}{l}0.12 \\
0.13 \\
-\end{array}$ & $\begin{array}{c}-0.12 \\
-0.18 \\
-\end{array}$ \\
\hline 16 & $\mathrm{H}$ & $2 s$ & - & - & - & 0.15 & -0.15 \\
\hline 17 & C & $\begin{array}{l}2 \mathrm{py} \\
2 \mathrm{pz}\end{array}$ & -0.2 & 0.15 & - & - & - \\
\hline
\end{tabular}


The effect of the carboxyl group (COOH) in aniline, para-Aminobenzoic Acid and Benzoic Acid:

Aniline (Figure 18)

HOMO: There is a node in the pi-type ring structure, the nitrogen is slightly lone pair (bonding to hydrogen); the energy is $-10.85 \mathrm{eV}$.

IEMO: This orbital is a non-bonding pi-type; the energy is $-7.530 \mathrm{eV}$. para-Aminobenzoic Acid (Planar) (Figure 19)

HOMO: The planar carboxyl group is bonding with lone pair character on the carbonyl oxygen; the energy is $-10.154 \mathrm{eV}$.

IEMO: The orbital is pi-type, partly bonding, partly non-bonding; the energy is -8.924 eV.

Thus, the introduction of a carboxyl group (planar to the ring) changes completely the HOMO and LEMO character and their energies, as well. Benzoic Acid (planar) (Figure 20)

HOMO: As in the case of para-Aminobenzoic acid, the planar carboxyl group is bonding with lone pair character on the carbonyl oxygen; the energy is $-10.453 \mathrm{eV}$.

LEMO: Similarly, this orbital is pi-type, partly bonding, partly non-bonding mainly on the 
carboxyl group; the energy is $-8.795 \mathrm{eV}$. The net result of the addition of the amino group to benzoic acid is that the amino group serves as an electron supplier to the carboxyl group; however, the effect on the HOMO or LEMO character or on their energies is not large, which explains the similarity of the LEMO's and HOMO's for benzoic acid and para-aminobenzoic acid.

The effect of spatial conformation as shown by Benzoic Acid planar (Figure 20) versus Benzoic Acid with the carboxyl group perpendicular to the ring (Figure 2l):

There is no significant charge redistribution.

\begin{tabular}{lrr} 
& \multicolumn{1}{c}{ HOMO } & LEMO \\
planar & $-10.453 \mathrm{eV}$ & $-8.795 \mathrm{eV}$ \\
perpendicular & $\frac{-10.416}{\mathrm{eV}}$ & $\frac{-7.925}{\mathrm{eV}}$ \\
differential & $0.037 \mathrm{eV}$ & $0.870 \mathrm{eV}$
\end{tabular}

These differentials show that raising the carboxyl group to a perpendicular position affects the HOMO, tending to make the carbonyl oxygen more lone pair like; while raising the carboxyl group to a perpendicular position affects the LEMO, converting it from a delocalized pi system to an antibonding orbital on the carboxyl group.

Therefore, we may conclude that there is a large 
perturbation of the LEMO from raising up the carboxyl group as reflected by a $0.87 \mathrm{eV}$ change in the energy of this orbital.

With regard to the conformational energies, the planar configuration is $3 \mathrm{Kcal} / \mathrm{mole}$ less stable than the perpendicular configuration. Since rotation barriers are sometimes poorly estimated in this theory this value should only be considered as an order of magnitude, and the main attention should be focused in change in orbital type.

The effect of the carboxyl group in phenol, parahydroxybenzoic acid and benzoic acid:

Phenol (Figure 22)

HOMO: There is a node in the pi-type ring structure; the oxygen is lone pair like; and the orbital energy is $-11.15 \mathrm{eV}$.

LEMO: There is pi-type orbital which is partially bonding; the energy is $-7.65 \mathrm{eV}$. para-Hydroxybenzoic Acid (planar) (Figure 23) HOMO: With the carboxyl in the plane there is bonding with a lone pair on the carbonyl oxygen; the energy is $-10.39 \mathrm{eV}$.

IEMO: This is a pi-type orbital which is partly bonding and partly non-bonding; the 


$$
\text { energy is }-8.60 \mathrm{eV} \text {. }
$$

Adding a carboxyl group planar to the ring has the effect of changing the character of the HOMO and its energy. The carboxyl group draws charge from the hydroxyl group.

Comparing benzoic acid (planar) (Figure 20) with para-hydroxybenzoic acid (Figure 23) the carboxyl group again draws charge from the hydroxy group. The HOMO and LEMO are similar to those of paraaminobenzoic acid.

As seen with para-aminobenzoic acid (Figure 19) the hydroxyl group, just as does the amino group, serves as an electron supplier to the carboxyl group in para-hydroxybenzoic acid.

The effect of spatial conformation as exhibited by parahydroxybenzoic acid planar (Figure 23) versus parahydroxybenzoic acid with the carboxyl group perpendicular to the ring (Figure 24):

There is no significant charge redistribution.

$\begin{array}{lcc} & \text { HOMO } & \text { LEMO } \\ \text { planar } & -10.394 \mathrm{eV} & -8.610 \mathrm{eV} \\ \text { perpendicular } & -10.449 \mathrm{eV} & -7.801 \mathrm{eV} \\ \text { differential } & 0.055 \mathrm{eV} & 0.809 \mathrm{eV}\end{array}$

HOMO: The orbital of the perpendicular conformer 
is virtually all lone pair on both of the carboxyl oxygens.

LEMO: Similarly, the perpendicular conformer is a non-bonding orbital centered on the carboxyl group.

Thus, raising the carboxyl group to a perpendicular position affects the IEMO, converting it from a delocalized pi system to a non-bonding orbital on the carboxyl group.

Conformational energies indicate that the planar compound is only $1.0 \mathrm{eV}$ more stable than is the perpendicular compound.

Therefore, we may conclude that a large perturbation of the IEMO results from raising up the carboxyl group, as is reflected by an $0.8 \mathrm{eV}$ change in the energy of this orbital.

Comparison of para-hydroxybenzoic acid (planar) (Figure 23) with para-aminobenzoic acid (planar) (Figure 19) There is similarity in both the HOMO and LEMO character of these compounds.

$\begin{array}{lcc} & \text { HOMO } & \text { LEMO } \\ \text { para-amino } & -10.154 \mathrm{eV} & -8.924 \mathrm{eV} \\ \text { para-hydroxy } & \frac{-10.394}{\mathrm{eV}} & \frac{-8.610}{\mathrm{eV}} \\ \text { differential } & 0.240 \mathrm{eV} & 0.314 \mathrm{eV}\end{array}$


The effect of the ester methyl group in para-hydroxybenzoic acid and methyl-para-hydroxybenzoate, both in the planar position:

Methyl-para-hydroxybenzoate (Figure 25) versus parahydroxybenzoic acid (Figure 23)

The HOMO and IEMO character is strikingly similar in both compounds, with the electron density distributed between the oxygen and the ester carbon rather than totally on the oxygen as in the acid in the HOMO; at the same time, a greater antibonding exists on the carboxyl group in the LEMO of the ester.

$\begin{array}{lrr} & \text { HOMO } & \text { LEMO } \\ \text { methyl-ester } & -10.203 \mathrm{eV} & -8.598 \mathrm{eV} \\ \text { parent acid } & \frac{-10.394 \mathrm{eV}}{-8.610} \mathrm{eV} \\ \text { differential } & 0.191 \mathrm{eV} & 0.012 \mathrm{eV}\end{array}$

The presence of the methyl group in the ester tends to reduce the power of the carboxyl group to withdraw electrons from the hydroxyl group; therefore, we find a greater charge residing in the hydroxyl group of the ester than of the acid. Effect of spatial configurational change as shown by the methyl ester:

Methyl-ester (planar) (Figure 25) versus the methyl ester with the carboxyl and ester group perpendicular 
(Figure 27)

Significant change in charge redistribution is seen in the carboxyl carbon, when the carboxyl is in a perpendicular position.

\begin{tabular}{lcc} 
& \multicolumn{1}{c}{ HOMO } & LEMO \\
planar & $-10.203 \mathrm{eV}$ & $-8.598 \mathrm{eV}$ \\
perpendicular & $\frac{-10.117}{\mathrm{eV}}$ & $\frac{-7.658}{0.94} \mathrm{eV}$ \\
differential & $0.086 \mathrm{eV}$ & 0.94
\end{tabular}

HOMO: In both the planar and perpendicular positions this orbital is virtually lone pair on the oxygens of the carboxyl group and the carbon of the ester methyl.

IFMO: In both the planar and perpendicular positions the non-bonding orbital is carried on the carboxyl group, while the perpendicular position also exhibits some pi-type bonding.

Thus, raising the ester group to the perpendicular position affects the HOMO, making it markedly more lone pair like on the ester portion of the molecule; and raising the ester group to the perpendicular position affects the IEMO, converting it from non-bonding on the carboxyl group to lone pair character on the carbonyl oxygen of the carboxyl group. 
Methyl ester in planar configuration (Figure 25) versus the carboxyl and ester group perpendicular with the methyl group under the ring (Figure 28). The only charge redistribution is to make the oxygen of the ester more lone pair like in character.

\begin{tabular}{lrr} 
& \multicolumn{1}{c}{ HOMO } & LEMO \\
planar & $-10.203 \mathrm{eV}$ & $-8.598 \mathrm{eV}$ \\
under ring & $\frac{-10.158 \mathrm{eV}}{-7.597} \mathrm{eV}$ \\
differential & $0.045 \mathrm{eV}$ & $1.001 \mathrm{eV}$
\end{tabular}

The planar configuration is $2 \mathrm{eV}$ more stable than the perpendicular under the ring configuration.

HOMO: Both conformers show lone pair orbitals on the carbonyl oxygen.

LEMO: Both conformers exhibit delocalized pitype orbitals which are mainly nonbonding.

Methyl ester perpendicular configuration (Figure 27) versus the perpendicular under the ring configuration (Figure 28).

HOMO

$\begin{array}{lrr}\text { perpendicular } & -10.117 \mathrm{eV} & -7.658 \mathrm{eV} \\ \text { under ring } & \frac{-10.158}{\mathrm{eV}} & \frac{-7.597}{0.06} \mathrm{eV} \\ \text { differential } & 0.041 \mathrm{eV} & 0.061 \mathrm{eV}\end{array}$


HOMO: Both conformers show lone pair orbitals on the carbonyl oxygen.

IEMO: Both conformers are primarily non-bonding pi-type orbitals.

The perpendicular-under-the-ring configuration

is $4 \mathrm{eV}$ more stable than the perpendicular form. The effect of the ethyl group as seen in Ethyl-parahydroxybenzoate with the methyl ester and the parent acid:

Ethyl-para-hydroxybenzoate in the hooked-planar position (Figure 29) versus the linear-and-planar configuration (Figure 32).

There is no significant charge redistribution.

\begin{tabular}{|c|c|c|c|}
\hline & $\underline{\mathrm{HOMO}}$ & & IEMO \\
\hline linear & -10.146 & $\mathrm{eV}$ & -8.521 \\
\hline hooked & -8.642 & eV & -8.590 \\
\hline ifferential & 1.504 & eV & 0.06 \\
\hline
\end{tabular}

The effect of the linear ester group is to make the HOMO mostly lone pair on the carbonyl oxygen, while the hooked configuration appears to have some hydrogen bonding capability with the methyl hydrogen of the ester group in the plane and the carbonyl oxygen.

The IEMO characteristics are similar in both 
cases with the pi orbitals partly bonding and partly non-bonding, with a significant shift of charge to the methyl carbon in the ester group.

The linear configuration is $4 \mathrm{eV}$ more stable than the hooked configuration. Ethyl-para-hydroxybenzoate linear and planar (Figure 32) versus the parent acid para-hydroxybenzoic acid in the planar configuration (Figure 23).

There is no significant charge redistribution.

$\begin{array}{lcc} & \text { HOMO } & \text { LEMO } \\ \text { ethyl ester } & -10.146 \mathrm{eV} & -8.521 \mathrm{eV} \\ \text { parent acid } & \frac{-10.394 \mathrm{eV}}{-8.610} \mathrm{eV} \\ \text { differential } & 0.248 \mathrm{eV} & 0.089 \mathrm{eV}\end{array}$

The HOMO and LEMO's are identical with bonding and Ione pair character on both oxygens in HOMO and pi-type partly bonding and partly non-bonding in the LEMO.

Methyl para-hydroxybenzoate in the planar configuration (Figure 25) versus the ethyl-para-hydroxybenzoate in the planar and linear conformation (Figure 32).

There is a greater negative charge residing in the $C_{1}-c_{2}$ bond in the methyl ester than there is in the same bond in the ethyl ester. 
HOMO

methyl ester $-10.203 \mathrm{eV}$

ethyl ester $\quad-10.146 \mathrm{eV}$

differential
LEMO

$-8.598 \mathrm{eV}$

$\underline{-8.521} \mathrm{eV}$

$0.077 \mathrm{eV}$

HOMO: This orbital still exhibits lone pair character on the carbonyl carbon, however, the charge shifts from the methyl carbon to the carboxyl carbon when changing from the methyl to ethyl ester.

IEMO: This orbital is virtually the same in both compounds with partly bonding and partly non-bonding character.

Ethyl ester in the planar and hooked position (Figure 29) versus the same ester with the carboxyl and ester group perpendicular to the ring (Figure 30).

There is no significant charge redistribution except that withdrawn from the para-hydroxy group.

$\begin{array}{lcc} & \text { HOMO } & \text { IEMO } \\ \text { planar } & -8.642 \mathrm{eV} & -8.590 \mathrm{eV} \\ \text { perpendicular } & \frac{-8.680}{\mathrm{eV}} & \frac{-7.722}{\mathrm{eV}} \\ \text { differential } & 0.038 \mathrm{eV} & 0.868 \mathrm{eV}\end{array}$

HOMO: The character of the orbitals is virtually the same with lone pair on the car- 
bonyl oxygen and possible hydrogen bonding.

IEMO: This orbital is partly bonding and partly non-bonding in the planar configuration and totally non-bonding in the perpendicular position.

The planar molecule is $3 \mathrm{eV}$ more stable than the perpendicular conformation.

Ethyl ester in the planar and linear position (Figure 32) versus this ester in the perpendicular position (Figure 33).

The only charge redistribution seen is the amount of charge withdrawn from the para-hydroxy group onto the ester moiety.

$\begin{array}{lrr} & \text { HOMO } & \text { IEMO } \\ \text { planar } & -10.146 \mathrm{eV} & -8.521 \mathrm{eV} \\ \text { perpendicular } & \frac{-10.157}{\mathrm{eV}} & \frac{-7.694 \mathrm{eV}}{0.827} \mathrm{eV}\end{array}$

HOMO: There is lone pair characteristics which exist on both oxygens of the carboxyl group with significant charge on the methylene carbon of the ester in the perpendicular position, while the HOMO of the planar compound is similar in nature to that of the parent acid. 
LEMO: There is lone pair character present in the perpendicular position, while nonbonding in the carboxyl group is evident in the planar molecule.

The planar configuration is $5 \mathrm{eV}$ more stable than the perpendicular conformation. Ethyl ester in the planar and linear conformation (Figure 32) versus the perpendicular and under the ring and down conformation of the same molecule (Figure 34).

The only charge redistribution is the greater amount of charge withdrawn from the para-hydroxy group onto the oxygens in the under-the-ring-and -down position.

\begin{tabular}{lcc} 
& \multicolumn{1}{c}{ HEMO } & \multicolumn{1}{l}{ IEMO } \\
planar & $-10.146 \mathrm{eV}$ & $-7.694 \mathrm{eV}$ \\
under ring & $\frac{-10.125}{0.02}$ & $\frac{-7.636}{\mathrm{eV}}$ \\
differential & $0.021 \mathrm{eV}$ & $0.058 \mathrm{eV}$
\end{tabular}

HOMO: The under-the-ring-and-down position exhibits lone pair character on both oxygens of the carboxyl group while the perpendicular-and-linear position has lone pair character on the carbonyl oxygen only.

IJMO: The planar-and-linear conformation is 
partly bonding and partly non-bonding with antibonding on the carboxyl group, while the perpendicular-and-under-thering-and-down conformation shows the same character as does the aforementioned position, except that the lone pair character is exhibited on the carbonyl oxygen only.

The planar-and-linear conformation is $4 \mathrm{eV}$ more stable than the perpendicular-and-under-the-ring -and-down position.

The analysis above can be summarized by discussing the compounds as they relate to each other by a common physical parameter.

\section{Energies}

The most stable conformations are exhibited in those compounds which have a planar-and-linear configuration; while the next most stable conformation in the ester series is the perpendicular dangling chain (under-the ring-and-down).

A change in energy is seen in the Total Energy and the LEMO of the compounds but not in their HOMO's. This occurs in the methyl ester, parahydroxybenzoic acid and benzoic acid itself. 
However, in benzoic acid the total energy does not change to any great extent.

In the ethyl ester series, it is important to keep all but one variable constant as comparisons are made.

a) Comparing the two hooked conformers, the planar case is similar to those of the methyl ester and the parent acid.

b) In the two linear conformers, the planar molecule gains in stability, but interestingly the non-planar geometry has a more stable LEMO.

c) In the two planar cases, hooked and linear, there is a decrease in stabilization from the linear to the hooked configuration. This is also reflected in a destabilization of the HOMO and a stabilization in the IEMO.

d) In the perpendicular-and-under-the-ringand-down configuration, taking away all resonance or hydrogen bonding stabilization, the molecule is most comparable to the most stable conformation (planar-andlinear); however, the whole ester substituent cannot participate in resonance 
stabilization as is possible in the planar molecule.

A conclusion which can be drawn, then, is that the molecule will tend to resonance stabilize if given a chance. This is evident throughout the whole series and is primarily reflected in the decreased energy of the IEMO.

It can be seen that the amino and hydroxyl groups in the para-position act in the same way and are therefore comparable.

There is no significant evidence that intramolecular hydrogen bonding exists or plays an important role in molecular configurational stabilization.

2. Charge Distribution

It is evident that, when a para-substituent is not present, there is no tendency for resonance stabilization and therefore there is no real charge redistribution. The resonance stabilization as seen in the energies is not reflected in the charge trends on the carbonyl oxygen nor on the ester group as a whole. There is only one case in which this can be seen: that of the carboxyl group of para-hydroxybenzoic acid. Even in this case the amount which occurs is 
relatively small as compared to that which left the para-hydroxy group.

There does not seem to be a real depository for the charge removed from the para-hydroxy group, and it appears to be evenly delocalized over the entire molecule.

3. IEMO Character planar and non-planar

a) para-Hydroxybenzoic acid planar and perpendicular

HOMO: The orbital is non-bonding and lone pair on the carbonyl oxygen in both cases.

IEMO: Planar - The orbital is a delocalized pi-type, mainly non-bonding in character. Non-planar - The charge is localized on the carboxyl group, and the orbital is of a non-bonding carbonyl pi-type.

b) Methyl ester

HOMO: A lone pair orbital on the carbonyl oxygen is exhibited by the planar and perpendicular conformers.

IEMO: Planar - The orbital is of a delocalized pi-type, mainly non- 
bonding in character; it is identical to the acid and is available for a donor molecule. Perpendicular - The orbital is primarily of a non-bonding pi-type when the methyl group is in the hooked position.

Perpendicular-and-under-the-ring The orbital is similar to that of the acid in this configuration.

c) Ethyl ester

HOMO: Planar - The orbital is lone pair on the carbonyl oxygen, and there appears to be hydrogen bonding capabilities when the ester moiety is in the hooked position. Non-planar - The orbital is very similar to that of the methyl ester and of the parent acid. Perpendicular-and-under-the-ringand-down - This orbital is similar to that of the methyl ester in a similar conformation.

LEMO: Planar - The orbital is a delocalized pi-type, mainly non-bonding in character; it is identical to 
the parent acid.

Perpendicular, linear, and underthe-ring-and-down conformers These orbitals are very similar to those for the parent acid. Perpendicular, hooked conformer The orbital is very similar to that of the parent acid itself in the perpendicular position.

The analysis given above leads to the hypothesis that the biological activity of the parabens, esters of para-hydroxybenzoic acid, is related to the ability of these molecules and/or an appropriate receptor to be mutually perturbed; the drug molecule may be in a non-preferred but equally acceptable conformation, which would provide for its activity. Since X-ray crystallographic experience has shown that esters tend to pack themselves in crystals as planar and linear moieties, MO theory should substantiate this fact; and indeed this is the case. However, keeping in mind the relationship of conformaltion with MO theory, X-ray crystallography, solutions and biological activity, we should be able to glean some evidence with may lead to the mechanism of action of these preservatives. Therefore, we should be able to assume that the esters in a biological milieu are present in their most stable 
form, namely that of the planar, linear form. Moreover, a biologically active substance which exerts a specific action for its class usually contains a moiety or moieties common to all members of the drug class, which is responsible for its action. Hence, if one were to inspect the structure of the parabens, it would soon become apparent that if the stable forms were perturbed into some common configuration, then they would be as depicted by Figure 25 for the methyl ester and Figure 32 for the ethyl ester. There is a great similarity in their HOMO and LEMO energies as well. The planar moieties, which are most stable, have an EIEMO of approximately 8.7, while the non-planar moieties have an ELEMO of approximately 7.6. Thus, if we examine those compounds with an EHOMO of approximately 10.2 and an ELEMO of 8.7, the group would include the planar configurations of para-aminobenzoic acid, benzoic acid, parahydroxybenzoic acid, and its methyl and ethyl ester. Comparing compounds having an EHOMO of 10.2 and an ELEMO of 7.6 , this group would include phenol and the non-planar configurations of the ethyl ester. Therefore, it can be reasoned that these compounds may have several mechanisms of action. One of these could include the planar compounds, in that they may act in competition with para-aminobenzoic acid in the formation of folic acid. Another may include the non-planar 
moieties in which the alkyl group of the ester fragment is directed downwards from the ring (the next most stable conformer) in that these compounds may react with a receptor site on the bacterial cell wall or membrane. Since the conformations of the non-planar. methyl and ethyl esters above differ only by the length of the ester chain, then any further lengthening of this ester chain may only serve to increase the lipid solubility of the compound. The solubility studies presented earlier have substantiated this fact.

Comparing the following conformations of the

ethyl paraben

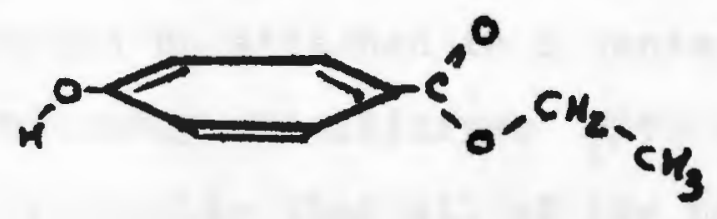

Linear and

perpendicular

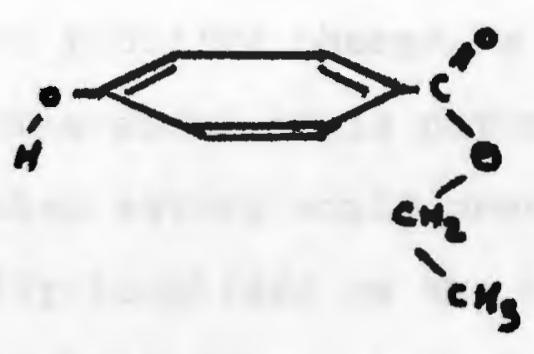

Perpendicular and under the ring and down

we see that lengthening the chain of the linear and perpendicular ester moiety may increase the requirement of the receptor site, while the other conformation does not require any modification of a receptor site. If this is a reasonable hypothesis, we should be able to apply chemical reasoning for a receptor site for these configurations at the membrane surface. The receptor site 
could consist of a lipid area or areas in which the alkyl groups of varying lengths for the ester chain are solubilized, sites of positive or negative charge resulting from ionic or ion-dipole interactions with protein functional groups, and relatively uncharged areas composed of hydrocarbon fragments. Such a general model utilizing these features is given in Figure 35. An application of our reasoning leads us to suggest an interaction of these intact esters, such that their alkyl ester groups would be buried in the lipid pool, the phenyl group would be in the vicinity of a relatively nonreactive hydrocarbon fragment, and the hydroxy fragment would be attached to a center of positive charge, a not unlikely possibility. With such a model it is not unreasonable that all of the paraben esters would present a $7.6 \mathrm{eV}$ non-bonding Mo primarily localized on the carboxyl group which could interact by a charge transfer or an acid-base interaction with molecules, and which could thereby prevent normal cell membrane transport. Notably, all parabens could operate in a similar fashion at the molecular level, and the increase in effectiveness as a series is ascended would be directly proportional to the solubility of the compound; therefore, solubility becomes a primary factor in determining the amount of drug reaching the receptor site, superseding the factor of chemical reaction whose char- 
acteristics change with alkyl chain lengthening.

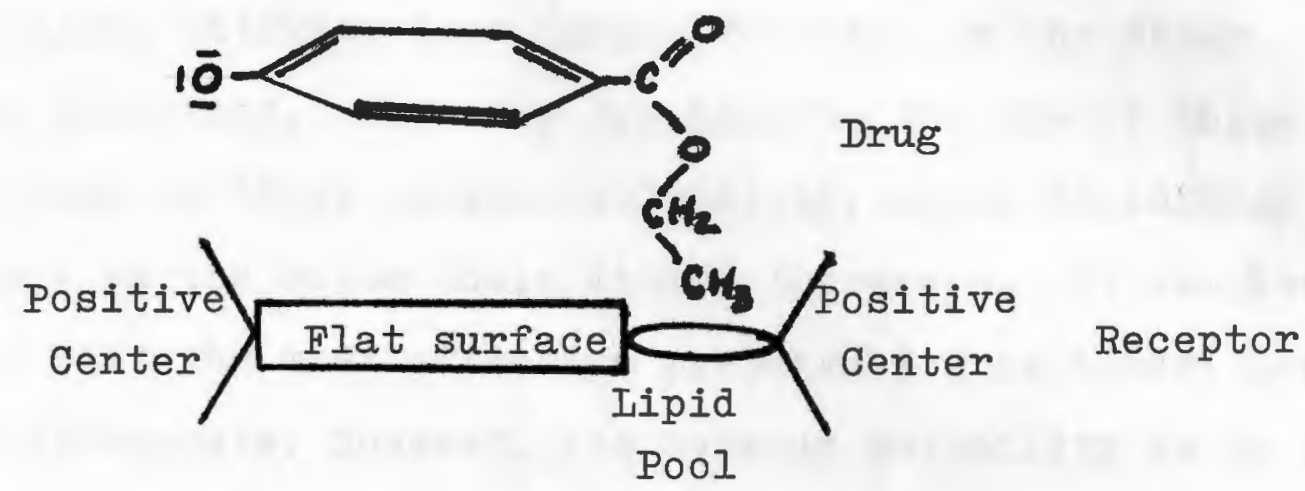

Figure 35.--Theoretical receptor for the postulated active form of the paraben preservatives.

Such a mechanism easily rationalizes the observed trend in activity from

Phenol (Benzoic Acid (p-Hydroxybenzoic Acid (Ester; and in the series from

Methyl (Ethyl Propyl (Butyl.

Para-hydroxybenzoic acid would not be as lipid-soluble as the methyl ester and may not readily be at such a site. Phenol and benzoic acid, while they may engage in the same mechanism of action do not have the same functional groups to act in precisely the same manner as the later members of the series.

The activity of these compounds should increase as the lipid portion of the molecule, the ester chain, becomes larger, since it may act as an anchor to retain the molecule at the site for a longer period of time. 
If sufficient sites are filled, function may be interrupted, causing the observed biological effect. In fact, biological activity does indeed increase as the ester chain increases. The only drawback to the use of these compounds is their aqueous solubility, which diminishes rapidly as the ester chain length increases. It has been found that the most effective preservative is benzyl parahydroxybenzoate; however, its aqueous solubility is so low that effective concentrations cannot be obtained. Oleagenous solutions of benzyl para-hydroxybenzoate have been used effectively as a scabicide against lice and mites. Pharmaceutical systems, however, are for the most part aqueous systems and, therefore, the problem of solubility in water is extremely important.

Enzyme systems within a biological environment are capable of splitting esters by the use of esterases, such that the parent acid as well as the ester form may be present. Since the parent acid is similar in character to the para-aminobenzoic acid, it is also safe to presume that either and/or both compounds would compete for reaction systems in which one or the other is involved. Therefore, an additional mechanism to be assumed is inhibition of folic acid formation. Since biological systems are capable of converting compounds from inactive forms to biologically active ones, then it is possible 
to justify the conversion of para-hydroxybenzoic acid to the biologically active para-aminobenzoic acid. Thus, when Boesken and Waterman (7) demonstrated that molds were capable of utilizing para-hydroxybenzoic acid, they may have in fact been witnessing a secondary shunt within that system to produce the biological material needed. This possibility was also shown by Davis (8) when he reported that para-hydroxybenzoic acid was a bacterial "vitamin". Since time is a factor for the development of a secondary shunt, however, we should discount this factor as the primary mechanism for preservative action.

Recently there has emerged an interest in the union of MO-calculated indices with thermodynamic properties, e.g., parameters reflecting partitioning between the lipid and aqueous phases in the body. Hansch (9) pioneered the technique, and the union of the two methods has been reported by several investigators (10). This approach can be fruitful only if the deficiencies in MO methods are minimized and if the methods are wisely employed. The greatest danger lies in the oversimplification of the relationship between the two methods.

Molecular orbital theory can advance our understanding of the chemical events associated with molecules of biological significance; however, prudence 
should be observed in the application of this research technique. One must bear in mind that a biological process does not occur in a conservative state, nor does it occur in a reaction vessel; rather, it occurs in a complex medium which can influence and alter events to a degree beyond the reach of presently available predictive methods.

The greatest danger in the use of Mo theory to study drug phenomena is the temptation to carry a correlation too far into the realm of mechanism prediction or receptor characterization. Therefore, limits must be placed on conclusions from MO studies so that the relationship between the method and the predicted result is always apparent. Nevertheless, the future opportunities for MO theory as a research technique are such that many scientists should be encouraged to familiarize themselves with this method. 


\section{CONCLUSION}

The solubility of a related series of solutes namely benzoic acid, para-hydroxybenzoic acid and the methyl, ethyl, propyl and butyl esters of para-hydroxybenzoic acid, in a series of n-alkanols over a small temperature range, illustrated the usual polarity effects. A twin peak solubility array was evidenced for the above compounds in ethanol or propanol and hexanol.

Thermodynamic elements for the solution process in the above solutes were determined and tabulated, utilizing temperature as an experimental parameter. Both the direction and the magnitude of these elements were in keeping with expectations, in fact, the ideal values were seen to be a balance between two factors, entropy and enthalpy, which either oppose or support each other relative to their own magnitudes. The twin peak array observed in the solubility spectrum is seen throughout the thermodynamic picture of the investigational compounds with the following generalizations to be made about the solution process: (1) Any solute in solution whose actual free energy approaches the ideal free energy will approach the ideal state; (2) For any particular solution there may be many combinations of values for the heat of solution and the entropy of solution, depending upon the solvent employed, in which the actual free energy will approximate the ideal free energy. Therefore, it can be said that a solute which is soluble in a few or many solvents may approach ideal solubility in one or several of these solvents and thus exhibit one or several maxima or peaks in its solu- 
bility scan. The dielectric requirement of one peak is now felt to be related to the thermodynamics of the total system; hence, a multi-peak system should signify that ideal solubility is being approximated in that particular solvent-solute system.

Partitioning data were correlated with past work, notably that of Hansch. The results indicate that partition coefficients are a useful tool and they should only be used with other substantial experimental techniques before definitive conclusions may be drawn.

Molecular parameters were determined by computerized Iterated Extended Huckel Theory Molecular Orbital method. The results were interpreted on the basis of charge distributions, Highest Occupied and Lowest Empty Molecular Orbital energies, and conformational energies of the molecules and configurations studied. This analysis can be summarized by a common physical parameter as it relates to the compounds studied.

\section{Energies}

The most stable conformations are exhibited in those compounds which have a planar-and-linear configuration; while the next most stable conformation in the ester series is the perpendicular dangling chain (under-the-ring-and-down). A change in the energy is seen in the Total Energy and the IEMO of the compounds but not in their HOMO's. A conclusion which can be drawn is that the molecules will tend to resonance stabilize if given a chance. This is 
evident throughout the whole series and is primarily reflected in the decreased energy of the IEMO. It was seen that the amino and hydroxyl groups in the para-position act as electron donors and are therefore comparable. There is no significant evidence that intramolecular hydrogen bonding exists or plays an important role in molecular configurational stabilization. Charge Distribution

When a para-substituent is not present there is no tendency for resonance stabilization and therefore there is no real charge redistribution. The resonance stabilization as seen in the energies is not reflected in the charge trends on the carbonyl oxygen nor on the ester group as a whole. There does not seem to be a real depository for the charge removed from the para-hydroxy group, and it appears to be evenly delocalized over the entire molecule. HOMO and LEMO Character planar and non-planar HOMO: In all cases the orbital is lone pair in character on the carbonyl oxygen. LEMO: Planar compounds- the orbital is a delocalized pi-type, mainly non-bonding in character. Non-planar- the charge is localized on the carboxyl group, and the orbital is of a non-bonding carbonyl pi-type.

This analysis leads to the hypothesis of a receptor site for the proposed biologically active form (Perpendicular-and-under- 
the-ring-and-down conformation). The receptor site should consist of a lipid area or areas in which the alkyl groups of varying lengths for the ester chain are solubilized, sites of positive or negative charge resulting from ionic or ion-dipole interactions with protein functional groups, and relatively uncharged areas composed of hydrocarbon fragments. Evidence is presented for the substantiation of this hypothesis as well as an alternative mechanism which would be time dependent. 
REFERENCES 
REFERENCES FOR PARABENS

1. Bohn, E., Parfumerie Moderne, 27, 373-83, 487 (1933)

2. Gershenfeld, I. and Perlstein, D., Am. J. Pharm., 111, 277 (1939)

3. Sabalitscka, Th., Z. f. Ernahrung, 2(7), 202 (1932)

4. Suess, A., The American Perfumer, 55, (6/1936)

5. Sabalitscka, Th., Pharm. Monatshefte, 5, 235 (1924); Chemiker Ztg., 48, 702 (1924); Apothekar-Ztg., 39, 1160 (1924) ; Pharm. Ztg., 69, 1018 (1924); Zeitschr. f. angew. Chemie, 37, 811 (1924)

6. Sabalitscka, Th., Arbeit a.d. pharmaz. Institut d. Universitat Berlin XIII: 79 (1929)

7. Sabalitscka, Th., The Pharm. Monatshefte, 9, 129-30 (1928); Apotheker-Ztg.; 73, 670 (1928); Zentralbl. f. Pharmazie, 24, 142 $(1928)$; Suddeutsche Apotheker Ztg., 9, 266 (1928)

8. Sabalitscka, Th., Zeitschr. f. angew. Chemie, 4l, 460,621 (1928); Chem.-Ztg., 52, 460 (1928); Anzeiger d. chem. Industrie, 43, T5 (1928); Pharm. Monatshefte, $\underline{9}, 136$ (1928); Pharm. Acta Helvetiae, 3, 103 (1928); Zentralbal. f. Pharmazie, 24, 285

9. Sabalitscka, Th., Archiv. d. Pharm., 267, 272-90

(1929); Mitt. d. Deutsch. Pharm. Ges., 6, 134 (1929); Zentralbal. f. Pharmazie, 25, I09 (1929); Pharm. ztg., 74, 337 (1929); Apoth.-Ztg., 44, 304 (1929); Schíeiz'. ApothrZtg.; 67, 154 (1929); Pharm. Monatshefte, 10 ( 73 (1929); suddeutsche Apoth.2tg., 10, 142 (1929)

10. Sabalitscka, Th., Arch. Pharm., 269; 228-46 (1931)

11. Sabalitscka, Th., The Manufacturing Chemist, 2, 5-7 (1931) 
12. Sabalitscka, Th., Arzt.-Apothker-Krankenhaus, 3, 141 (1933); Pharm.-Ztg., 78, 1265 (1933)

13. Sabalitscka, Th., Pharm. Ztg., 81, 1301 (1936); Pharm. Monatshefte, 17, 237 (1936)

14. Sabalitscka, Th., Ole, Fette, Wachse, Seifen, Kosmetik, No. $3 / 4,4(1938) ;$ Deutsche Lebensmittelrundschau, 1938, 55

15. Sabalitscka, Th. and Dietrich, R. K., Desinfection, 11, 67-71 (1929)

16. Sabalitscka, Th. and Schweitzer, F.I., Arch. Pharm., 267, 675-85 (1929)

17. Sabalitscka, Th. and Jeglinski, H., Arch. Pharm., 269, 228 (1931)

18. Sabalitscka, Th. and Tietz, H., Arch. Pharm., 269, 545 (1931)

19. Sabalitscka, Th. and Tiedge, K.H., Arch. Pharm., Part 3; 383 (1934)

20. Sabalitscka, Th., Dietrich, K.R., and Bohn, E., Pharm. Ztg, 71, 834-6 (1926)

21. Sabalitscka, Th., Pharm. Presse Wissprakt Heft, 1931, 173-5; Zentralbl. f. Pharmazie, 27, 174 (I931)

22. Sabalitscka, Th., Mitt. Ges. Vorratsschutz, 8, 6-10 (1932); Rev. Applied Mycol., 11, 466 (19332)

23. Neidig, G.P. and Burrell, H., Drug and Cosmetic Industry, 54, 408 (1944)

24. Aalto, T.R., Firman, M.C. and Rigler, N.E., J.Am. Pharm. Assoc., Sci. Ed., 42, 449 (1953)

25. MacDonald, E.M., J. Am. Pharm. Assoc., Pract. Pharm. Ed., 3 , $181(1942)$

26. Kossodo, M., Report to the Ministry of Public Health and Social Aid (Iima, Peru), 1949

27. Sabalitscka, Th., Oesterr. Apoth. Ztg., 3, 458 (1949)

28. Sokol, H., Drug Standards, 20, 89 (1952) 
29. Boeseken, J. and Waterman, H.J., Verslag Kon. Aked. Wtenschap, Amsterdam, 20, 552 (1911)

30. Davis, B.D., Nature, 116, 1120 (1950)

31. Hildebrand, J.H. and Scott, R.L., The Solubility of Non-Electrolytes, Rheinhold Publishing Co., New York, 1950

32. Mauger, J.W., Ph.D. Thesis, University of Rhode Island, 1971

33. Chertkoff, M.J., and Martin, A.N., "The Solubility of Benzoic Acid in Mixed Solvents," J. Am. Pharm. Assoc., Sci. Ed., 49, 441 (1960)

34. Restaino, F.A. and Martin, A.N., "Solubility of Benzoic Acid and Related Compounds in a Series of n-Alkanols," J. Pharm. Sci., 53, 636 (1964)

35. Paruta, A.N. and Sheth, B.B., "Solubility of Parabens in Syrup Vehicle," J. Pharm. Sci., 55, 1208 (1966)

36. Paruta, A.N., "Solubility of the Parabens in DioxaneWater Mixtures," J. Pharm. Sci., 58, 204 (1969)

37. Paruta, A.N., "Solubility of the Parabens in FthanolWater Mixtures," J. Pharm. Sci., 58, 364 (1969)

38. Paruta, A.N., "Solubility of Parabens in Alcohols," J. Pharm. Sci., 58, 216 (1969) 
REFERENCES FOR SOLUBILITY AND PARTITION

COEFFICIENT EXPERIMENTAL

1. Mauger, J., Ph. D Thesis, University of Rhode Island 1971

2. Sherrick, P., Dawe, G., Karr, R. and Ewan, E., Manuel of Chemical Oscillometry, E.H. Sargent and Co., Chicago, Illinois

3. Maryott, A. and Smith, Table of Dielectric Constants of Pure Liquids, National Bureau of Standards Circular 514, 1951

4. West, P., Senise, P. and Burkhalter, T.S., Anal. Chem., 24, 1250 (1952)

5. Handbook of Chemistry and Physics, 49th Ed., The Chemical Rubber Co., 1968

6. Restino, F.A. and Martin, A.N., J. Pharm. Sci., 53, 636 (1964)

7. Martin, A., Physical Pharmacy, Lea and Febiger, Philadelphia, Pa. 1960

8. Doluisio, J. and Swintosky, J., J. Pharm. Sci., 53, 597 (1964) 


\section{REFERENCES FOR RESULTS AND DISCUSSION}

OF PARTITION COEFFICIENTS

1. Meyer, K.H. and Hemmi, I., Biochem. Z., 277, 39 (1935)

2. Belleau, B. and Lacasse, G., J. Med. Chem., I, 768 (1964)

3. Belleau, B., ibid., I, 776 (1964)

4. Belleau, B., Advance Drug Res., 2, 89 (1965)

5. Hansch, C., Maloney, P.P., Fujita, T. and Muir, R.M., Nature, 178 ( 1962 )

6. Hansch, C. and Fujita, T., J.A.C.S., 86, 1616 (1964)

7. Hansch, C., Ann. Rept. Med. Chem., 1966, 347

8. Hansch, C., ibid., 1967, 348

9. Hansch, C., Farmaco, Sci. Ed., 23, 293 (1968)

10. Hansch, C., Proc. Int. Pharmacol. Meet, 3rd, 1967, 141

11. Hansch, C., Steward, A.R. and Iwasa, I., J. Med. Chem., 8, 868 (1965)

12. Hansch, C. and Lien, E.J., Biochem. Pharmacol., 17, 709 (1968)

13. Hansch, C., J.Med. Chem., II, 920 (1968)

14. Hansch, C., Muir, R.M., Fujita, T., Maloney, P.P., Geiger, F. and Streich, M., J.A.C.S., 85, 2817 (1963)

15. Hansch, C., Kiehs, K. and Lawrence, G.I., ibid, 87, 5770 (1965) 
D

REFERENCES FOR RESULTS AND DISCUSSION OF SOLUBIIITY AND THERMODYNAMIC CONSIDERATIONS

1. Paruta, A.N., "Solubility of Parabens in Alcohols," J. Pharm. Sci., 58216 (1969)

2. Hildebrand, J.H. and Scott, R.I., The Solubility of Non-Electrolytes, Rheinhold Publishing Co., New York 1950

3. Daniels, F. and Alberty, R.A., Physical Chemistry, 3rd ed., John Wiley and Sons, Inc., New York 1966

4. Castallan, G.W., Physical Chemistry, 2nd ed., Addison-Wesley Publishing Co., Reading, Mass. I971

5. Moore, W.J., Physical Chemistry, 3rd ed., PrenticeHall, Inc., Englewood Cliffs, N.J. 1962 
REFERENCES FOR MOLECULAR ORBITAL CONSIDERATIONS INTRODUCTION

I. Kier, I.B., J. Med. Chem., II, 441 (1968)

2. Kier, I.B., Mol. Pharmacol., 4, 20 (1968)

3. Kier, I.B., J. Pharm. Sci., 59, 112 (1970)

4. Pullman, A. and Pullman, B., Nature, 196, 228 (1963)

5. Pullman, A. and Pullman, B., ibid., 199, 4892 (1965)

6. Dewar, J.S., The Molecular Orbital Theory of Organic Chemistry, McGraw-Hill, Inc., New York 1969

7. Streitweiser, A., Jr., Molecular Orbital Theory for Organic Chemists, John Wiley \& Sons, Inc., New York 1961

8. Roberts, J.D., Notes on Molecular Orbital Calculations, W.A. Benjamin, Inc., New York 1962 9. Purcell, W.P. and Sundstrem, K., J. Med. Chem., 12,

10. Martin, A.N. and Schnaare, R.S., J. Pharm. Sci., 54, 1707 (1965) 
REFERENCES FOR STRUCTURE ACTIVITY RELATIONSHIPS

OF ANTIMICROBIAL AGENTS

1. Green, D.E. and Goldberger, R.F., Molecular Insights Into the Living Process, Academic Press, New York, 1967

2. Carpenter, P.I., Microbiology, 2nd Ed., W.B. Saunders Co., Phila., 1968

3. Goodman, L.S. and Gilman, A., The Pharmacological Basis of Therapeutics, 3rd Ed., The Macmillan Co., New York, 1965

4. Reddish, G.F., ed., Antiseptics, Disinfectants, Fungicides, and Chemical and Physical Sterilization, Lea and Febiger, 1954

5. Wedderburn, D.L., "Preservation of Emulsions Against Microbial Attack," Advances in Pharmaceutical Sciences, Academic Press, Iondon, 1964, pp. 195270 .

6. Ariens, E.J., ed., Molecular Pharmacology, Vol. I, The Mode of Action of Biologically Active Compounds, Academic Press, New York, 1964 7. Gale, E.F. and Taylor, E.S., J.Gen. Microbiol., I,

8. Maurice, P., Proc. Soc. Appl. Bact., 15, 144 (1952)

9. Judis, J., J. Pharm. Sci,, 51, 261 (1962)

10. Von Schelhorn, M., Food Technol., Champaign, I, 97 (1953)

11. Wyss, 0., Advances in Food Research, Vol. I, Academic Press Inc., New York (1948) 373 pp. 
G

REFERENCES FOR MOLECULAR ORBITAL

EXPERIMENTAL SECTION

1. Hoffman, R. and Lipscomb, W.N., J. Chem. Phys., 36, $2179 ; 3489$ (1962)

2. Quantum Chemistry Program Exchange, Chemistry Department, Indiana University, No. 20.

3. Sim, G.A., Robertson, J.M. and Goodwin, T.H., Acta Cryst., 8, 157 (1955)

4. Hulme, R. and Scruton, J.C., J. Chem. Soc., A, 2448 (1967)

5. Giller-Panraud, H., Bull. Soc. Chim. Fr., 1988 (1967)

6. Scheringer, C., Z. Kristallogr., 119, 273 (1963)

7. Manojlovic, I., Acta Cryst. (B), 24, 326 (1968)

8. Alleaume, M., Salas-Cimingo, G. and Decap, J., C.R.

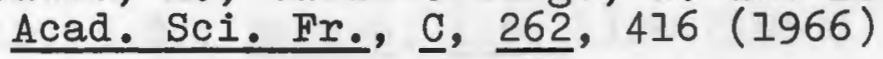

9. Lai, T.F. and Marsh, R.E., Acta Cryst., 22, 885 (1967)

10. Cusacks, I.C. and Linn, J.R., Jr., J. Chem. Phys., 46, 2919 (1967)

11. Basch, I., Viste, A. and Gray, H., Theoret. Chim. Acta (Berlin), $\underline{3}, 458$ (1965)

12. Basch, I., Viste, A. and Gray, H., J. Chem. Phys., 44, 10 (1966) 
$\mathrm{H}$

REFERENCES FOR RESULTS AND DISCUSSION FOR MOLECULAR ORBITAL CALCULATIONS AND CONSIDERATIONS OF MECHANISMS OF ACTION OF THE PARABENS

1. Kier, I.B., Molecular Orbital Theory in Drug Research, Academic Press, New York, 1971

2. Mulliken, R.S., J.A.C.S., 74, 811 (1952)

3. Hoffman, R., J. Chem. Phys., 39, 1397 (1963)

4. Hoffman, R. and Iipscomb, W.N., J. Chem. Phys., 36, 3489 (1962); 37, 2872 (1962); 36,2179 (1962)

5. Pope, J.A., Santry, D.P. and Segal, G.A., J. Chem. Phys., 43, 5129 (1965)

6. Quantum Chemistry Program Exchange, Chemistry Department, Indiana University

7. Boeseken, J. and Waterman, H.J., Verslag Kon. Akad. Wetenschap, Amsterdam, 20, 552 (1911)

8. Davis, B.D., Nature, 116, 1120 (1950)

9. Hansch, C. and Fujita, J., J.A.C.S., 86, 1516 (1964)

10. Cammarata, A., Neeley, B., Purcell, W. and Wohl, A. in Molecular Orbital Studies in Chemical Pharmacology, (Kier, I.B., ed.), Springer-Verlag, New York, 1970 
APPENDIX 
TABLE A

CARTESIAN COORDINATE CALCULATION

(USING COMPUTER PROGRAM CORCAI ${ }^{\mathrm{a}}$ ) FOR ANILINE ${ }^{\mathrm{b}}$

\begin{tabular}{|c|c|c|c|c|}
\hline$\#$ & ATOM & $\mathrm{X}$ & $Y$ & $\mathrm{Z}$ \\
\hline 1 & $\mathrm{~N}$ & 4.104907 & 0.038792 & 0.000016 \\
\hline 2 & C & 2.754972 & 0.026035 & 0.0 \\
\hline 3 & C & 2.059926 & 1.229779 & 0.0 \\
\hline 4 & C & 0.679999 & 1.177799 & 0.0 \\
\hline 5 & C & 0.0 & 0.0 & 0.0 \\
\hline 6 & C & 0.685011 & -1.186446 & 0.0 \\
\hline 7 & $\mathrm{C}$ & 2.055008 & -1.186418 & 0.0 \\
\hline 8 & $\mathrm{H}$ & -1.129944 & -0.010678 & 0.000013 \\
\hline 9 & $\mathrm{H}$ & 0.169054 & 1.990530 & 0.0 \\
\hline 10 & $\mathrm{H}$ & 2.630019 & -2.182339 & 0.0 \\
\hline 11 & $\mathrm{H}$ & 0.205036 & -2.017843 & 0.0 \\
\hline 12 & $\mathrm{H}$ & 2.559054 & 2.175910 & 0.0 \\
\hline 13 & $\mathrm{H}$ & 4.527379 & -0.764233 & -0.465881 \\
\hline 14 & $\mathrm{H}$ & 4.512127 & 0.849659 & -0.465881 \\
\hline
\end{tabular}

a Cartesian Coordinate Calculation program obtained from the "Qauntum Chemistry Program Exchange," Indiana State University.

$\mathrm{b}_{\text {Figure }} 18$. 
TABLE B

CARTESIAN COORDINATE CALCULATION (USING COMPUTER PROGRAM CORCAL ${ }^{a}$ ) FOR P-AMINO BENZOIC ACID

\begin{tabular}{|c|c|c|c|c|}
\hline \# & ATOM & $\mathrm{X}$ & $Y$ & $\mathrm{Z}$ \\
\hline 1 & C & 4.242996 & 0.031820 & 0.0 \\
\hline 2 & $\mathrm{C}$ & 2.788039 & 0.020920 & 0.0 \\
\hline 3 & $\mathrm{C}$ & 2.088101 & 1.197458 & 0.0 \\
\hline 4 & $\mathrm{C}$ & 0.713155 & 1.208269 & 0.0 \\
\hline 5 & C & 0.0 & 0.0 & 0.0 \\
\hline 6 & C & 0.713141 & -1.208235 & 0.0 \\
\hline 7 & $c$ & 2.062781 & -1.178912 & 0.0 \\
\hline 8 & $\mathrm{~N}$ & -1.377958 & -0.010323 & 0.0 \\
\hline 9 & 0 & 4.802277 & 1.221956 & 0.0 \\
\hline 10 & $\mathrm{H}$ & 5.734277 & 1.037905 & 0.0 \\
\hline 11 & $\mathrm{H}$ & 0.164208 & 2.138359 & 0.0 \\
\hline 12 & $\mathrm{H}$ & 2.589818 & 2.050909 & 0.0 \\
\hline 13 & $\mathrm{H}$ & 0.232460 & -2.016036 & 0.0 \\
\hline 14 & $\mathrm{H}$ & 2.576537 & -2.060075 & 0.0 \\
\hline 15 & 0 & 4.932883 & -0.993726 & 0.0 \\
\hline 16 & $\mathrm{H}$ & -1.815250 & 0.764837 & -0.465881 \\
\hline 17 & $\mathrm{H}$ & -1.813024 & -0.843580 & -0.465881 \\
\hline
\end{tabular}

${ }^{a}$ Cartesian Coordinate Calculation program obtained from the "Quantum Chemistry Program Exchange," Indiana State University.

$\mathrm{b}_{\text {Figure }} 19$. 
TABLE C

CARTESIAN COORDINATE CALCULATION

(USING COMPUTER PROGRAM CORCAI ${ }^{a}$ ) FOR BENZOIC ACID

\begin{tabular}{|c|c|c|c|c|}
\hline$\#$ & ATOM & $\underline{X}$ & $Y$ & $\mathrm{Z}$ \\
\hline 1 & C & 4.302985 & -0.014309 & 0.000017 \\
\hline 2 & C & 2.822996 & -0.009387 & 0.0 \\
\hline 3 & $\mathrm{C}$ & 2.117486 & 1.188255 & 0.0 \\
\hline 4 & $\mathrm{C}$ & 0.703019 & 1.169999 & 0.0 \\
\hline 5 & C & 0.0 & 0.0 & 0.0 \\
\hline 6 & C & 0.703025 & -1.170032 & 0.0 \\
\hline 7 & C & 2.117540 & -1.207061 & 0.0 \\
\hline 8 & $\mathrm{H}$ & -0.909992 & 0.003026 & 0.000010 \\
\hline 9 & 0 & 4.904802 & -1.155323 & 0.000010 \\
\hline 10 & $\mathrm{H}$ & 5.795538 & -0.969081 & 0.000006 \\
\hline 11 & $\mathrm{H}$ & 0.219416 & -1.999321 & 0.0 \\
\hline 12 & $\mathrm{H}$ & 2.500536 & -1.898010 & 0.0 \\
\hline 13 & $\mathrm{H}$ & 0.230455 & 2.005630 & 0.0 \\
\hline 14 & $\mathrm{H}$ & 2.494726 & 1.848019 & 0.0 \\
\hline 15 & 0 & 4.963567 & 1.035082 & 0.000012 \\
\hline
\end{tabular}

${ }^{a}$ Cartesian Coordinate Calculation program obtained from the "Quantum Chemistry Program Exchange," Indiana State University.

$\mathrm{b}_{\text {Figure }} 20$. 
TABLE D

CARTESIAN COORDINATE CALUCLATION

(USING COMPUTER PROGRAM CORCAI ${ }^{a}$ ) FOR BENZOIC ACID

\begin{tabular}{|c|c|c|c|c|}
\hline \# & ATOM & $\mathrm{X}$ & $\mathbf{Y}$ & Z \\
\hline 1 & C & 4.302985 & -0.014309 & 0.000017 \\
\hline 2 & C & 2.822996 & -0.009387 & 0.0 \\
\hline 3 & C & 2.117486 & 1.188255 & 0.0 \\
\hline 4 & C & 0.703019 & 1.169999 & 0.0 \\
\hline 5 & C & 0.0 & 0.0 & 0.0 \\
\hline 6 & C & 0.703025 & -1.170032 & 0.0 \\
\hline 7 & C & 2.117540 & -1.207061 & 0.0 \\
\hline 8 & $\mathrm{H}$ & -0.909992 & 0.003026 & 0.000010 \\
\hline 9 & 0 & 4.904802 & 0.000010 & -1.155323 \\
\hline 10 & $\mathrm{H}$ & 5.795538 & 0.000006 & -0.969081 \\
\hline 11 & $\mathrm{H}$ & 0.219416 & -1.999321 & 0.0 \\
\hline 12 & $\mathrm{H}$ & 2.500536 & -1.898010 & 0.0 \\
\hline 13 & $\mathrm{H}$ & 0.230453 & 2.005630 & 0.0 \\
\hline 14 & $\mathrm{H}$ & 2.494726 . & 1.848019 & 0.0 \\
\hline 15 & 0 & 4.963567 & 0.000012 & 1.035082 \\
\hline
\end{tabular}

${ }^{a}$ Cartesian Coordinate Calculation program obtained from the "Quantum Chemistry Program Exchange," Indiana State University.

$\mathrm{b}_{\text {Figure } 21 .}$ 
TABLE E

CARTESIAN COORDINATE CALCULATION

(USING COMPUTER PROGRAM CORCAL ${ }^{\mathrm{a}}$ ) FOR PHENOL ${ }^{\mathrm{b}}$

\begin{tabular}{|c|c|c|c|c|}
\hline$\#$ & ATOM & $X$ & $Y$ & $\mathrm{Z}$ \\
\hline 1 & 0 & 4.089862 & 0.051791 & 0.000016 \\
\hline 2 & C & 2.739972 & 0.034697 & 0.0 \\
\hline 3 & C & 2.049927 & I. 229784 & 0.0 \\
\hline 4 & C & 0.699999 & 1.212439 & 0.0 \\
\hline 5 & C & 0.0 & 0.0 & 0.0 \\
\hline 6 & C & 0.670011 & -1.160463 & 0.0 \\
\hline 7 & C & 2.050008 & -1.160434 & 0.0 \\
\hline 8 & $\mathrm{H}$ & -1.129908 & -0.014308 & 0.000013 \\
\hline 9 & $\mathrm{H}$ & 0.209366 & 2.037591 & 0.0 \\
\hline 10 & $\mathrm{H}$ & 2.6250 & -2.1564 & 0.0 \\
\hline 11 & $\mathrm{H}$ & 0.190037 & -1.991861 & 0.0 \\
\hline 12 & $\mathrm{H}$ & 2.572969 & 2.163231 & 0.0 \\
\hline 13 & $\mathrm{H}$ & 4.434118 & -0.908357 & 0.000008 \\
\hline
\end{tabular}

${ }^{a}$ Cartesian Coordinate Calculation program obtained from the "Quantum Chemistry Program Exchange," Indiana State University.

$\mathrm{b}_{\text {Figure } 22 .}$. 
TABLE F

CARTESIAN COORDINATE CALCULATION (USING COMPUTER PROGRAM CORCAL ${ }^{a}$ ) FOR p-HYDROXY BENZOIC ACID ${ }^{b}$

\begin{tabular}{|c|c|c|c|c|}
\hline$\#$ & ATOM & $\mathrm{X}$ & $\mathrm{Y}$ & Z \\
\hline 1 & C & 4.220592 & -0.004848 & 0.000018 \\
\hline 2 & C & 2.720598 & -0.003125 & 0.0 \\
\hline 3 & C & 2.012947 & 1.181618 & 0.0 \\
\hline 4 & C & 0.706089 & 1.191459 & 0.0 \\
\hline 5 & C & 0.0 & 0.0 & 0.0 \\
\hline 6 & C & 0.712729 & -1.170003 & 0.0 \\
\hline 7 & C & 2.027462 & -1.196419 & 0.0 \\
\hline 8 & 0 & -1.339993 & 0.001539 & 0.000016 \\
\hline 9 & 0 & 4.784747 & -1.164943 & 0.000009 \\
\hline 10 & $\mathrm{H}$ & 5.681102 & -1.007952 & 0.000006 \\
\hline 11 & $\mathrm{H}$ & 0.234173 & -2.002219 & 0.0 \\
\hline 12 & $\mathrm{H}$ & 2.414656 & -1.885025 & 0.0 \\
\hline 13 & $\mathrm{H}$ & 0.250701 & 2.036573 & 0.0 \\
\hline 14 & $\mathrm{H}$ & 2.403587 & 1.833536 & 0.0 \\
\hline 15 & 0 & 4.875303 & 1.000809 & 0.000012 \\
\hline 16 & $\mathrm{H}$ & -1.677447 & 0.985269 & 0.000011 \\
\hline
\end{tabular}

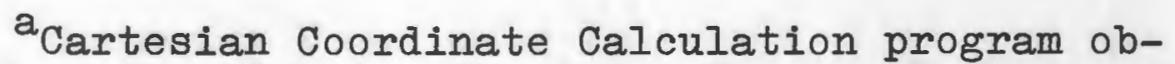
tained from the "Quantum Chemistry Program Exchange," Indiana State University.

$\mathrm{b}_{\text {Figure } 23 .}$ 
TABIE G

CARTESIAN COORDINATE CAICULATION (USING COMPUTER PROGRAM CORCAI ${ }^{\mathrm{a}}$ ) FOR p-HYDROXY BENZOIC ACID

\begin{tabular}{|c|c|c|c|c|}
\hline$\#$ & ATOM & $\mathrm{X}$ & $\mathrm{Y}$ & $\mathbf{Z}$ \\
\hline 1 & C & 4.220592 & -0.004848 & .0 .000018 \\
\hline 2 & C & 2.720598 & -0.003125 & 0.0 \\
\hline 3 & C & 2.012947 & 1.181618 & 0.0 \\
\hline 4 & C & 0.706089 & 1.191459 & 0.0 \\
\hline 5 & C & 0.0 & 0.0 & 0.0 \\
\hline 6 & C & 0.712729 & -1.170003 & 0.0 \\
\hline 7 & C & 2.027462 & -1.196419 & 0.0 \\
\hline 8 & 0 & -1.339993 & 0.001539 & 0.000016 \\
\hline 9 & 0 & 4.784747 & 0.000009 & -1.164943 \\
\hline 10 & $\mathrm{H}$ & 5.681102 & 0.000006 & -1.007952 \\
\hline 11 & $\mathrm{H}$ & 0.234173 & -2.002219 & 0.0 \\
\hline 12 & $\mathrm{H}$ & 2.414656 & -1.885025 & 0.0 \\
\hline 13 & $\mathrm{H}$ & 0.250701 & 2.036573 & 0.0 \\
\hline 14 & $\mathrm{H}$ & 2.403587 & 1.833536 & 0.0 \\
\hline 15 & 0 & 4.875303 & 0.000012 & 1.000809 \\
\hline 16 & $\mathrm{H}$ & -1.677447 & 0.985269 & 0.000011 \\
\hline
\end{tabular}

aCartesian Coordinate Calculation program obtained from the "Quantum Chemistry Program Exchange," Indiana State University.

$\mathrm{b}_{\text {Figure }} 24$. 
TABLE $\mathrm{H}$

CARTESIAN COORDINATE CALCULATION (USING COMPUTER PROGRAM CORCAI ${ }^{a}$ ) FOR METHYL PARABEN ${ }^{b}$

\begin{tabular}{|c|c|c|c|c|}
\hline$\#$ & ATOM & $\mathrm{X}$ & $\underline{Y}$ & Z \\
\hline 1 & $\mathrm{C}$ & 4.220592 & -0.004848 & 0.000018 \\
\hline 2 & C & 2.720598 & -0.003125 & 0.0 \\
\hline 3 & C & 2.012947 & 1.181618 & 0.0 \\
\hline 4 & C & 0.706089 & 1.191459 & 0.0 \\
\hline 5 & C & 0.0 & 0.0 & 0.0 \\
\hline 6 & C & 0.712729 & -1.170003 & 0.0 \\
\hline 7 & C & 2.027462 & -1.196419 & 0.0 \\
\hline 8 & 0 & -1.339993 & 0.001539 & 0.000016 \\
\hline 9 & 0 & 4.784747 & -1.164943 & 0.000009 \\
\hline 10 & C & 6.207081 & -1.017103 & 0.000003 \\
\hline 11 & $\mathrm{H}$ & 0.234173 & -2.002219 & 0.0 \\
\hline 12 & $\mathrm{H}$ & 2.414656 & -1.885025 & 0.0 \\
\hline 13 & $\mathrm{H}$ & 0.250701 & 2.036573 & 0.0 \\
\hline 14 & $\mathrm{H}$ & 2.403587 & 1.833536 & 0.0 \\
\hline 15 & 0 & 4.875303 & 1.000809 & 0.000012 \\
\hline 16 & $\mathrm{H}$ & -1.677785 & 0.697251 & -0.695311 \\
\hline 17 & $\mathrm{H}$ & 6.495644 & 0.040223 & 0.000014 \\
\hline 18 & H & 6.654110 & -1.483082 & 0.884927 \\
\hline 19 & $\mathrm{H}$ & 6.654102 & -1.484287 & -0.884936 \\
\hline
\end{tabular}

${ }^{a}$ Cartesian Coordinate Calculation program obtained from the "Quantum Chemistry Program Exchange," Indiana State University.

$\mathrm{b}_{\text {Figure }} 25$. 
TABLE I

CARTESIAN COORDINATE CALCULATION (USING COMPUTER PROGRAM CORCAI ${ }^{a}$ ) FOR METHYI PARABEN ${ }^{b}$

\begin{tabular}{|c|c|c|c|c|}
\hline \# & ATOM & X & $Y$ & Z \\
\hline 1 & C & 4.220592 & -0.004848 & 0.000018 \\
\hline 2 & C & 2.720598 & -0.003125 & 0.0 \\
\hline 3 & C & 2.012947 & 1.181618 & 0.0 \\
\hline 4 & C & 0.706089 & 1.191459 & 0.0 \\
\hline 5 & C & 0.0 & 0.0 & 0.0 \\
\hline 6 & C & 0.712729 & -1.170003 & 0.0 \\
\hline 7 & C & 2.027462 & -1.196419 & 0.0 \\
\hline 8 & 0 & -1.339993 & 0.001539 & 0.000016 \\
\hline 9 & 0 & 4.784747 & -1.164943 & 0.000009 \\
\hline 10 & C & 3.790188 & -2.192439 & -0.000010 \\
\hline 11 & $\mathrm{H}$ & 0.234173 & -2.002219 & 0.0 \\
\hline 12 & $\mathrm{H}$ & 2.414656 & -1.885025 & 0.0 \\
\hline 13 & $\mathrm{H}$ & 0.250701 & 2.036573 & 0.0 \\
\hline 14 & $\mathrm{H}$ & 2.403587 & 1.833536 & 0.0 \\
\hline 15 & 0 & 4.875303 & 1.000809 & 0.000012 \\
\hline 16 & $\mathrm{H}$ & -1.677785 & 0.697251 & -0.695311 \\
\hline 17 & $\mathrm{H}$ & 4.248755 & -3.187893 & -0.000010 \\
\hline 18 & $\mathrm{H}$ & 3.147428 & -2.121886 & 0.884915 \\
\hline 19 & $\mathrm{H}$ & 3.147452 & -2.121874 & -0.884951 \\
\hline
\end{tabular}

${ }^{a}$ Cartesian Coordinate Calculation program obtained from the "Quantum Chemistry Program Exchange," Indiana State University.

$\mathrm{b}_{\text {Figure }} 26$. 
TABLE $J$

CARTESIAN COORDINATE CALCULATION (USING COMPUTER PROGRAM CORCAI ${ }^{a}$ ) FOR METHYL PARABEN ${ }^{b}$

\begin{tabular}{|c|c|c|c|c|}
\hline \# & ATOM & $\mathrm{X}$ & $Y$ & Z \\
\hline 1 & C & 4.220592 & -0.000484 & 0.000018 \\
\hline 2 & C & 2.720598 & -0.003125 & 0.0 \\
\hline 3 & C & 2.012947 & 1.181618 & 0.0 \\
\hline 4 & C & 0.706089 & 1.191459 & 0.0 \\
\hline 5 & C & 0.0 & 0.0 & 0.0 \\
\hline 6 & C & 0.712729 & -1.170003 & 0.0 \\
\hline 7 & C & 2.027462 & -1.196419 & 0.0 \\
\hline 8 & 0 & -1.339993 & 0.001539 & 0.000016 \\
\hline 9 & 0 & 4.784747 & 0.000009 & -1.164943 \\
\hline 10 & C & 6.207081 & 0.000003 & -1.017103 \\
\hline 11 & $\mathrm{H}$ & 0.234173 & -2.002219 & 0.0 \\
\hline 12 & $\mathrm{H}$ & 2.414656 & -1.885025 & 0.0 \\
\hline 13 & $\mathrm{H}$ & 0.250701 & 2.036573 & 0.0 \\
\hline 14 & $\mathrm{H}$ & 2.403587 & 1.833536 & 0.0 \\
\hline 15 & 0 & 4.875303 & 0.000012 & 1.000809 \\
\hline 16 & $\mathrm{H}$ & -1.677785 & 0.697251 & -0.695311 \\
\hline 17 & $\mathrm{H}$ & 6.495644 & 0.000014 & 0.040223 \\
\hline 18 & $\mathrm{H}$ & 6.654110 & 0.884927 & -1.484308 \\
\hline 19 & $\mathrm{H}$ & 6.654102 & -0.884936 & -1.484287 \\
\hline
\end{tabular}

${ }^{a}$ Cartesian Coordinate Calculation program obtained from the "Quantum Chemistry Program Exchange," Indiana State University.

$\mathrm{b}_{\text {Figure }} 27$. 
TABIE K

CARTESIAN COORDINATE CALCULATION (USING COMPUTER PROGRAM CORCAI ${ }^{a}$ ) FOR METHYL PARABEN ${ }^{b}$

\begin{tabular}{|c|c|c|c|c|}
\hline$\#$ & ATOM & $X$ & $Y$ & $\mathrm{Z}$ \\
\hline 1 & C & 4.220592 & -0.004848 & 0.000018 \\
\hline 2 & C & 2.720598 & -0.003125 & 0.0 \\
\hline 3 & C & 2.012947 & 1.181618 & 0.0 \\
\hline 4 & C & 0.706089 & 1.191459 & 0.0 \\
\hline 5 & C & 0.0 & 0.0 & 0.0 \\
\hline 6 & C & 0.712729 & -1.170003 & 0.0 \\
\hline 7 & C & 2.027462 & -1.196419 & 0.0 \\
\hline 8 & 0 & -1.339993 & 0.001539 & 0.000016 \\
\hline 9 & 0 & 4.786095 & -0.002834 & -1.159417 \\
\hline 10 & C & 3.797341 & -0.001369 & -2.188068 \\
\hline 11 & $\mathrm{H}$ & 0.234173 & -2.002219 & 0.0 \\
\hline 12 & $\mathrm{H}$ & 2.414656 & -1.885025 & 0.0 \\
\hline 13 & $\mathrm{H}$ & 0.250701 & 2.036573 & 0.0 \\
\hline 14 & $\mathrm{H}$ & 2.403587 & 1.833536 & 0.0 \\
\hline 15 & 0 & 4.874136 & -0.003286 & 1.006431 \\
\hline 16 & $\mathrm{H}$ & -1.677785 & 0.697251 & -0.695311 \\
\hline 17 & $\mathrm{H}$ & 2.782381 & 0.000218 & -1.763340 \\
\hline 18 & $\mathrm{H}$ & 3.886298 & 0.883377 & -2.828129 \\
\hline 19 & $\mathrm{H}$ & 3.883566 & -0.886486 & -2.828011 \\
\hline
\end{tabular}

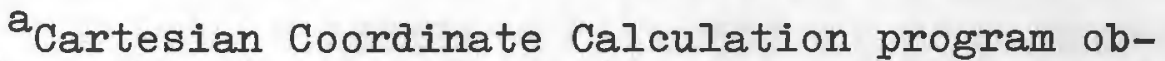
tained from the "Quantum Chemistry Program Exchange," Indiana State University.

$\mathrm{b}_{\text {Figure }} 28$. 
TABLE I

CARTESIAN COORDINATE CALCULATION（USING COMPUTER PROGRAM CORCAL ${ }^{\mathrm{a}}$ ) FOR ETHYI PARABEN ${ }^{\mathrm{b}}$

\begin{tabular}{rrrrrl}
\hline \hline \# & ATOM & & \multicolumn{1}{c}{$\mathrm{X}$} & \multicolumn{1}{c}{$\mathrm{Z}$} \\
\cline { 5 - 6 } 1 & $\mathrm{C}$ & 4.220592 & & -0.004848 & 0.000018 \\
2 & $\mathrm{C}$ & 2.720598 & -0.003125 & 0.0 \\
3 & $\mathrm{C}$ & 2.012947 & 1.181618 & 0.0 \\
4 & $\mathrm{C}$ & 0.706089 & 1.191459 & 0.0 \\
5 & $\mathrm{C}$ & 0.0 & 0.0 & 0.0 \\
6 & $\mathrm{C}$ & 0.712729 & -1.170003 & 0.0 \\
7 & $\mathrm{C}$ & 2.027462 & -1.196419 & 0.0 \\
8 & $\mathrm{O}$ & -1.339993 & 0.001539 & 0.000016 \\
9 & $\mathrm{O}$ & 4.784747 & -1.164943 & 0.000009 \\
10 & $\mathrm{C}$ & 6.207081 & -1.017103 & 0.000003 \\
11 & $\mathrm{H}$ & 0.234173 & -2.002219 & 0.0 \\
12 & $\mathrm{H}$ & 2.414656 & -1.885025 & 0.0 \\
13 & $\mathrm{H}$ & 0.250701 & 2.036573 & 0.0 \\
14 & $\mathrm{H}$ & 2.403587 & 1.833536 & 0.0 \\
15 & $\mathrm{O}$ & 4.875303 & 1.000809 & 0.000012 \\
16 & $\mathrm{H}$ & -1.679706 & 0.73539 & -0.73539 \\
17 & $\mathrm{H}$ & 6.548461 & -1.467942 & -0.884920 \\
18 & $\mathrm{H}$ & 6.654109 & -1.484304 & 0.884929 \\
19 & $\mathrm{C}$ & 6.562141 & 0.477293 & 0.000031 \\
20 & $\mathrm{H}$ & 7.660223 & 0.591431 & 0.000028 \\
21 & $\mathrm{H}$ & 6.138475 & 0.954026 & -0.904776 \\
22 & $\mathrm{H}$ & 6.138484 & 0.953989 & 0.904863 \\
\hline
\end{tabular}

${ }^{a}$ Cartesian Coordinate Calculation program obtained from the "Quantum Chemistry Program Exchange," Indiana State University.

${ }^{b}$ Figure 29. 
TABLE M

CARTESIAN COORDINATE CALCULATION (USING COMPUTER PROGRAM CORCAI ${ }^{a}$ ) FOR ETHYI PARABEN ${ }^{b}$

\begin{tabular}{|c|c|c|c|c|}
\hline \# & ATOM & $\mathrm{X}$ & $Y$ & $\mathrm{Z}$ \\
\hline 1 & C & 4.220592 & -0.004848 & 0.000018 \\
\hline 2 & C & 2.720598 & -0.003125 & 0.0 \\
\hline 3 & $\mathrm{C}$ & 2.012947 & 1.181618 & 0.0 \\
\hline 4 & $\mathrm{C}$ & 0.706089 & 1.191459 & 0.0 \\
\hline 5 & C & 0.0 & 0.0 & 0.0 \\
\hline 6 & C & 0.712729 & -1.170003 & 0.0 \\
\hline 7 & C & 2.027462 & -1.196419 & 0.0 \\
\hline 8 & 0 & -1.339993 & 0.001539 & 0.000016 \\
\hline 9 & 0 & 4.784747 & 0.000009 & -1.164943 \\
\hline 10 & C & 6.207081 & 0.000003 & -1.017103 \\
\hline 11 & $\mathrm{H}$ & 0.234173 & -2.002219 & 0.0 \\
\hline 12 & $\mathrm{H}$ & 2.414656 & -1.885025 & 0.0 \\
\hline 13 & $\mathrm{H}$ & 0.250701 & 2.036573 & 0.0 \\
\hline 14 & $\mathrm{H}$ & 2.403587 & 1.833536 & 0.0 \\
\hline 15 & 0 & 4.875303 & 0.000012 & 1.000809 \\
\hline 16 & $\mathrm{H}$ & -1.679706 & 0.73539 & -0.73539 \\
\hline 17 & $\mathrm{H}$ & 6.548461 & -0.884920 & -1.467942 \\
\hline 18 & $\mathrm{H}$ & 6.654109 & 0.884929 & -1.484304 \\
\hline 19 & $\mathrm{C}$ & 6.562141 & 0.000031 & 0.477293 \\
\hline 20 & $\mathrm{H}$ & 7.660223 & 0.000028 & 0.591431 \\
\hline 21 & $\mathrm{H}$ & 6.138475 & -0.904776 & 0.954026 \\
\hline 22 & $\mathrm{H}$ & 6.138484 & 0.904863 & 0.953989 \\
\hline
\end{tabular}

${ }^{a}$ Cartesian Coordinate Calculation program obtained from the "Quantum Chemistry Program Exchange," Indiana State University.

bigure 30 . 
TABLE N

CARTESIAN COORDINATE CALCULATION (USING COMPUTER PROGRAM CORCAI ${ }^{a}$ ) FOR ETHYL PARABEN ${ }^{b}$

\begin{tabular}{|c|c|c|c|c|}
\hline$\#$ & ATOM & $\underline{X}$ & $\underline{Y}$ & $\mathrm{Z}$ \\
\hline 1 & $\mathrm{C}$ & 4.220592 & -0.004848 & 0.000018 \\
\hline 2 & C & 2.720598 & -0.003125 & 0.0 \\
\hline 3 & C & 2.012947 & 1.181618 & 0.0 \\
\hline 4 & C & 0.706089 & 1.191459 & 0.0 \\
\hline 5 & C & 0.0 & 0.0 & 0.0 \\
\hline 6 & C & 0.712729 & -1.170003 & 0.0 \\
\hline 7 & C & 2.027462 & -1.196419 & 0.0 \\
\hline 8 & 0 & -1.339993 & 0.001539 & 0.000016 \\
\hline 9 & 0 & 4.786095 & -0.002834 & -1.159417 \\
\hline 10 & C & 3.792734 & -0.001369 & -2.188068 \\
\hline 11 & $\mathrm{H}$ & 0.234173 & -2.002219 & 0.0 \\
\hline 12 & $\mathrm{H}$ & 2.414656 & -1.885025 & 0.0 \\
\hline 13 & $\mathrm{H}$ & 0.250701 & 2.036573 & 0.0 \\
\hline 14 & $\mathrm{H}$ & 2.403587 & 1.833536 & 0.0 \\
\hline 15 & 0 & 4.874136 & -0.003286 & 1.006431 \\
\hline 16 & $\mathrm{H}$ & -1.678588 & 0.001925 & -0.983321 \\
\hline 17 & C & 2.397277 & 0.000826 & -1.546211 \\
\hline 18 & $\mathrm{H}$ & 3.886298 & 0.883377 & -2.828129 \\
\hline 19 & $\mathrm{H}$ & 3.883566 & -0.886486 & -2.828011 \\
\hline 20 & $\mathrm{H}$ & 2.501195 & 0.001515 & -0.447115 \\
\hline 21 & $\mathrm{H}$ & 1.847705 & 0.906083 & -1.868583 \\
\hline 22 & $\mathrm{H}$ & 1.845475 & -0.903550 & -1.867239 \\
\hline
\end{tabular}

${ }^{a}$ Cartesian Coordinate Calculation program obtained from the "Quantum Chemistry Program Exchange," Indiana State University.

bigure 31. 
TABLE 0

CARTESIAN COORDINATE CALCULATION (USING COMPUTER PROGRAM CORCAL ${ }^{a}$ ) FOR ETHYL PARABEN ${ }^{b}$

\begin{tabular}{rrrrr}
\hline \hline \# & ATOM & \multicolumn{1}{c}{$\mathrm{X}$} & \multicolumn{1}{c}{$\mathrm{Y}$} & \multicolumn{1}{c}{$\mathrm{Z}$} \\
\cline { 2 - 3 }$I$ & $\mathrm{C}$ & 4.220592 & -0.004848 & 0.000018 \\
2 & $\mathrm{C}$ & 2.720598 & -0.003125 & 0.0 \\
3 & $\mathrm{C}$ & 2.012947 & 1.181618 & 0.0 \\
4 & $\mathrm{C}$ & 0.706089 & 1.191459 & 0.0 \\
5 & $\mathrm{C}$ & 0.0 & 0.0 & 0.0 \\
6 & $\mathrm{C}$ & 0.712729 & -1.170003 & 0.0 \\
7 & $\mathrm{C}$ & 2.027462 & -1.196419 & 0.0 \\
8 & $\mathrm{O}$ & -1.339993 & 0.001539 & 0.000016 \\
9 & $\mathrm{O}$ & 4.784747 & -1.164943 & -0.000021 \\
10 & $\mathrm{C}$ & 6.207081 & -1.017103 & -0.000034 \\
11 & $\mathrm{H}$ & 0.234173 & -2.002219 & 0.0 \\
12 & $\mathrm{H}$ & 2.414656 & -1.885025 & 0.0 \\
13 & $\mathrm{H}$ & 0.250701 & 2.036573 & 0.0 \\
14 & $\mathrm{H}$ & 2.403587 & 1.833536 & 0.0 \\
15 & $\mathrm{O}$ & 4.875303 & 1.000809 & -0.000013 \\
16 & $\mathrm{H}$ & -1.678588 & 0.001925 & -0.983321 \\
17 & $\mathrm{C}$ & 6.861891 & -2.406531 & -0.000022 \\
18 & $\mathrm{H}$ & 6.548474 & -0.467958 & 0.884893 \\
19 & $\mathrm{H}$ & 6.548456 & -0.467939 & -0.884958 \\
20 & $\mathrm{H}$ & 7.959974 & -2.292395 & -0.000008 \\
21 & $\mathrm{H}$ & 6.545337 & -2.960190 & 0.904843 \\
22 & $\mathrm{H}$ & 6.545313 & -2.960185 & -0.904793 \\
\hline & & & & \\
\hline
\end{tabular}

aCartesian Coordinate Calculation program obtained from the "Quantum Chemistry Program Exchange," Indiana State University.

$\mathrm{b}_{\text {Figure }} 32$. 
TABLE P

CARTESIAN COORDINATE CALCULATION (USING COMPUTER PROGRAM CORCAL ${ }^{a}$ ) FOR ETHYL PARABEN ${ }^{b}$

\begin{tabular}{|c|c|c|c|c|}
\hline \# & ATOM & $\mathrm{X}$ & $\mathrm{Y}$ & $\mathrm{Z}$ \\
\hline 1 & C & 4.220592 & -0.004848 & 0.000018 \\
\hline 2 & C & 2.720598 & -0.003125 & 0.0 \\
\hline 3 & C & 2.012947 & 1.181618 & 0.0 \\
\hline 4 & C & 0.706089 & 1.191459 & 0.0 \\
\hline 5 & C & 0.0 & 0.0 & 0.0 \\
\hline 6 & $\mathrm{C}$ & 0.712729 & -1.170003 & 0.0 \\
\hline 7 & C & 2.027462 & -1.196419 & 0.0 \\
\hline 8 & 0 & -1.339993 & 0.001539 & 0.000016 \\
\hline 9 & 0 & 4.838108 & -0.002955 & -1.132572 \\
\hline 10 & C & 6.252019 & -0.001005 & -0.918716 \\
\hline 11 & $\mathrm{H}$ & 0.234173 & -2.002219 & 0.0 \\
\hline 12 & $\mathrm{H}$ & 2.414656 & -1.885025 & 0.0 \\
\hline 13 & $\mathrm{H}$ & 0.250701 & 2.036573 & 0.0 \\
\hline 14 & $\mathrm{H}$ & 2.403587 & 1.833536 & 0.0 \\
\hline 15 & 0 & 4.874136 & -0.003286 & 1.006431 \\
\hline 16 & $\mathrm{H}$ & -1.678588 & 0.001925 & -0.983321 \\
\hline 17 & C & 6.970772 & -0.000892 & -2.276174 \\
\hline 18 & $\mathrm{H}$ & 6.568533 & -0.884826 & -0.353126 \\
\hline 19 & $\mathrm{H}$ & 6.566440 & 0.884825 & -0.355420 \\
\hline 20 & $\mathrm{H}$ & 8.062356 & -0.000511 & -2.111066 \\
\hline 21 & $\mathrm{H}$ & 6.681402 & -0.903409 & -2.842336 \\
\hline 22 & $\mathrm{H}$ & 6.680797 & 0.901324 & -2.842506 \\
\hline
\end{tabular}

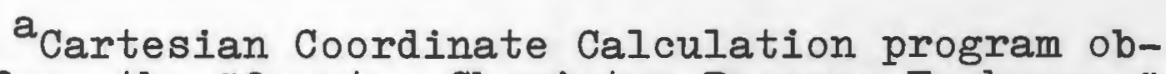
tained from the "Quantum Chemistry Program Exchange," Indiana State University.

$\mathrm{b}_{\text {Figure }} 33$. 
TABIE Q

CARTESIAN COORDINATE CALCULATION (USING COMPUTER PROGRAM CORCAI ${ }^{a}$ ) FOR ETHYI PARABEN

\begin{tabular}{|c|c|c|c|c|}
\hline$\#$ & ATOM & $X$ & $Y$ & $\mathrm{Z}$ \\
\hline 1 & C & 4.220592 & -0.004848 & 0.000018 \\
\hline 2 & C & 2.720598 & -0.003125 & 0.0 \\
\hline 3 & C & 2.012947 & 1.181618 & 0.0 \\
\hline 4 & C & 0.706089 & 1.191459 & 0.0 \\
\hline 5 & c & 0.0 & 0.0 & 0.0 \\
\hline 6 & C & 0.712729 & -1.170003 & 0.0 \\
\hline 7 & C & 2.027462 & -1.196419 & 0.0 \\
\hline 8 & 0 & -1.339993 & 0.001539 & 0.000016 \\
\hline 9 & 0 & 4.786095 & -0.002834 & -1.159417 \\
\hline 10 & C & 3.792734 & -0.001369 & -2.188068 \\
\hline 11 & $\mathrm{H}$ & 0.234173 & -2.002219 & 0.0 \\
\hline 12 & $\mathrm{H}$ & 2.414656 & -1.885025 & 0.0 \\
\hline 13 & $\mathrm{H}$ & 0.250701 & 2.036573 & 0.0 \\
\hline 14 & $\mathrm{H}$ & 2.403587 & 1.833536 & 0.0 \\
\hline 15 & 0 & 4.874136 & -0.003286 & 1.006431 \\
\hline 16 & $\mathrm{H}$ & -1.678588 & 0.001925 & -0.983321 \\
\hline 17 & C & 4.482892 & 0.003504 & -3.560273 \\
\hline 18 & $\mathrm{H}$ & 3.151187 & -0.887427 & -2.120759 \\
\hline 19 & $\mathrm{H}$ & 3.148623 & 0.882430 & -2.115761 \\
\hline 20 & $\mathrm{H}$ & 5.577694 & 0.004458 & -3.418065 \\
\hline 21 & $\mathrm{H}$ & 4.181735 & -0.900045 & $-4 \cdot 124494$ \\
\hline 22 & $\mathrm{H}$ & 4.179471 & 0.909581 & -4.119204 \\
\hline
\end{tabular}

${ }^{a}$ Cartesian Coordinate Calculation program obtained from the "Quantum Chemistry Program Exchange," Indiana State University.

$\mathrm{b}_{\text {Figure }} 34$. 
VITA

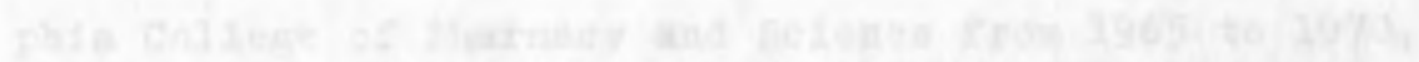

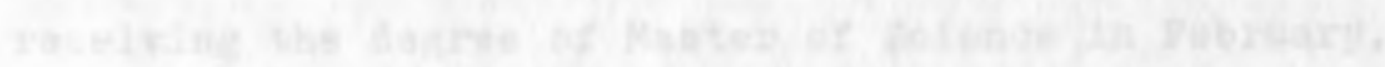

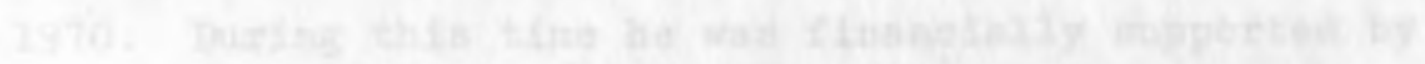

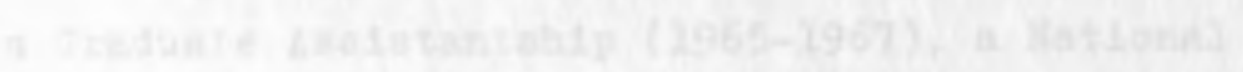

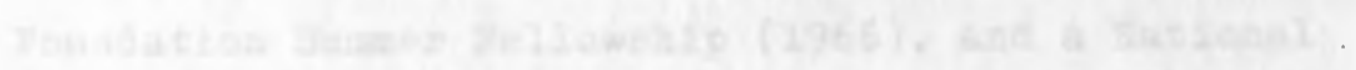

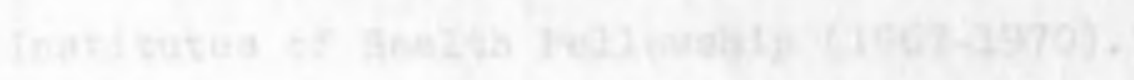

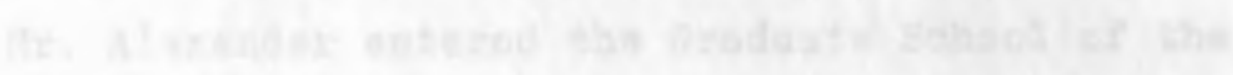

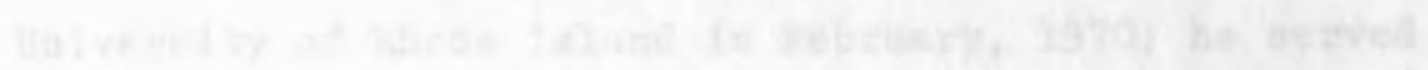

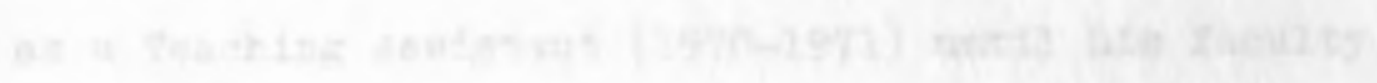

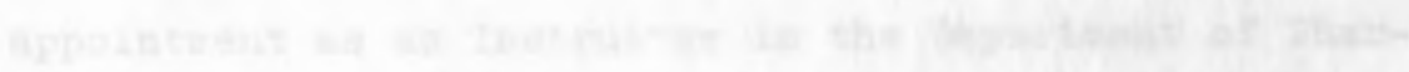

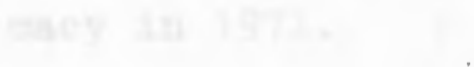


VITA

Kenneth Saul Alexander was born on November 27, 1942 in Philadelphia, Pennsylvania. He received his primary and secondary education in the public school system of Philadelphia. After graduation from Northeast High School, Philadelphia, Pennsylvania in 1960, he entered the Philadelphia College of Pharmacy and Science and received the Bachelor of Science in Pharmacy degree from the college in 1965.

He attended the Graduate School of the Philadelphia College of Pharmacy and Science from 1965 to 1970, receiving the degree of Master of Science in February, 1970. During this time he was financially supported by a Graduate Assistantship (1965-1967), a National Science Foundation Summer Fellowship (1966), and a National Institutes of Health Fellowship (1967-1970).

Mr. Alexander entered the Graduate School of the University of Rhode Island in February, 1970; he served as a Teaching Assistant (1970-1971) until his faculty appointment as an Instructor in the Department of Pharmacy in 1971.

$\mathrm{He}$ is a registered pharmacist in the states of Pennsylvania and Rhode Island and is presently a member 
of Rho Chi, The Society of Sigma Xi, Phi Sigma, Rho Pi Phi, The American Pharmaceutical Association, The Academy of Pharmaceutical Sciences of the American Pharmaceutical Association, The Academy of General Practice of the American Pharmaceutical Association, The American Chemical Society and the Association of American Colleges of Pharmacy.

He was married, August 18, 1968 to Karen Lee Haury of Conyngham, Pennsylvania.

Kenneth S. Alexander is the co-author of the following articles presented at the American Pharmaceutical Association Convention, Houston, Texas, 1971: "Solubility Profiles for Barbiturates in n-Alkanols," by Laprade, B.J., Alexander, K.S., Petersen, H., Jr., Mauger, J.W. and Paruta, A.N. "Molecular Orbital Calculations for Barbiturate Moieties," by Petersen, H., Jr., Laprade, B.J., Alexander, K.S., and Paruta, A.N. 